DEIVID EFRAIN TELLEZ PORRAS

\title{
DESENVOLVIMENTO DE TRANSMISSORES DE PRESSÃO COM SENSOR PIEZORESISTIVO E PROTOCOLO DE COMUNICAÇÃO HART.
}

\author{
Dissertação apresentada à Escola Po- \\ litécnica da Universidade de São Paulo \\ para obtenção do Título de Mestre em \\ Engenharia Elétrica.
}




\title{
DEIVID EFRAIN TELLEZ PORRAS
}

\section{DESENVOLVIMENTO DE TRANSMISSORES DE PRESSÃO COM SENSOR PIEZORESISTIVO E PROTOCOLO DE COMUNICAÇÃO HART.}

\author{
Dissertação apresentada à Escola Po- \\ litécnica da Universidade de São Paulo \\ para obtenção do Título de Mestre em \\ Engenharia Elétrica.
}

Área de Concentração:

Microeletrônica

Orientador:

Edgar Charry Rodriguez 
Este exemplar foi revisado e alterado em relação à versão original, sob responsabilidade única do autor e com a anuência de seu orientador.

São Paulo, 22 de julho de 2014.

Assinatura do autor

Assinatura do orientador

\section{Catalogação-na-publicação}

Tellez Porras, Deivid Efrain

Desenvolvimento de Transmissores de Pressão com Sensor Piezoresistivo e Protocolo de Comunicação HART./ D. E. Tellez Porras. - - versão corr. - São Paulo, 2014.

$101 \mathrm{p}$.

Dissertação (Mestrado) - Escola Politécnica da Universidade de São Paulo. Departamento de Engenharia de Computação e Sistemas Digitais.

1. Microeletrônica 2. Dispositivos Eletrônicos 3. Sensor 4. Comunicação Digital. I. Universidade de São Paulo. Escola Politécnica. Departamento de Engenharia de Computação e Sistemas Digitais. II. t. 
A Mamá y a Ángela. 


\section{AGRADECIMENTOS}

Quero agradecer ao CNPq - Conselho Nacional de Desenvolvimento Científico e Tecnológico pelo apoio financeiro. Ao Departamento de Engenharia de Sistemas Eletrônicos - PSI Escola Politécnica, Universidade de São Paulo. À Universidad del Valle, Cali, Colômbia, em especial ao professor Asfur Barandica pelo apoio e ajuda durante toda a duração do projeto. Ao professor Jorge Ramirez e a toda sua equipe de pesquisa da CUJAE - Cuba e finalmente à empresa MEMS Ltda sem a qual não teria sido possível a realização deste projeto. 


\section{RESUMO}

O presente trabalho é uma pesquisa tecnológica (P\&D) de inovação tecnológica de produto para o mercado brasileiro, que visa desenvolver um transmissor de pressão inteligente de alta exatidão com protocolo HART e sensor piezoresistivo em parceria LSI-USP / MEMS Ltda. Fornecendo assim um protótipo de um produto competitivo no mercado brasileiro.

Neste trabalho se apresenta uma arquitetura baseada nos transmissores 4-20 $\mathrm{mA}$ de alta exatidão da MEMS Ltda. Essa arquitetura mantém as características de desemprenho da medição analógica e adiciona os componentes necessários para suportar as funções do padrão HART com camada física Bell 202.

Além da arquitetura, neste documento é apresentado: o desenvolvimento das interfaces entre o algoritmo de compensação e os algoritmos responsáveis da comunicação digital, as modificações no circuito de controle da corrente de laço para permitir a modulação do sinal de $1200 \mathrm{~Hz}$ e $2200 \mathrm{~Hz}$ usado pela comunicação digital, e o projeto de alimentação do transmissor, que foi projetado visando a eficiência para respeitar os limites de consumo de corrente.

Os resultados obtidos com essa nova arquitetura, apresentam que são mantidas as características dos transmissores 4-20 mA usados como base, e que a medição digital tem um nível de erro 0,05 \%FS (porcentagem de fundo de escala) menor do que a saída analógica do mesmo transmissor, valor considerável comparado com o 0,2 \%FS que é o nível de erro total do sistema. Os protótipos usados para as medições foram caracterizados num processo que levou 35 dias de operação continua, validando assim o projeto elétrico e software desenvolvido. 


\begin{abstract}
This thesis consists of a technical research (P\&D) on technological innovations of a highly accurate intelligent pressure transmitter using a HART protocol and piezoresistive sensors in collaboration with LSI-USP / MEMS Ltda. The outcome consists of a prototype of a competitive product in the Brazilian market.

This project presents a product architecture based on highly accurate 4-20mA MEMS Ltda. transmitters. It maintains the features necessary for analogical measurements and adds components, which are compatible with the functions of HART with a Bell 202 physical layer.

In addition to the architecture, this document presents the development of: interfaces between the compensation algorithm and digital communication algorithms, modifications of the current loop control circuit to allow signal modulation used by digital communications of $1200 \mathrm{~Hz}$ and $2000 \mathrm{~Hz}$, a voltage source project, which envisioned efficiency and considered the limits of current consumption.

Results of this architecture show that the 4-20mA transmitter's characteristics, used as a starting point for the product, are maintained and that digital measurements present $0.05 \%$ FS (Full Scale) less error than analogical measurements taken by the same transmitter. This presents a significant error reduction when compared to the total error of the system, which is 0, $2 \% F S$. The prototypes used for measurements were tested during 35 continuous days, validating their electrical installation and software.
\end{abstract}




\section{SUMÁRIO}

\section{Lista de llustrações}

\section{Lista de Abreviaturas e Siglas}

1 Introdução e Apresentação do Problema.

1.1 Objetivos e Justificativa . . . . . . . . . . . . . . . . 15

1.1 .1 Objetivo Geral . . . . . . . . . . . . . . . . . 15

1.1 .2 Objetivos específicos . . . . . . . . . . . . 15

1.1 .3 Justificativa . . . . . . . . . . . . . . . . . 15

1.2 Metodologia de Trabalho . . . . . . . . . . . . . 17

1.3 Cronograma . . . . . . . . . . . . . . . 20

2 Transmissor de Pressão Piezoresistivo 22

2.1 Fundamentação Teórica. . . . . . . . . . . . . . . . . . . 22

2.1.1 Sensores de Pressão . . . . . . . . . . . . . . . . . . . 22

2.1.1.1 Sensores de Pressão Piezoresistivos MEMS . . . . 23

2.1.2 Teoria dos Algoritmos de Compensação . . . . . . . . . . . . 24

2.1.2.1 Compensação Baseada em Resistências . . . . . . 26

2.1.2.2 Compensação Baseada na Modificação da Fonte de Excitação . . . . . . . . . . . . . . . . . . . 27

2.1 .3 Calibração . . . . . . . . . . . . . . . . . . . 27 
2.1.3.1 Calibração Polinomial . . . . . . . . . . . . . . . . 28

2.1.4 Protocolos de Comunicação Industrial . . . . . . . . . . . . 28

2.1.4.1 Introdução: . . . . . . . . . . . . . . 28

2.1.4.2 Foundation Fieldbus, HART e ModBus . . . . . . 30

2.2 Estado da arte . . . . . . . . . . . . . . . . . . . 32

2.2.1 Sensores Piezoresistivo de pressão . . . . . . . . . . . . . . 32

2.2.2 Arquitetura dos Transmissores de Pressão . . . . . . . . . . . 34

2.2.3 Compensação e Calibração . . . . . . . . . . . . . . . 34

2.2.4 Comunicações Industriais . . . . . . . . . . . . . . . 35

2.3 Transmissor de Pressão Piezoresistivo da MEMS Ltda. . . . . . . . . 35

2.3.1 Transmissor com Saída 4-20 mA a dois fios. . . . . . . . . 35

2.3.2 Algoritmo de Compensação e Calibração. . . . . . . . . . . . 37

2.4 Protocolo de Comunicação HART ${ }^{\circledR} \ldots$. . . . . . . . . . . . . . . . . 39

2.4.1 Camada Física . . . . . . . . . . . . . . . . . . . 40

2.4.2 Camada de Enlace de Dados . . . . . . . . . . . . . . . . 41

2.4.2.1 Controle de Acesso ao Meio . . . . . . . . . . . 43

2.4.3 Camada de Aplicação . . . . . . . . . . . . . . . . . . . . . . 44

2.5 Arquitetura Proposta . . . . . . . . . . . . . . . . . . . . 47

2.5.1 Requisitos Arquitetura Proposta . . . . . . . . . . . . . 48

3 Projeto do Transmissor 51

3.1 Projeto do hardware do transmissor . . . . . . . . . . . . . . 51 
3.1.1 Seleção dos Componentes . . . . . . . . . . . . . . . . 51

3.1.2 Projeto Bloco Fonte Chaveada . . . . . . . . . . . . . . . 53

3.1.2.1 Projeto Bloco Fonte Linear $3 v \ldots 56$

3.1.2.2 Projeto Bloco Fonte de Excitação do Sensor . . . . 56

3.1.3 Projeto Bloco Fonte de Corrente de Laço . . . . . . . . . . . 57

3.1.4 Projeto Circuitos Adicionais Para o Modem HART ${ }^{\circledR}$. . . . . 58

3.1.5 Microcontrolador e as Suas Interfaces . . . . . . . . . . 60

3.1 .6 Simulações . . . . . . . . . . . . . . . 6 60

3.1 .7 Projeto de Circuito Impresso . . . . . . . . . . . . . . 62

3.1.8 Projeto do firmware do transmissor . . . . . . . . . . 65

3.1.8.1 Projeto SAPs Camada Física . . . . . . . . . . . . . 65

3.1 .9 Projeto SAPs Subcamada MAC . . . . . . . . . . 66

3.1.9.1 Recepção: . . . . . . . . . . . . . . . . . . 67

3.1.9.2 Transmissão: . . . . . . . . . . . . . 69

3.1.9.3 Erros: . . . . . . . . . . . . . 69

3.1.10 Projeto SAPs Sub-camada LLC . . . . . . . . . . . . . . 69

3.1.11 Projeto SAPs Camada de Aplicação . . . . . . . . . . . . . 71

3.1.12 Projeto SAPs Camada de LLM . . . . . . . . . . . . . . . . 74

3.1.12.1 Firmware MAX1464 . . . . . . . . . . . . 74

3.1.12.2 Modificações Firmware MAX1464 . . . . . . . . . 75

3.1.12.3 Camada LLM no PIC . . . . . . . . . . . . . 76

3.2 Procedimento de Compensação e Calibração. . . . . . . . . . . . . 76 
4.1 Medições de Validação dos Blocos do Protótipo . . . . . . . . . . . 78

4.1 .1 Regulador Chaveado . . . . . . . . . . . . . . 78

4.1 .2 Regulador Linear . . . . . . . . . . . . . . . . . 80

4.1.2.1 Corrente do Transmissor . . . . . . . . . . . . 81

4.1 .3 Modem HART ${ }^{\circledR} \ldots \ldots \ldots$. . . . . . . . . . . . . . 81

4.1 .4 Corrente de Laço . . . . . . . . . . . . . . . . . . . . . . . 83

4.1 .5 Circuito Modem HART DS8500 . . . . . . . . . . . . . . . . 84

4.1.6 Deslocadores de tensão . . . . . . . . . . . . . 85

4.2 Testes protocolo de comunicação HART ${ }^{\circledR} \ldots$. . . . . . . . . . . 86

4.3 Caracterização dos Protótipos . . . . . . . . . . . . . . . . . . . 87

4.4 Conclusões dos testes dos protótipos . . . . . . . . . . . . . . . 91

5 Conclusões 96

Referências 


\section{LISTA DE ILUSTRAÇÕES}

1 Wet etching usando $\mathrm{KOH}$ ou $\mathrm{TMAH} . \ldots . . . . . . . . . . .24$

2 Pirâmide da automação . . . . . . . . . . . . . . . . . . . . . . . . . 29

3 Uso dos protocolos de comunicação na indústria . . . . . . . . . . 30

4 Vista lateral de um sensor de pressão piezoresistivo . . . . . . . . . 33

5 Blocos de um transmissor $4-20 \mathrm{~mA} \ldots \ldots$. . . . . . . . . . 36

6 Blocos do transmissor $4-20 m A$ da MEMS Ltda. . . . . . . . . . . 37

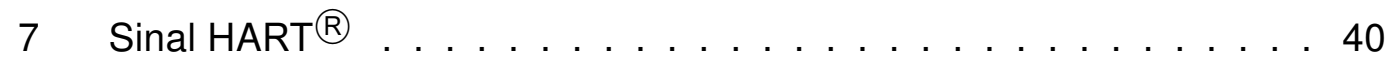

8 Limites sinalização digital para $1200 \mathrm{~Hz}$ e $2200 \mathrm{~Hz}$. . . . . . . . . . . 42

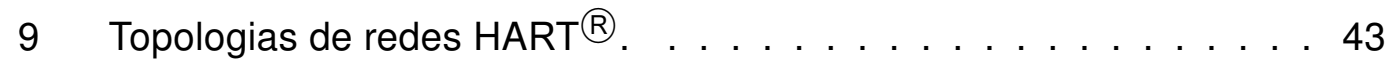

10 Controle de acesso ao meio no HART ${ }^{\circledR} \ldots \ldots . . . . . . . . .43$

11 Proposta Arquitetura transmissor HART ${ }^{\circledR}$. . . . . . . . . . . . . . . 48

12 Proposta Arquitetura transmissor HART ${ }^{\circledR}$ modificada. . . . . . . . . . 54

13 Esquemático da Fonte Comutada . . . . . . . . . . . . . . . . 56

14 Esquemático da Fonte Linear . . . . . . . . . . . . . . . . 56

15 Fonte de excitação do sensor . . . . . . . . . . . . . . . . 57

16 Esquemático da Fonte de Corrente do laço . . . . . . . . . . . . . 59

17 Circuito do modem HART ${ }^{\circledR} \ldots \ldots$. . . . . . . . . . . . . 59

18 Deslocador de nível . . . . . . . . . . . . . . . . . . 6 60

19 simulaçõo saída fonte comutada . . . . . . . . . . . . . . . 61 
20 simulação ruído na corrente de laço. . . . . . . . . . . . . . . . . 62

21 Saturação no sinal HART ${ }^{\circledR} . \ldots \ldots$. . . . . . . . . . . . . . 62

22 Consumo Regulador Comutado . . . . . . . . . . . . . . 63

23 Esquemático do Circuito . . . . . . . . . . . . . . . . . . . 64

24 Diagrama implementação SAPs camada física. . . . . . . . . . . . 67

25 Quadro Padrão HART ${ }^{\circledR} \ldots$. . . . . . . . . . . . . . . . . . . 67

26 máquina de estados de recepção da subcamada MAC. . . . . . . . 68

27 SAPs subcamada MAC. . . . . . . . . . . . . . . . . . 70

28 Sub-camada LLC . . . . . . . . . . . . . . . . . . . . . . . . . . 71

29 Firmware MAX1464. . . . . . . . . . . . . . . . 76

30 Transmissores usados para testes. . . . . . . . . . . . . . 79

31 Corrente de laço vs. saída normalizada do MAX1464. . . . . . . . . 84

32 Esquema para os testes do protótipo . . . . . . . . . . . . 87

33 Testes comandos universais (Descrição do equipamento) . . . . . . . 87

34 Testes comandos universais (Variáveis dinâmicas). . . . . . . . . . 88

35 Testes comandos pratica comum. . . . . . . . . . . . . 89

36 Erro da saída analógica do protótipo \#4 em a 50 Cdo primeiro ciclo de temperatura. . . . . . . . . . . . . . . 90

37 Mudanças do erro com o tempo para o protótipo \#2. . . . . . . . . . 92

38 Erro da saída digital do protótipo \#5 em $0^{\circ} \mathrm{Cdo}$ último ciclo de temperatura. ......................... 93

39 Superfícies do erro para a saída analógica de todos os protótipos. 94 
40 Superfícies do erro para a saída digital de todos os protótipos. . . . . 95 


\section{LISTA DE ABREVIATURAS E SIGLAS}

ABINEE Associação Brasileira da Indústria Elétrica e Eletrônica

ADC Analogue to Digital Converter

CAN Controller Area Network

CFS Courtois-Finiasz-Sendrier

CI Circuito Integrado

C\&C Compensação e Calibração

CLP Controlador Lógico Programável

DAC Digital to Analogue Converter

DSSP Digital Sensor Signal Processor

EEPROM Electrically Erasable Programmable Read-Only Memory

FF Fieldbus Foundation

FSK Frequency Shift Keying

GPIO General Purpose Input/Output

HCF HART Comunication Fundation

IEC International Electrotechnical Commission

IPS Integrated Pressure Sensors

LLC Logical Link Control

MAC Media Access Control

MEMS Microelectromechanical Systems 
OLE Object Linking and Embedding

OPC OLE for Process Control

PGA Programmable-gain Amplifier

PV Primary Variable

PWM Pulse-with Modulation

RAM Random-access Memory

ROM Read-Only Memory

RMS Root Mean Square

RTOS Real-time Operating System

SAP Service Access Point

SPI Serial Peripheral Interface

TBE Total Error Band

TCR Temperature Coefficient of Resistance

UART Universal Asynchronous Receiver-Transmitter

USP Universidade de Sao Paulo 


\section{INTRODUÇÃO E APRESENTAÇÃO DO PROBLEMA.}

Este trabalho foi motivado pela necessidade desenvolver tecnologia brasileira para os sistemas de automação de processos produtivos, pois atualmente esses sistemas são um requisito para a sobrevivência de qualquer empresa no sector industrial. Na literatura foram identificadas as duas variáveis físicas mais usadas nos sistemas de automação: pressão e a temperatura. Também foi identificado que os sistemas de automação atuais fazem uso de transmissores inteligentes, as principais vantagens destes são a capacidade de comunicação digital e a disponibilidade de opções de configuração e monitoração de parâmetros de estado do equipamento. Finalmente o custo é um fator importante para qualquer produto no mercado, e pensando nisso foram identificados os sensores baseados em semicondutores como os mais indicados para este tipo de projetos. A principal desvantagem desses sensores entretanto, é a necessidade de realizar uma calibração para garantir um nível de erro determinado. (EATONY; SMITH, 1997).

Tomando como base essas ideias é proposto neste trabalho contribuir com o desenvolvimento de equipamentos de medição de alta exatidão e baixo custo usando sensores de pressão piezoresistivos que possam ser utilizados em ambientes industriais, com os padrões de comunicação industrial HART ${ }^{\circledR}$ e 4 - 20 mA. 


\subsection{Objetivos e Justificativa}

\subsubsection{Objetivo Geral}

Desenvolver um protótipo de transmissor de pressão digital de altíssima exatidão compensado e calibrado em temperatura com comunicação HART, baseado em sensores de silício piezoresistivos.

\subsubsection{Objetivos específicos}

- Projetar o sistema eletrônico necessário para o transmissor.

- Desenvolver a engenharia de software necessária para o firmware e as ferramentas compensação e calibração do transmissor.

- Construir protótipos do transmissor.

- Testar os protótipos do transmissor.

- Adequar e aplicar aos protótipos à tecnologia de compensação, calibração e caracterização.

\subsubsection{Justificativa}

Dados da Associação Brasileira da Indústria Elétrica e Eletrônica (ABINEE) mostram que o faturamento relativo a fabricação local na área de automação passa de 503 milhões de dólares no ano 2002 a 1475 no ano 2009, enquanto as importações passaram de 776,1 a $2.015,0$ milhões de dólares no mesmo período (ABINEE, 2010). Portanto, é necessário para o Brasil o desenvolvimento de equipamentos nesta área visando nivelar a balança comercial.

A MEMS (Microssistemas Integrados de pressão Ltda.) é uma microempresa brasileira, a qual tem desenvolvido uma serie de transmissores de pressão: com saída 
em corrente 4-20 mA a dois fios, transmissores de pressão com saída em tensão, e está nas etapas finais do desenvolvimento de transmissores com Comunicação digital ModBus. Todos eles fazem uso da tecnologia de processamento digital do sinal para sensores ( Digital Sensor Signal Processor DSSP) para o processamento do sinal de saída do sensor piezoresistivo.

Levando em consideração que os transmissores já desenvolvidos têm características que podem ser aproveitadas para desenvolver um transmissor com comunicação digital com o padrão HART, considera-se importante desenvolver uma nova linha de produtos num estagio superior e com possibilidades de se introduzir num setor do mercado mais exigente. Assim, é proposto neste trabalho desenvolver um transmissor de pressão com sensor piezoresistivo e protocolo de comunicação HART com camada física Bell202 tomando como base os sistemas desenvolvidos anteriormente. Os benefícios do HART com camada física Bell 202 são (HELSON, 2011):

- Capacidade Digital: permite o acesso a todos os parâmetros e o diagnostico do dispositivo de campo, o que permite o acompanhamento online do instrumento. Também suporta instrumentos multivariáveis.

- Compatibilidade Analógica: permite a comunicação analógica e digital simultaneamente e não é necessária uma fiação adicional à usada nos equipamentos 4-20 mA já existentes, sendo útil para a atualização dos sistemas de automação tradicionais que têm sistemas de controle 4-20 mA.

- Interoperabilidade: é um padrão de fato totalmente aberto, no qual são especificados completamente os comandos universais e a estrutura dos dados.

- Disponibilidade: tecnologia provada em campo com mais de 20.000 .000 instalações, é o protocolo mais usado na indústria nos instrumentos inteligentes de campo atualmente. 
As outras duas camadas físicas suportadas atualmente pelo protocolo HART são a RS-485 e una versão modificada da IEEE 802.15.4 chamada wirelessHART, estas não possuem a compatibilidade com o sinal analógico 4-20 mA, o que implica que não são compatíveis com os sistemas de automação tradicionais. O uso de sensores piezoresistivos e da camada Bell 202 para o desenvolvimento do transmissor permitirá ter um produto de alta qualidade e baixo custo, fazendo com que as empresas possam atualizar de forma progressiva seus sistemas de automação e controle.

Este trabalho será desenvolvido em parceria entre o LSI-USP e a MEMS Ltda e, pretende suprir as necessidades de atualização dessas empresas, que atualmente usam tecnologias tradicionais em seus sistemas de automação. E serve como base para o desenvolvimento do transmissor de pressão piezoresistivo com protocolo wirelessHART, pois as duas camadas físicas compartilham a mesma camada de aplicação, permitindo reutilizar os programas desenvolvidos e as interfases com o firmware do DSSP, portanto, um futuro desenvolvimento deverá se focar só nos problemas próprios da comunicação sem fios. Fato importante, posto que é esperado que o wirelessHART seja amplamente utilizado nos sistemas de automação futuros (CASSIOLATO, 2011).

\subsection{Metodologia de Trabalho}

O ciclo de vida de qualquer projeto de engenharia pode-se dividir em 4 etapas, problema inicial, modelo do problema, modelo da solução e solução inicial. As atividades planejadas para o desenvolvimento deste projeto em cada uma das etapas são apresentadas a continuação:

- Problema inicial: a definição do problema geral foi feita conjuntamente com o orientador, levando em consideração as necessidades e limitações do grupo 
atualmente. O resultado deste processo foi a definição dos objetivos apresentados na seção 1.1 .

- Modelo do problema: nesta etapa foram identificados claramente os requisitos do sistema, bem como os subsistemas e as relações entre eles. Obtendo um diagrama geral no qual são especificados os requisitos de cada subsistema para garantir o sucesso do projeto. As atividades executadas nessa etapa foram:

- Estudo do transmissor de pressão piezoresistivo já desenvolvido e do algoritmo de compensação e calibração implementado no processador digital do sinal do sensor (DSSP): foi efetuado um estudo detalhado da documentação técnica dos transmissores já desenvolvidos e do procedimentos usados na compensação e calibração.

- Estudo da informação técnica da $H A R T^{\circledR}$ Communication Foundation (HCF): HART ${ }^{\circledR}$ é um protocolo aberto desde 1993, promovido e suportado pela HCF, portanto, um estudo detalhado de toda a informação técnica disponível foi feita, antes de enfrentar o desenvolvimento tecnológico para conseguir um transmissor compatível com todos os requisitos da HCF.

- Proposta da arquitetura de sistema: com base nos estudos das diferentes partes que compõem o sistema, foi especificada uma versão inicial do projeto completo a desenvolver. Esta versão contem o diagrama do sistema com as entradas e as saídas de cada componente, assim como a função deles. Além disso, inclui a seleção dos componentes usados no hardware do transmissor.

- Modelo da solução: Com os requisitos definidos na etapa anterior, se projetou cada um dos subsistemas, tanto em hardware como em software, res- 
peitando os limites definidos. Nesta etapa verificações do funcionamento de cada subsistema devem ser feitas. As atividades nesta etapa foram:

- Projeto e desenvolvimento do hardware do transmissor: o DSSP em que está baseada a tecnologia da MEMS não é compatível com o formato de comunicação digital de HART. Portanto, foi desenvolvido: uma interface entre a saída serial do DSSP e o microprocessador que suportará o protocolo HART; os filtros analógicos necessários para o modem HART que será utilizado e, finalmente, otimizado o consumo de corrente do circuito para atingir o requisito de consumo total inferior a 4 $\mathrm{mA}$.

- Projeto e desenvolvimento do firmware: o protocolo HART precisa de um dispositivo que processe a informação enviada digitalmente, por tanto, o uso de um micro-controlador é necessário. E foi preciso desenvolver o firmware para esse microprocessador, também foi preciso modificar o firmware atual do DSSP para que suporte os requisitos do protocolo HART.

- Desenvolvimento das ferramentas de caracterização do transmissor digital: como o transmissor digital a ser desenvolvido terá aplicações que não estão no campo de aplicações do transmissor com saída analógica, novas ferramentas de caracterização foram desenvolvidas usando o ambiente de medição já implementado para o transmissor analógico. Desta forma será possível testar e caracterizar as novas aplicações relacionadas com a comunicação digital $\mathrm{HART}^{\circledR}$.

- Adequação do procedimento de compensação e calibração: os procedimentos de compensação e calibração anteriormente desenvolvidos devem ser adaptados para cumprir com os requisitos dos dispositivos HART ${ }^{\circledR}$. 
- Solução inicial: é a ultima etapa do processo de desenvolvimento neste trabalho, e tem como objetivo a verificação dos resultados do sistema, comparando as medições com os requisitos definidos durante a execução e nos objetivos propostos. As atividades que compõem esta etapa são:

- Teste do protótipo e validação do sistema: inicialmente deve-se testar o desempenho do hardware para verificar se ele atende os requisitos do protocolo HART e do sensor piezoresistivo. Posteriormente validar o firmware do transmissor usando os testes descritos na especificação HART. Finalmente caracterizar todo o transmissor de pressão piezoresistivo para determinar a precisão, exatidão, linearidade e dependência com a temperatura do transmissor

- Elaboração de trabalhos para divulgação e apresentação da dissertação: Durante cada estagio da pesquisa serão feitos relatórios com as experiências adquiridas, os problemas, as soluções propostas e as conclusões.

\subsection{Cronograma}

Ver tabela 1. 


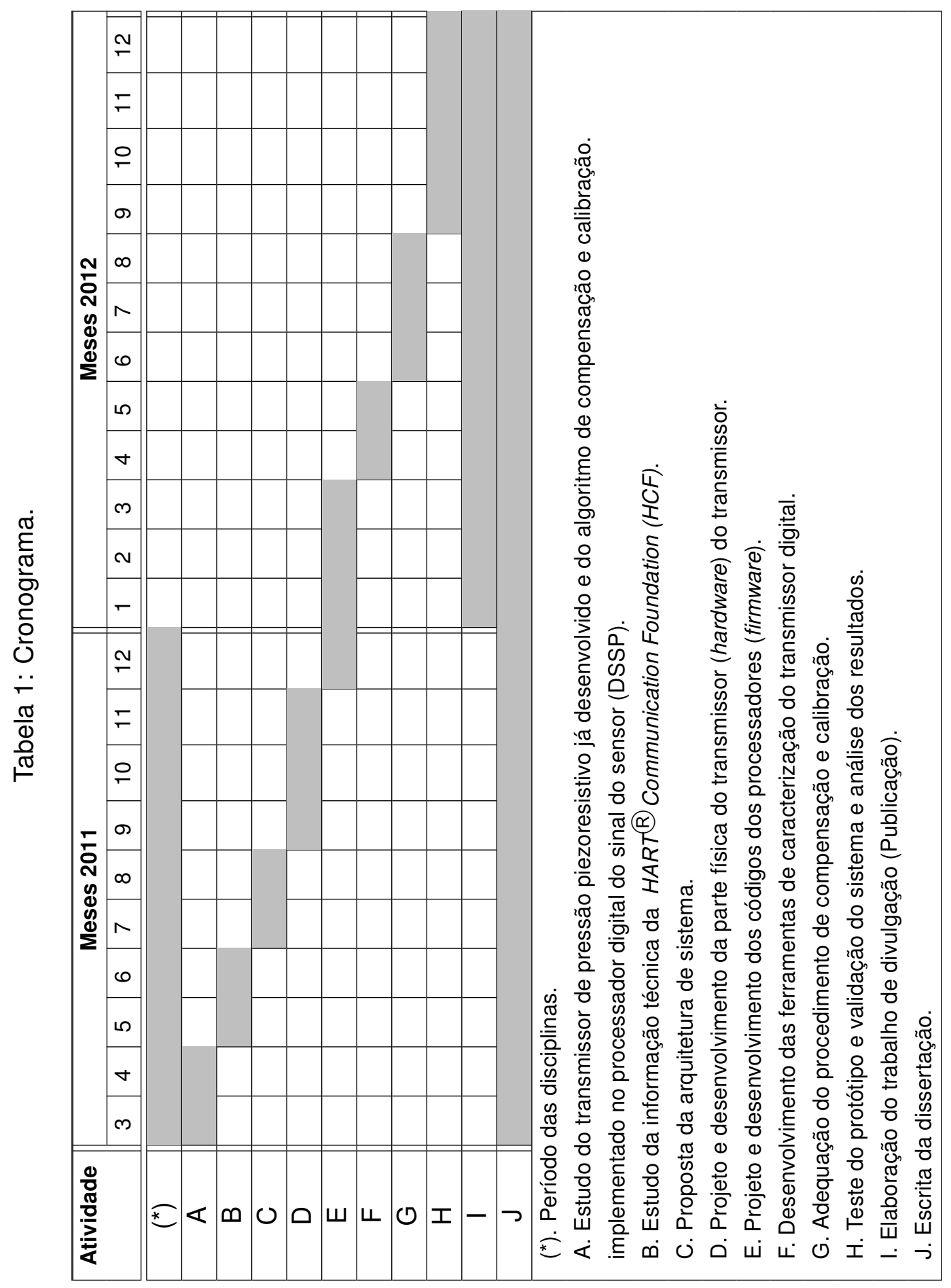




\section{TRANSMISSOR DE PRESSÃO PIEZORESISTIVO}

Nesta seção inicialmente são apresentados de forma resumida os fundamentos teóricos de um transmissor de pressão piezoresistivo e o estado da arte nas áreas relacionadas ao tema. Posteriormente serão discutidos os resultados da etapa de modelo do problema (seção 1.2), finalizando com a proposta da arquitetura do sistema transmissor de pressão piezoresistivo com protocolo de comunicação HART ${ }^{\circledR}$.

\subsection{Fundamentação Teórica do Transmissor de Pressão Piezoresistivo Inteligente}

\subsubsection{Sensores de Pressão}

Comummente a medição da pressão é baseada na deformação causada por ela. Diferentes configurações mecânicas tem sido usadas, mas atualmente a que possui maior aceitação é o uso de uma membrana ou diafragma. A principal razão para aquilo é que a deflexão do diafragma é linear com a pressão, como indicam as equações seguintes (TIMOSHENKO; WOINOSKY-KRIEGER, 1959):

$$
w(r)=\frac{P a^{4}}{64 D}\left[1-\left(\frac{r}{a}\right)^{2}\right]^{2},
$$

onde:

$w=$ deflexo. 
$r=$ distanciaradialaocentro.

$a=$ raiododiafragma.

$D=$ rigidezflexural.

$P=$ presso.

Estas equações somente são válidas para uma membrana circular com deformações menores à metade da espessura do diafragma e sem (??) interno na membrana.

\subsubsection{Sensores de Pressão Piezoresistivos MEMS}

os sensores piezoresistivos são possivelmente os mais usados como transductores para força, pressão ou medidas relativas (H. et al., 1995). A historia destes sensores inicia depois da invenção do transistor bipolar no ano 1947, quando as pesquisas focaram-se principalmente na caracterização das propriedades dos semicondutores. Para o ano 1954, Smith reportou a mudança na resistência eléctrica devido a um stress mecânico aplicado no cristal (piezoresistividade) tanto no silício como no germânio (SMITH, 1954). Propriedade que permitiu a construção de strain-gauge nesses semicondutores.

As strain-gauge medem a deformação num material fazendo-as ideais para a medição de pressão. Diferentes sistemas de medição usando semicondutores foram usados, iniciado com strain-gauge piezoresistivas fixadas em diafragmas metálicos, e progredindo até diafragmas construídos no silício na década dos 70 e 80 (EATONY; SMITH, 1997). Os diafragmas de silício mono cristalino apresentam ótimas propriedades mecânicas: força, flexibilidade, repetividade e não possuem histerese mecânica, mas os coeficientes de temperatura da resistência ( Temperature Coefficient of Resistance - TCR) são grandes. No caso dos materiais policristalinos as propriedades mecânicas não são tão boas como no caso anterior, pois o stress interno afeta a linearidade e diminui a sensibilidade, mas controlando 
o processo de fabricação é possível diminuí-lo e controlar os TCR.

Atualmente os projetos de sensores piezo resistivos variam muito entre eles, mas todos compartilham o uso de silício como material do diafragma e o uso de quatro strain-gauge tipo P numa configuração de ponte de Wheatston (JANUSZ; BRYZEK, 1983).Para a produção dos sensores piezoresistivos as técnicas mais usadas para a fabricação do diafragma são o wet etching com Potassium hydroxide $(\mathrm{KOH})$ ou com Tetramethylammonium hydroxide (TMAH). Por gerar uma membrana com bordas trapezoidais (ver figura 1), permitir um bom controle no tamanho e localização do diafragma, melhorar o desempenho dos piezoresistores e facilitar a produção em massa (NGO H. D. AMD THAM; SIMON; OBERMEIER, 2008).
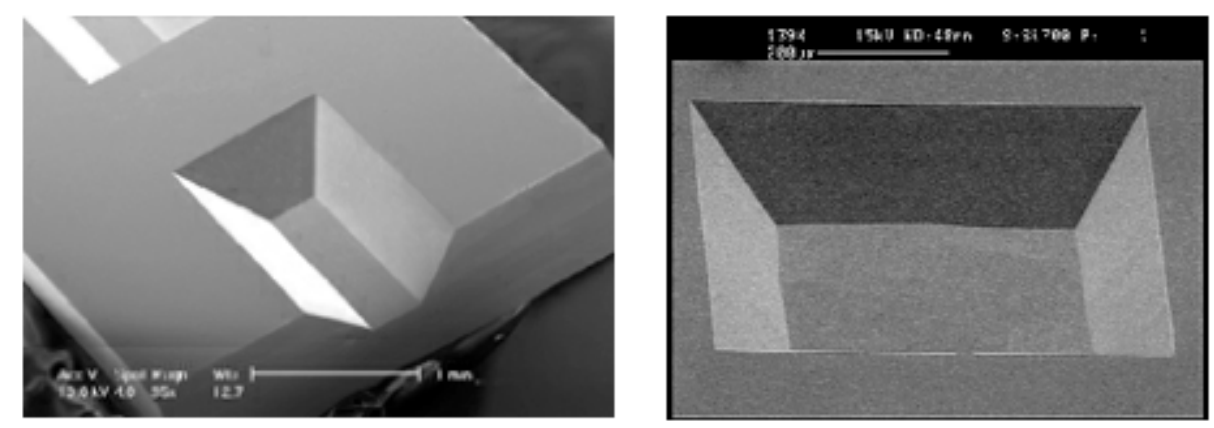

Figura 1: Wet etching usando KOH ou TMAH. (MNX, 2014).

\subsubsection{Teoria dos Algoritmos de Compensação}

Devido a que a fabricação dos sensores de pressão piezoresistivos utiliza técnicas de construção de circuitos integrados $(\mathrm{Cl})$, algumas características entre diferentes lotes de produção podem variar consideravelmente, e numa menor proporção entre sensores de um mesmo lote. Alguns dos erros apresentados pelas variações dos sensores são (JANUSZ; BRYZEK, 1983):

- Erros estáticos: são erros de baixa frequência, conhecidos como erros de calibração, classificados como erros de não linearidade, repetibilidade e histerese. 
- Não linearidade: se calcula a partir do maior desvio entre a media das medições e a reta de melhor ajuste, depende principalmente da fonte de excitação da ponte piezoresistiva, se for uma fonte de corrente continua a mudança da resistência com a pressão induz componentes de segunda ordem. Também no caso de sensores relativos, as assimetrias no diafragma introduzem componentes não lineares dependendo da direção da pressão.

- Repetitividade: a não repetibilidade é a diferença algébrica entre os valores extremos obtidos por uma sequência de medições consecutivas da saída por um pequeno período de tempo e depende, principalmente, do stress no invólucro.

- Histerese: é a propriedade de um dispositivo ou instrumento pela qual mostra valores de saída diferentes em relação aos valores de entrada dependendo da direção da sequência em que os valores de entrada são aplicados e geralmente causado pelo stress no empacotamento.

- Erros com a temperatura: este tipo de erro é a maior limitação das aplicações dos sensores de pressão piezoresistivos. Um efeito importante nos sensores é que devido a dependência com a temperatura todos os parâmetros do sensor variam dependendo da fonte de excitação, pelo auto-aquecimento.

○ Erro em zero de pressão: é o desvio de zero do sinal de saída quando a entrada é zero (pressão), causado pela incompatibilidade térmica dos materiais usados para a fabricação do sensor, stress térmico transferido desde o encapsulamento e as cargas armazenadas no oxido de silício.

- Erro na sensibilidade: definido como o desvio máximo na sensibilidade quando a temperatura varia desde a temperatura de referencia (Tref) até qualquer outra temperatura ( $T$ ), e é devido à dependência da piezoresistividade com a temperatura. Em sensores corretamente desaco- 
plados, tem um coeficiente negativo, pelo que a sensibilidade diminui e a resistência da ponte aumenta.

- Erros de estabilidade do ruido: Pelo fato de ser um sensor de tecnologia MEMS (Sistemas Micro-Eletromecânicos), possui duas fontes de ruido, mecânico e elétrico.

- Mecânico: Geralmente de baixa frequência, é devido a stress não estável introduzido no processo de fabricação e no processo de encapsulamento do chip. Ruídos que podem ser eliminados com um processo de fabricação bem controlado.

- Elétrico: são os mesmo que afetam aos circuitos integrados lineares, mas boas técnicas de processo permitem níveis de ruido perto do ruido térmico.

Todos os tipos de erros antes descritos podem ser corrigidos num processo de Compensação e Calibração (C\&C). Portanto o desempenho de ditas técnicas determinará o desempenho do sistema de medição.

\subsubsection{Compensação Baseada em Resistências}

O problema de balancear pontes resistivas para um ou vários sensores piezoresistivos é apresentado em (CHAN, 2008), onde apresentada uma técnica que de resistências externas para compensar as variações com a temperatura. Nesse artigo o sensor está configurado em meia ponte de Wheatstone, e para a compensação são usados duas resistências adicionais.

Em (AKBAR; SHANBLATT, 1992) é usada a técnica Double bridge temperaturecompensation, para eliminar as variações devidas à temperatura. Essa técnica consiste em usar uma segunda ponte resistiva no mesmo chip em que está feito o diafragma do sensor, assim as variações dessa ultima ponte resistiva serão devi- 
das unicamente à temperatura, compensando deste modo a ponte piezoresistivo sensível à pressão e temperatura. O trabalho é validado usando simulações de ponte resistivas com modelos desenvolvidos pelos autores.

\subsubsection{Compensação Baseada na Modificação da Fonte de Excitação}

Para compensar com a temperatura e calibrar a saída do sensor, em (YAMADA et al., 1983) é apresentado um sensor de pressão piezoresistivo integrado ou (IPS) para aplicações automotivas, no qual a compensação do fundo de escala (ou span) é feita pela variação da tensão de excitação da ponte piezoresistiva, usando um circuito analógico integrado no mesmo chip.

Nesta mesma linha de ideias Beltran propõe em (BELTRáN; PRIETO; R., 2002) o uso de uma fonte de corrente com coeficientes de temperatura inversos aos do sensor de pressão piezoresistivo para compensar o sensor com a temperatura, usando para aquilo resistores na fonte de corrente com coeficientes térmicos semelhantes aos encontrados no sensor. Resultados similares são apresentados em (GAKKESTAD; OHLCKERS; HALBO, 1995), nesse artigo os autores propõem o uso de uma fonte de tensão variável para corrigir as variações na sensibilidade do sensor de pressão piezoresistivo. Os resultados apresentados são baseados em simulações feitas com um modelo de sensor desenvolvido por eles. A variação da sensibilidade foi aproximada usando um modelo linear, mostrando um erro da sensibilidade de 0,6\% após C\&C em sensores que sem compensação apresentam variações de entro o $7 \%$ ao $16 \%$.

\subsubsection{Calibração}

Calibração faz referência ao processo de aplicar vários valores de pressão conhecidos ao sensor, e medir o sinal (elétrico) de saída, para assim obter a função de transferência de forma experimental. A calibração também inclui o processo de 
modificar a função de transferência, para garantir um sinal de saída numa forma padrão e com certa exatidão (sob certas condições) (HORN; HUIJSING, 1997).

\subsubsection{Calibração Polinomial}

Van Der Horn em (HORN; HUIJSING, 1997) apresenta os métodos de calibração polinomial, de uma e duas dimensões. Algoritmos que permitem realizar a calibração de um sensor fazendo o calculo dos coeficientes em cada medição sem modificar os pontos de ajuste anteriores, evitando a necessidade de os armazenar numa tabela para depois calcular os coeficientes de ajuste. A versão bidimensional é o algoritmo proposto para a calibração de sensores sensíveis a duas variáveis, como é o caso dos sensores piezoresistivos de pressão. Caso em que são usadas medições a diferentes temperaturas num valor fixo de pressão. Técnica pode ser implementada tanto analogicamente como digitalmente.

Outra técnica foi introduzida pela empresa Maxim, que desenvolveu um chip especificamente para realizar a compensação e calibração de sensores. Composto de dois amplificadores operacionais, um ADC, um processador digital e um DAC basicamente. Em (MAXIM, 2003) apresenta-se um algoritmo para a compensação digital do sinal da saída de um sensor, o qual usa uma matriz de dados de três por três ( três temperaturas e três pressões) para o calculo dos coeficientes de ajuste. O algoritmo faz uso dos polinômios de segunda ordem usados para calibrar o sinal de saída.

\subsubsection{Protocolos de Comunicação Industrial}

\subsubsection{Introdução:}

Atualmente nos sistemas de controle moderno, os transmissores além da informação da grandeza medida precisam fornecer: a informação de estado do equipamento, a informação de diagnostico (self-test), e a capacidade de configuração. 
O que obriga ao transmissor ter um sistema de comunicação digital que ofereça suporte a esses requisitos. Os dispositivos com ditas características são classificados como transmissores inteligentes.

Com o desenvolvimento dos transmissores inteligentes foram desenvolvidos diferentes protocolos de comunicação digital, cada um deles possuindo características que o fazem adequado para diferentes aplicações. As redes que usam estes protocolos são conhecidas como redes de campo, sendo os protocolos principalmente usados na atualidade nas indústrias o PROFIBUS, o Foundation Fieldbus (FF), o HART ${ }^{\circledR}$, o ModBus, o DeviceNet e o CAN ( The Controller Area Network) (ELSHAFEI, 2000).

Numa fabrica moderna o sistema de automação pode-se organizar em forma de

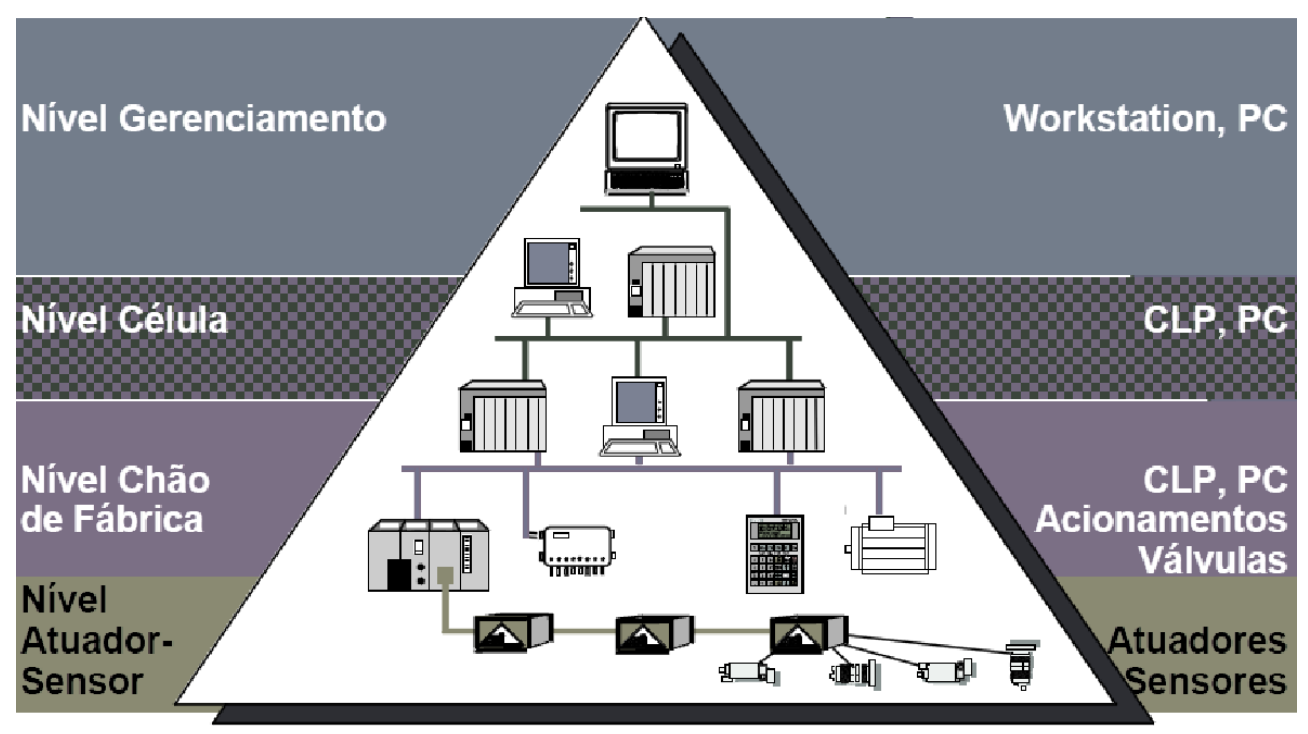

Figura 2: Pirâmide da automação (PEREIRA, 2001).

pirâmide, dividida em quatro níveis: gerenciamento, célula, chão de fábrica e nível atuador-sensor (PEREIRA, 2001) em ordem decrescente de complexidade e velocidade de dados requeridas na comunicação digital (ver figura 2).

Portanto diferentes protocolos de redes de campo são usados para cada nível. Os transmissores de pressão pertencem ao nível atuador-sensor, no qual os protocolos usados são Foundation Fieldbus, Hart, ModBus, DeviceNet e CAN. Os dois 
últimos foram criados para comunicar equipamentos simples como interruptores, leitores de códigos de barras, e outros que precisam de baixas velocidades de comunicação (ELSHAFEI, 2000). Os protocolos maiormente usados para a comunicação de transmissores são o FF (Foundation Fieldbus), ModBus e o HART ${ }^{\circledR}($ ver figura 3).

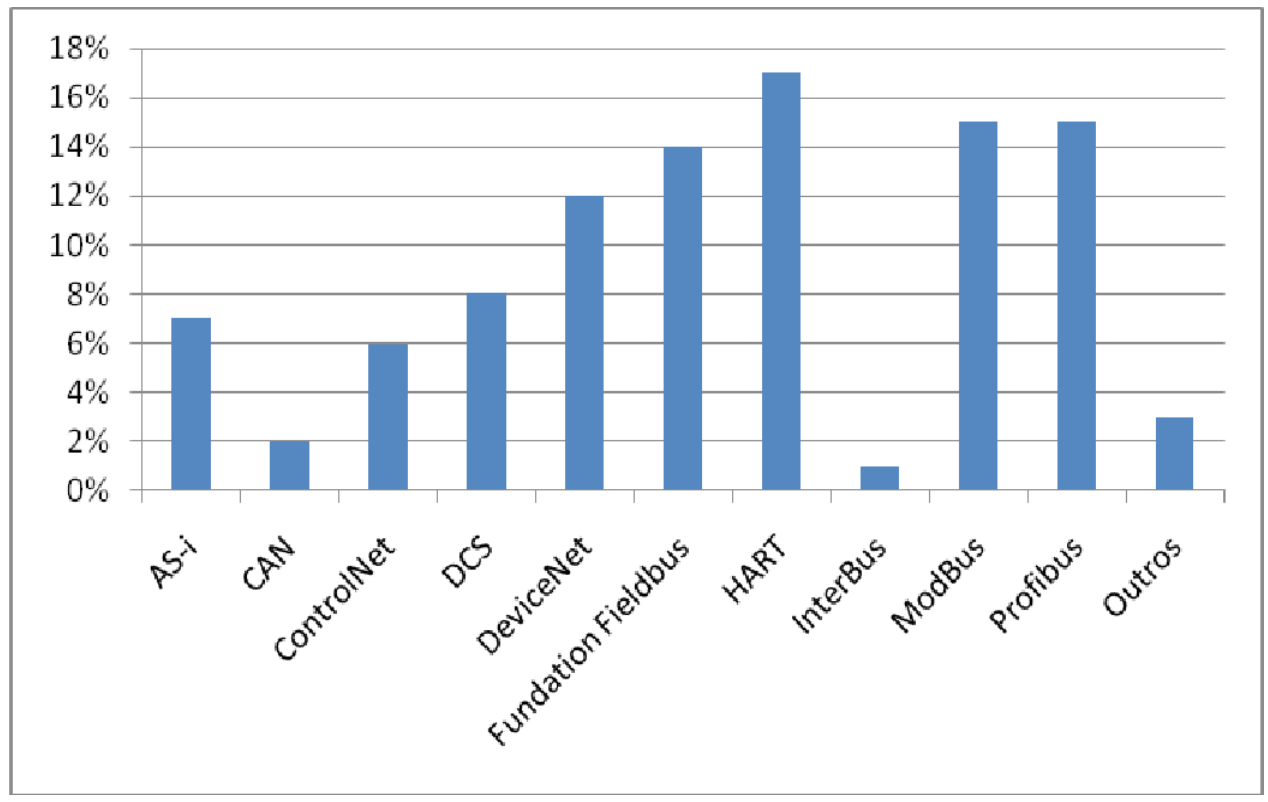

Figura 3: Uso dos protocolos de comunicação na indústria tomada de (MCALLISTER, 2007).

\subsubsection{Foundation Fieldbus, HART e ModBus}

O protocolo ModBus foi inicialmente criado para a comunicação entre CLP's e define o quadro (frame), mensagens e funções de leitura e escrita ao nível de bits e registros, sendo responsabilidade do fabricante do equipamento especificar como é organizada a informação nos registros e a forma em que se deve interpretá-la (MODBUS-IDA, 2006). Após de 1979 tornou-se um padrão devido a sua adoção pela Modicom (KASCHEL; PINTO, 2006). Embora o ModBus não fosse concebido especificamente para uso em transmissores, é comumente usado por fabricantes para os transmissores inteligentes devido a sua simplicidade.

Os equipamentos com o protocolo HART foram introduzidos no mercado na dé- 
cada de 1980 e neste momento a HART Comunication Foundation (HCF) estima uma quantidade de mais de 20 milhões de equipamentos em uso (HELSON, 2011). O padrão FF inicia na década de 1990 e a Foundation Fieldbus estima haver milhões de equipamentos instalados atualmente, mas não divulga um valor preciso (FOUNDATION, 2010).

O protocolo HART como o protocolo FF fornecem a informação de diagnóstico e permitem a configuração remota dos transmissores, mas cada qual possui características que o diferencia. A mais importante é que nos dispositivos HART com camada física Bell 202, a sinalização digital é enviada de forma simultânea com o sinal 4-20 mA, permitindo a compatibilidade com os sistemas tradicionais. Devido a isto muitos sistemas de controle fazem uso do sinal 4-20 mA para enviar a informação da Variável Primaria (PV) e ignoram a informação digital. Também é possível a configuração dos dispositivos HART numa rede de vários equipamentos onde a variável primaria de cada dispositivo é obtida de maneira puramente digital.

O protocolo FF é $100 \%$ digital e todos os dispositivos são conectados em paralelo. Podendo-se conectar até 32 equipamentos por segmento sem uso de repetidores (MCALLISTER, 2007). Na tabela 2 é mostrado que o HART e o FF são similares tecnicamente, porém o HART permite o uso do sinal analógico, e tem uma maior base instalada atualmente.

O HART é mantido pela HCF, que em setembro de 2007 liberou a versão 7.0, na qual foi incluída a camada física IEEE 802.15.4 versão do padrão chamada wirelessHART. Espera-se que o uso de redes sem fio na indústria aumente, pois numa pesquisa feita no ano 2005 pela ISA ((??)) mostrou que $30 \%$ das indústrias não usavam redes sem fio pela falta de um padrão internacional (HENNIG, 2009). 
Tabela 2: Comparação HART vs. FF (DEWEY, 2004).

\begin{tabular}{|l|c|c|}
\hline \multicolumn{1}{|c|}{ Característica } & HART ${ }^{\circledR 2}$ & Fieldbus \\
\hline \hline $\begin{array}{l}\text { Uso da sinalização 4-20 mA para indicar a } \\
\text { PV. }\end{array}$ & Sim & Não \\
\hline $\begin{array}{l}\text { Os dados enviados usando sinalização digi- } \\
\text { tal. }\end{array}$ & Sim & Sim \\
\hline Tipo de comunicação. & Token Passing & Token Passing \\
\hline Velocidade de comunicação. & 1200 bps & $31.25 K b p s$ \\
\hline Configuração e calibração remota. & Sim & Sim \\
\hline Permite o diagnóstico do equipamento. & Sim & Sim \\
\hline $\begin{array}{l}\text { Configuração de múltiplos dispositivos na } \\
\text { rede. }\end{array}$ & Sim (limitado) & Sim \\
\hline $\begin{array}{l}\text { Numero aproximado de dispositivos em ser- } \\
\text { viço. }\end{array}$ & $>20.000 .000$ & Não disponível \\
\hline $\begin{array}{l}\text { Permite o desenvolvimento de equipamentos } \\
\text { intrinsecamente seguro. }\end{array}$ & Sim & Sim \\
\hline Vendedor neutro. & Sim & Sim \\
\hline Suporta control in field & Não & Sim \\
\hline
\end{tabular}

\subsection{Estado da arte}

Para o desenvolvimento de um transmissor de pressão digital precisa-se de conhecimento de quatro temas principalmente: fabricação de sensores de pressão piezoresistivos, arquitetura dos transmissores de pressão, compensação e calibração de sensores e finalmente comunicações industriais. A continuação são descritos de forma resumida os últimos trabalhos científicos e técnicos apresentados sobre esses temas.

\subsubsection{Sensores Piezoresistivo de pressão}

Atualmente os projetos de sensores piezo resistivos variam muito entre si, mas todos compartilham o uso de silício como material do diafragma e de quatro straingauge tipo P numa configuração de ponte de Wheatstone (JANUSZ; BRYZEK, 1983).Para a produção dos sensores piezoresistivos as técnicas principalmente 
usadas para a fabricação do diafragma são o KOM ou TMAH, pelo fato de permitir um bom controle no tamanho e localização do diafragma, melhorar o desempenho dos piezoresistores e facilitar a produção em massa (NGO H. D. AMD THAM; SIMON; OBERMEIER, 2008).

$\mathrm{Na}$ área dos MEMS, pesquisas recentes visam otimizar alguns parâmetros. Em (NGO H. D. AMD THAM; SIMON; OBERMEIER, 2008) é proposto o uso de (??) para aumentar a sobrepressão suportada pelos sensores com o uso de etching plasma, processo que gera umas bordas arredondadas, diferente dos processo tradicionalmente usados que geram bordas retas, como observado na figura 4. Hsieh em (HSIEH et al., 2010) apresenta uma optimização da sensibilidade dos

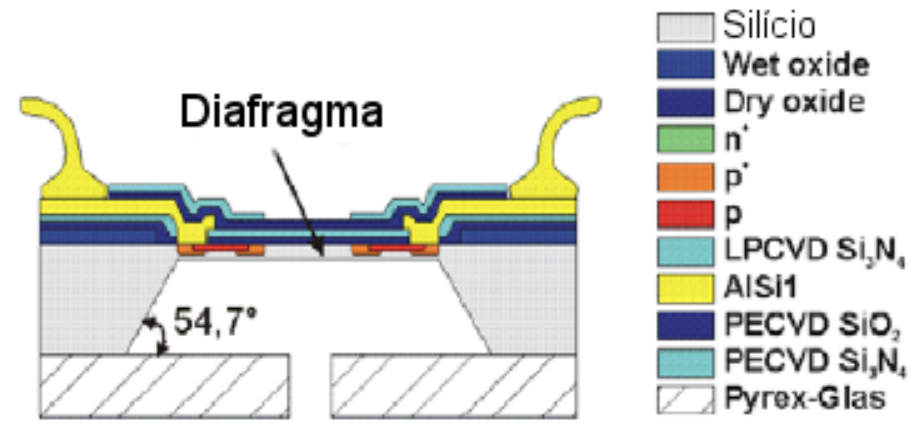

Figura 4: Vista lateral de um sensor de pressão piezoresistivo (NGO H. D. AMD THAM; SIMON; OBERMEIER, 2008).

sensores piezoresistivos, modificando diferentes fatores no processo de fabricação, tais como a quantidade, desvio, largura e comprimento dos piezoresistores, assim como a largura da membrana. Nos resultados desse trabalho são apresentados o melhor conjunto de parâmetros, com os quais se consegue um aumento na sensibilidade de 78.3mV/Bar a $94 \mathrm{mV} /$ Bar.

Finalmente uma nova linha de pesquisa está estudando os efeitos piezoresistivos em nano-fios. Como é o caso em (MONTES et al., 2011), onde são apresentados resultados do uso de hétero estruturas para aumentar o efeito piezoresistivo em nano-fios, o que indica um possível uso deles em sensores de tecnologia NEMS (nano-electro-mechanical sensors) para medição de pressão e força (como strain- 
gauge para a medição da deformação).

\subsubsection{Arquitetura dos Transmissores de Pressão}

Varias propostas de arquitetura para transmissores de pressão com protocolos de comunicação digital estão disponíveis na literatura atualmente: Jordana propõe um transmissor basado num micro controlador, no qual a resistência do sensor é medida diretamente pelo tempo de carga y descarga de um capacitor, evitando assim, os circuitos analógicos requeridos para a fonte de corrente usada para excitar os sensores piezoresistivos (JORDANA; ARENY, 2006). Una arquitetura mais complexa é presentada por Saponjic (SAPONJIC; ZIGIC, 2001), nesta se implementa um transmissor com protocolo de comunicação HART mediante um micro controlador y grande quantidade de componentes adicionais (transistores, amplificadores operacionais, etc.). Outra es basada num microcontrolador e um ADC externo que se utiliza para compensar y calibrar sensores piezoresistivos (JOHN et al., 2010). Por último, Chuan, presenta um transmissor basado num processador digital de sinal (DSP) (CHUAN; CHEN, 2010).

\subsubsection{Compensação e Calibração}

Nesta área na literatura existem diferentes métodos, baseados na linearização, ou no uso de modelos polinomiais para compensar e calibrar sensores. Mas os últimos trabalhos estão focados no uso de algoritmos adaptativos, como é o caso do artigo de Zatorre (ZATORRE et al., 2010), que apresenta um processador análogo-digital em tecnologia CMOS para a compensação da saída de um sensor. O circuito é composto por uma rede neural artificial analógica, a qual usa coeficientes armazenados em memorias no caso dos multiplicadores, permitindo modificar esses coeficientes facilmente, simplificando a calibração e re-calibração do sensor. O treinamento da rede é feito usando Single-Parameter Perturbation, 
devido ao bom desempenho deste e a sua simplicidade para a implementação no hardware. Nos resultados apresentados a rede consegue compensar o sensor com 400 iterações do algoritmo de treinamento.

\subsubsection{Comunicações Industriais}

Nas comunicações industriais atualmente as pesquisas estão focadas na área das redes sem fio, como no caso do $\mathrm{HART}^{\circledR}$, que na versão 7.0 inclui uma camada física sem fio. Portanto o padrão $\mathrm{HART}^{\circledR}$, neste momento, suporta as camadas físicas RS-485, Bell 202 e IEEE 802.15.4 (wirelessHART), mantendo a mesma camada de aplicação, pelo que pode-se mudar de camada física sem alterar os programas nos controladores e demais equipamentos da rede de campo. O wirelessHART tornou-se o primeiro padrão aceito internacionalmente para redes de instrumentação sem fio pela International Electrotechnical Commission (IEC), com o nome IEC 62591 Ed. 1.0, em março de 2010 (BOND, 2010).

\subsection{Transmissor de Pressão Piezoresistivo da MEMS Ltda.}

A empresa MEMS tem desenvolvido diferentes tipos de transmissores de pressão, mas para os objetivos deste trabalho será estudado unicamente o transmissor de pressão com saída 4-20 mA a dois fios. A continuação se apresenta uma breve descrição dele, bem como do algoritmo de compensação e calibração usado.

\subsubsection{Transmissor com Saída 4-20 mA a dois fios.}

Este tipo de transmissores varia a corrente do laço entre $4 \mathrm{~mA}$ e $20 \mathrm{~mA}$ dependendo da variável medida, neste caso a pressão. Como os transmissores possuem somente dois fios, a alimentação da eletrônica usada para o proces- 
samento do sinal pode consumir até $4 \mathrm{~mA}$. Um transmissor 4-20mA é composto fundamentalmente de quatro blocos principais: sensor, uma fonte de excitação para o sensor; eletrônica para o processamento do sinal e uma fonte de corrente dependente do sinal de saída do sensor, ver figura 5.

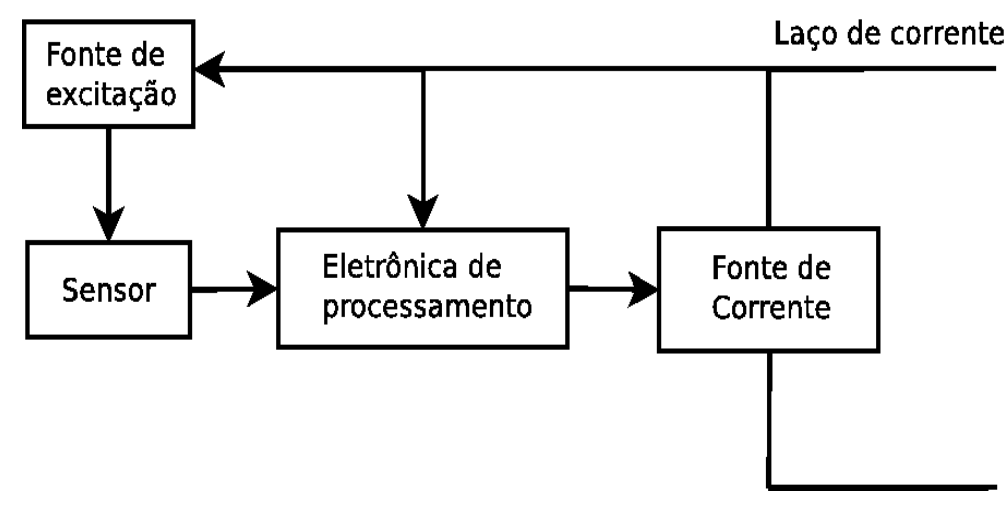

Figura 5: Blocos de um transmissor 4-20 mA.

O digrama geral do transmissor 4-20 mA da MEMS Ltda. é apresentado na figura 6 e uma descrição detalhada pode ser encontrada em (LUZ, 2006). O núcleo destes equipamentos é em um DSSP, composto de: uma CPU de 16 bits, Memória Flash programável de $4 \mathrm{kB}$, um amplificador de ganho programável (Programmable-Gain Amplifier - PGA) com offset, um conversor analógico-digital sigma-delta de 16 bits com três canais, dois conversores digital-analógico de 16 bits, duas saídas digitais PWM (modulação por largura de pulso) de 12 bits, quatro amplificadores operacionais (rail-to-rail), uma Interface serial (SPI), duas GPIOs (Entradas e saídas de propósito geral), um sensor de temperatura (on-chip). Com este chip se pode implementar com ajuda de poucos componentes externos três dos quatro blocos principais que compõem um transmissor.

A fonte de excitação do sensor é implementada usando um dos amplificadores operacionais com três resistências externas e o sensor, configurando uma fonte de corrente constante. Ao sinal de saída do sensor é somado um offset (programá- 


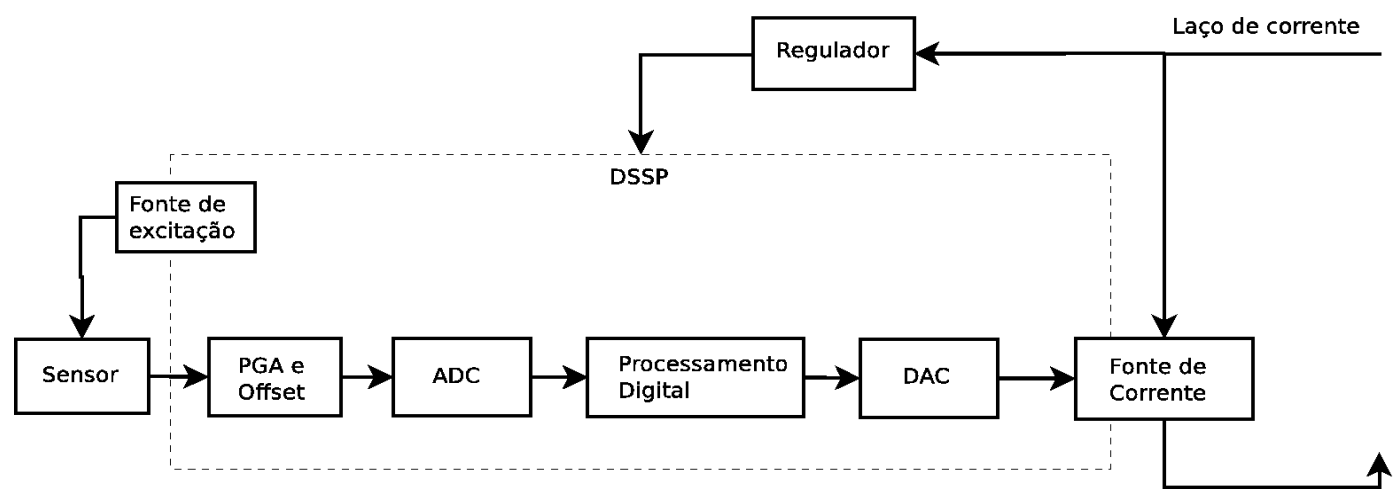

Figura 6: Blocos do transmissor 4-20mA da MEMS Ltda.

vel), para posteriormente ser amplificado usando o PGA.

O processamento de sinal é feito totalmente no domínio digital, pelo que o sinal de saída do sensor é convertido usando o conversor analógico-digital em modo diferencial, e processado usando o algoritmo apresentado em (MAXIM, 2003). O sinal de saída já compensado e calibrado é convertido novamente ao domínio analógico usando um dos conversores digital-analógico. Por limitações próprias do chip é preciso usar um amplificador operacional para que o sinal seja disponível num dos pinos do chip. Finalmente com um dos amplificadores operacionais restantes é configurada uma fonte de corrente controlada por tensão. Como o sinal de saída é normalizado durante a compensação e calibração, tomará o valor $0,5 \mathrm{~V}$ para pressão minima (saída igual a $4 \mathrm{~mA}$ ) e 4,5V para pressão máxima (saída igual a 20mA). Portanto, a fonte de corrente de saída deve ser ajustada para garantir essas correntes no laço. O circuito para garantir a corrente de laço, precisa além de resistores, um transistor que possa dissipar a potencia requerida.

\subsubsection{Algoritmo de Compensação e Calibração.}

O algoritmo usado pela MEMS Ltda. é o apresentado em (MAXIM, 2003), o qual usa uma matriz de $3 \times 3$ (pressões $x$ temperaturas) para o calculo dos coeficientes de ajuste e dois valores de saída do DAC. Para a medição da temperatura é usado o sensor interno do chip DSSP. O processo de compensação e calibra- 
ção (C\&C) é o seguinte: inicialmente deve-se usar uma câmara climática para controlar a temperatura do transmissor, depois de um tempo de estabilização são coletados os dados de saída do conversor analógico-digital para três pressões diferentes, e o sensor de temperatura. Os valores de saída da corrente para dois valores do DAC também são armazenados na mesma temperatura. O procedimento anterior deve-se repetir para as outras duas temperaturas de compensação desejadas. Durante o tempo todo da coleta de dados os valores de ganho do PGA e de offset devem permanecer constantes.

Com a matriz completa são gerados os coeficientes para modelar cada um dos componentes do sistema usando polinômios de ordem 2. Os modelos gerados são aqueles da pressão em cada uma das temperaturas, dos coeficientes do modelo da pressão com a temperatura, do ganho do DAC, do offset do DAC e finalmente do sensor de temperatura interno do chip.

As funções de correção são baseadas nos modelos calculados, da seguinte forma: a primeira correção é feita ao sensor de temperatura, pois as demais variáveis serão compensadas usando a temperatura medida por ele. O passo inicial para a correção é o calculo do offset, depois com os valores extremos ajustados em offset (Temperatura máxima e mínima) é calculada a inclinação da reta que une esses pontos. A não linearidade do sensor é calculada como a diferença entre os valores medidos do sensor e a linha calculada no passo anterior. Como o comportamento desejado do sensor é linear, são calculados os coeficientes de um polinômio de ordem 4 que é o inverso da função de não linearidade do sensor calculada no passo anterior. O resultado neste ponto são seis coeficientes (cinco do polinômio e um do offset).

Para a correção dos dados da pressão o procedimento é semelhante ao do sensor de temperatura: inicia com o calculo da inclinação da reta que une os pontos extremos da pressão, calculados usando o modelo antes definido, a não linearidade é calculada como a distância dos pontos medidos à linha calculada, a função de 
correção é um polinômio de ordem 3 calculada como o inverso da função de não linearidade. O comportamento com a temperatura de cada um dos coeficientes calculados no passo anterior é modelado usando um polinômio de ordem 3 . Ao todo são calculados 16 coeficientes para a correção do offset e da não linearidade do sensor de pressão. Por último a variação do span com a temperatura é compensada com um polinômio de ordem 4. Procedimento que leva os dados de saída ao intervalo desejado de -0,9 a 0,9 do sinal normalizado. Finalmente, o DAC é compensado usando duas equações de ordem 2 para o offset e span, as quais linearizam o comportamento deste.

\subsection{Protocolo de Comunicação HART ${ }^{\circledR}$.}

O HART ${ }^{\circledR}$ é um protocolo de comunicação digital que foi desenvolvido para ser compatível com os sistemas de sinalização tradicionais 4-20mA, suporta a comunicação digital em dois sentidos, permitindo fazer medições de processos e controle de equipamentos. As aplicações deste protocolo incluem monitoramento remoto de variáveis do processo, acesso a dados de processo, configuração de parâmetros e diagnóstico do transmissor.

O protocolo $\mathrm{HART}^{\circledR}$ na versão 6.0 implementa três camadas do modelo OSI 7-Layer (1, 2 e 7), a camada 1 (física) permite a sinalização analógica e digital simultaneamente, usando a fiação 4-20mA tradicional. A camada 2 (enlace de dados) é tipo mestre-escravo e para o controle de acesso ao meio usa Token Passing . A última camada implementada no padrão HART ${ }^{\circledR}$ é a camada 7 (aplicação), que é orientada ao comando, e possui procedimentos e tipos de dados definidos (FOUNDATION, 2006). A continuação será descrito o funcionamento de cada uma das camadas. 


\subsubsection{Camada Física}

O sinal digital é uma extensão do sinal convencional 4-20mA. Faz uso de Frequency-Shif-Keying (FSK) de fase contínua a 1200 bps (ver figura 7). Para tanto, um sinal de alta frequência é somado ao sinal de baixa frequência $4-20 \mathrm{~mA}$ típico, de forma tal que os dois sinais compartilham o mesmo meio físico. O padrão faz diferença entre dois tipos de equipamentos, de alta e baixa impedância, sendo os primeiros os que modulam a corrente (escravos) e os segundos os que medem a corrente (mestres). Os requisitos da sinalização digital são apresentados a continuação, e os limites do sinal e dos tempos na tabela 3 (FOUNDATION, 1999).

- O espectro de frequências permitido para o sinal digital é de $500 \mathrm{~Hz}$ a $10 \mathrm{kHz}$ (com -40dB por década abaixo de $500 \mathrm{~Hz}$ e -20 dB por década acima de 10 $\mathrm{kHz})$.

- A modulação tem que ser FSK de fase contínua, representando o 1 lógico como uma frequência de $1200 \mathrm{~Hz}$ e o 0 lógico com $2200 \mathrm{~Hz}$.

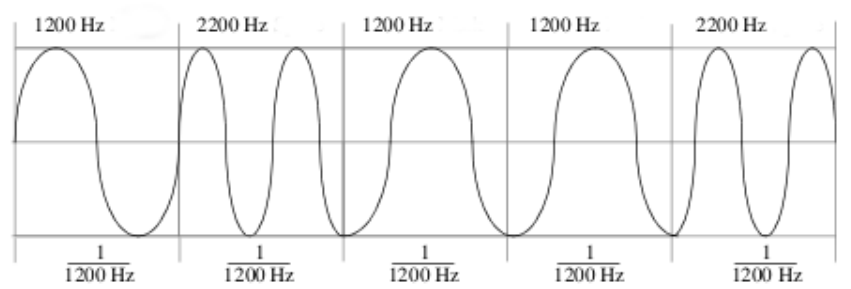

Figura 7: Sinal HART ${ }^{\circledR}$ (FOUNDATION, 1999).

A onda usada para a comunicação digital possui as limitações apresentadas nas figura 8, na qual Vmax é de 600mVpp e Vmin de 400mVpp, medidos usando uma resistência de carga de $500 \Omega$ no laço de corrente. A principal limitação para o sinal analógico 4-20mA é que deve permanecer entre 0 e $25 \mathrm{~Hz}$, para não interferir no 
Tabela 3: Limites camada física protocolo HART ${ }^{\circledR}($ FOUNDATION, 1999).

\begin{tabular}{|l|l|}
\hline \multicolumn{1}{|c|}{ Parâmetros } & \multicolumn{1}{c|}{ Limites } \\
\hline Taxa de bits & $1200 \pm 1 \%$ \\
\hline 1 logico & $1200 \mathrm{~Hz} \pm 1 \%$ \\
\hline 0 logico & $2200 \mathrm{~Hz} \pm 1 \%$ \\
\hline Tempo de inicio da portadora & 5 tempos de bit máximo \\
\hline Tempo de parada da portadora & 5 tempos de bit máximo \\
\hline $\begin{array}{l}\text { Tempo de decaimento da porta- } \\
\text { dora }\end{array}$ & 15 tempos de bit máximo \\
\hline $\begin{array}{l}\text { Tempo de indicação da detecção } \\
\text { de portadora }\end{array}$ & 6 tempos de bit \\
\hline $\begin{array}{l}\text { Tempo de indicação da não detec- } \\
\text { ção de portadora }\end{array}$ & 6 tempos de bit \\
\hline
\end{tabular}

sinal digital.

O padrão recomenda uma capacitância máxima de 5000pF e uma resistência de $100 \mathrm{~K} \Omega$ nos terminais do transmissor, para facilitar a conexão de vários equipamentos na mesma fiação e finalmente a especificação indica que se deve manter um nível de ruído na banda de $500 \mathrm{~Hz}$ a $10 \mathrm{KHz}$ menor que 2,2mV RMS num tempo superior ou igual a um segundo.

\subsubsection{Camada de Enlace de Dados}

A especificação define os serviços que devem ser prestados pela camada física à camada de enlace de dados, e os serviços que esta presta à camada de aplicação. A implementação desta camada está dividida em duas subcamadas: a Logical Link Coltrol (LLC), que é a encargada de dar formato aos dados enviados pela camada de aplicação ( cria os frames), de gerenciar os endereços e da detecção de erros (FOUNDATION, 2001a); e a subcamada Medium Access Control (MAC), que é a encarregada de cumprir com as especificações de tempo próprias do padrão para garantir transmissões ordenadas.

o padrão permite várias topologias de rede: ponto a ponto com um mestre e um 
escravo, ponto a ponto com dois mestres (primário e secundário) e um escravo, um mestre e vários escravos em série, dois mestres (primário e secundário) e vários escravos em serie, e finalmente, um ou dois mestres com um ou vários escravos em serie com um equipamento de sinalização analógica. No caso de vários escravos HART ${ }^{\circledR}$ em serie, somente um deles pode usar o sinal analógico como indicação da medição, um exemplo dessas topologias é apresentado na figura 9. O numero de equipamentos em serie depende da impedância total do laço, sendo $500 \Omega$ o máximo valor permitido.

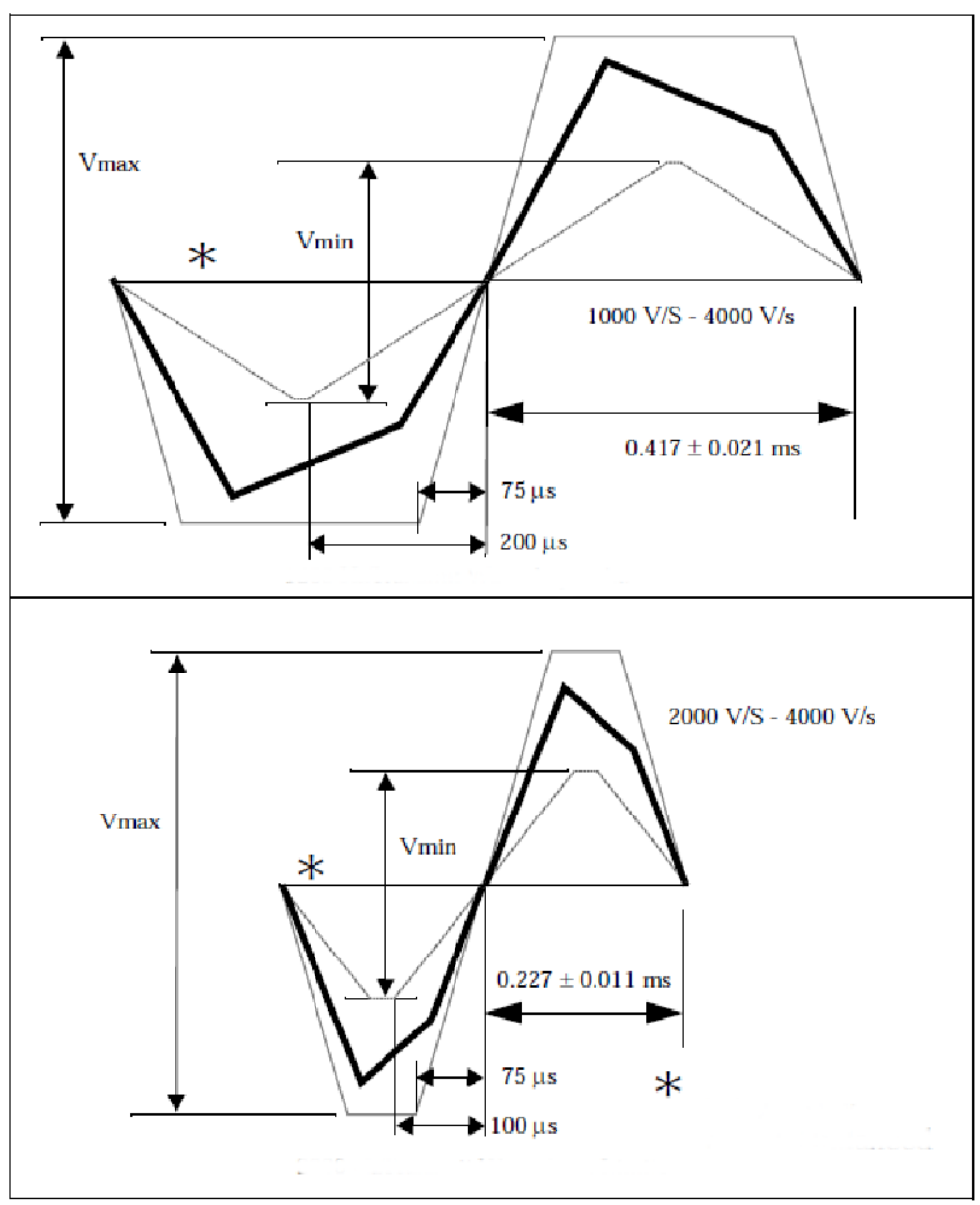

Figura 8: Limites sinalização digital para $1200 \mathrm{~Hz}$ (imagem superior) e $2200 \mathrm{~Hz}$ (imagem inferior) (FOUNDATION, 1999). 


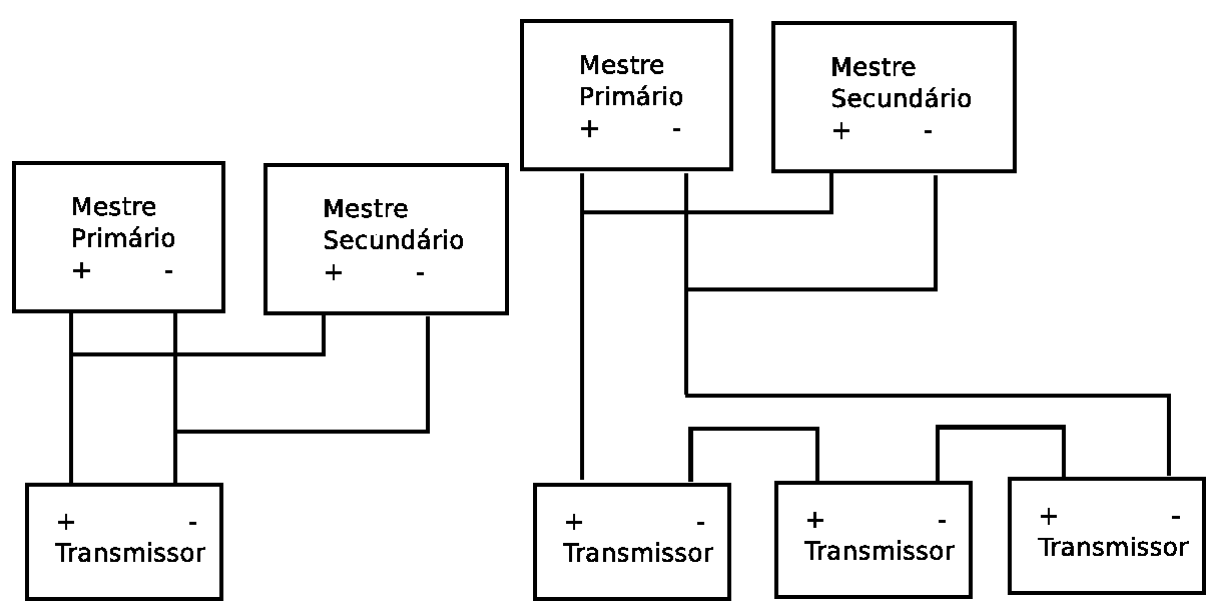

(a) Topologia ponto a ponto.

(b) Topologia em serie.

Figura 9: Topologias de redes $\mathrm{HART}^{\circledR}$.

\subsubsection{Controle de Acesso ao Meio}

É baseado em Token Passing, no qual o token (direito de usar o meio de comunicação para transmitir uma mensagem) e passado entre os integrantes da rede usando três tipos de mensagens: STX, ACK e BACK. Na primeira mensagem o token é passado do mestre primário para o escravo responder a um comando, com a mensagem ACK é finalizada a resposta do escravo e o token passa a um mestre, primário ou secundário.

BACK é uma mensagem envaida para o mestre como parte de una transmissão tipo burst (modo no qual o escravo envia dados periodicamente sem esperar uma solicitação do mestre). na figura 10 pode-se observar o diagrama de estados.

O padrão define 5 tempos: STO, HOLD, RT1 (primário), RT1(secundário) e RT2.

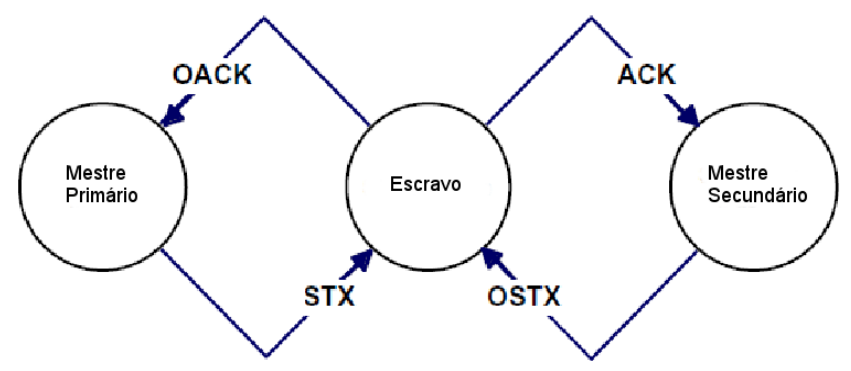

Figura 10: Controle de acesso ao meio no HART $^{\circledR}($ FOUNDATION, 2001a). 
A sequência de tempos é a seguinte: o mestre primário esperará RT1 tempo antes de iniciar uma transmissão (envio de STX), depois de receber a mensagem STX o escravo tem STO tempo para iniciar o envio da resposta (envio de dados e um ACK). Depois do mestre secundário receber o ACK têm um tempo RT2 para iniciar uma transmissão, se não acontecer isto, o mestre primário pode iniciar outra transmissão depois de esperar um tempo definido por HOLD. O valor desses tempos é apresentado na tabela 4 .

Tabela 4: Limites nos tempos da MAC HART $^{\circledR}($ FOUNDATION, 2001a).

\begin{tabular}{|c|l|}
\hline Parâmetro & \multicolumn{1}{|c|}{ Requisito } \\
\hline Preambulo & 5 bytes 0xFF \\
\hline Detecção do Star of Message (SOM) & $\begin{array}{l}\text { Dois 0xFF consecutivos seguidos de } \\
\text { um delimitador válido, sem erros de co- } \\
\text { municação ou de gap. }\end{array}$ \\
\hline Formato do caracter & $\begin{array}{l}\text { Assíncrono, 11 bits ( 1 bit de inicio, 8 } \\
\text { de dados, paridade impar e um bit de } \\
\text { parada). }\end{array}$ \\
\hline Slave Time-Out (STO) & 28 tempos de caracter. \\
\hline HOLD & Dois tempos de caracter. \\
\hline Link Grant time (RT2) & 8 tempos de caracter. \\
\hline Pink Quiet Time (RT1) & $\begin{array}{l}33 \text { Tempos de caracter. } \\
41 \text { tempos de caracter. }\end{array}$ \\
\hline Secundário & $\begin{array}{l}\text { deve ser menos de um tempo de carac- } \\
\text { ter entre dois caracteres. }\end{array}$ \\
\hline Erro de GAP &
\end{tabular}

\subsubsection{Camada de Aplicação}

A especificação HART ${ }^{\circledR}$ define diferentes comandos, e agrupá-los segundo o tipo, mas, só um tipo desses é obrigatório, os comandos universais, um resumo deles é apresentado na tabela 5. 
Tabela 5: Comandos Universais HART ${ }^{\circledR}($ FOUNDATION, 2001b).

\begin{tabular}{|c|c|c|}
\hline Comando & Descrição & Resposta / descrição \\
\hline 0 & $\begin{array}{l}\text { Ler Identificador } \\
\text { único. }\end{array}$ & 16 bytes de identificação e estado. \\
\hline 1 & $\begin{array}{l}\text { Ler variável Prima- } \\
\text { ria. }\end{array}$ & $\begin{array}{l}5 \text { bytes que contêm o float da variável principal } \\
\text { e a unidade. }\end{array}$ \\
\hline 2 & $\begin{array}{l}\text { Ler corrente de laço } \\
\text { e porcentagem da } \\
\text { faixa. }\end{array}$ & $\begin{array}{l}8 \text { bytes dos valores representados em ponto flu- } \\
\text { tuante da corrente e da porcentagem do span. }\end{array}$ \\
\hline 3 & $\begin{array}{l}\text { Ler variáveis dinâ- } \\
\text { micas e laço de cor- } \\
\text { rente. }\end{array}$ & $\begin{array}{l}\text { Pode ser } 9,14,19 \text { e } 24 \text { bytes com o valor da } \\
\text { corrente em mA, e até quatro variáveis com as } \\
\text { respectivas unidades. }\end{array}$ \\
\hline 6 & $\begin{array}{l}\text { Escrever endereço } \\
\text { curto. }\end{array}$ & $\begin{array}{l}\text { Recebe o endereço curto que deve armazenar e } \\
\text { o estado que configurará no laço de corrente }{ }^{1} \text {. }\end{array}$ \\
\hline 7 & Ler endereço curto. & $\begin{array}{l}2 \text { Bytes indicando o endereço curto e o estado } \\
\text { que esta o laço de corrente }{ }^{1} \text {. }\end{array}$ \\
\hline 8 & $\begin{array}{l}\text { Ler classifica- } \\
\text { ção das variáveis } \\
\text { dinâmicas. }\end{array}$ & $\begin{array}{l}4 \text { bytes indicando o tipo ao que corresponde } \\
\text { cada variável dinâmica, por exemplo, pressão, } \\
\text { temperatura, etc. }\end{array}$ \\
\hline 9 & $\begin{array}{l}\text { Ler variáveis do } \\
\text { equipamento com } \\
\text { estado }\end{array}$ & $\begin{array}{l}9,17,25 \text { ou } 33 \text { bytes dependendo da quanti- } \\
\text { dade de variáveis transmitidas (1,2,3 ou } 4) \text { com } \\
\text { a informação de estado do equipamento, e } 8 \text { by- } \\
\text { tes por cada variável com o valor, classificação, } \\
\text { unidades, código e estado da variável. }\end{array}$ \\
\hline
\end{tabular}




\begin{tabular}{|c|c|c|}
\hline Comando & Descrição & Resposta / descrição \\
\hline 10 & $\begin{array}{l}\text { Ler identificador } \\
\text { único usando o tag. }\end{array}$ & 16 bytes de identificação e estado. \\
\hline 12 & Ler mensagem. & $\begin{array}{l}\text { Envia a mensagem armazenada no equipa- } \\
\text { mento, ate } 23 \text { bytes. }\end{array}$ \\
\hline 13 & $\begin{array}{l}\text { Ler tag, descritor e } \\
\text { data. }\end{array}$ & 20 bytes contendo o tag, descritor e data. \\
\hline 14 & $\begin{array}{l}\text { Ler informação do } \\
\text { dispositivo. }\end{array}$ & $\begin{array}{l}\text { Retorna o serial, limites máximo e minimo, span } \\
\text { minimo, unidade usada para os limites. Usa } 15 \\
\text { Bytes. }\end{array}$ \\
\hline 15 & $\begin{array}{l}\text { Ler informação da } \\
\text { variável primária do } \\
\text { transmissor. }\end{array}$ & $\begin{array}{l}\text { Retorna informações várias do equipamento en- } \\
\text { tre elas: os limites da variável primaria, as unida- } \\
\text { des e o tempo de amortecimento. em } 17 \text { bytes. }\end{array}$ \\
\hline 16 & $\begin{array}{l}\text { Ler numero de en- } \\
\text { samblagem final. }\end{array}$ & 2 bytes com o número de ensamblagem. \\
\hline 17 & $\begin{array}{l}\text { Escrever mensa- } \\
\text { gem. }\end{array}$ & $\begin{array}{l}\text { Escreve uma mensagem no transmissor, até } 23 \\
\text { bytes. }\end{array}$ \\
\hline 18 & $\begin{array}{l}\text { Escrever tag, des- } \\
\text { critor e data. }\end{array}$ & $\begin{array}{l}\text { Escreve } 20 \text { bytes contendo o tag, descritor e } \\
\text { data. }\end{array}$ \\
\hline 19 & $\begin{array}{l}\text { Escrever numero } \\
\text { de ensamblagem } \\
\text { final. }\end{array}$ & 2 bytes com o numero de ensamblagem. \\
\hline 20 & escrever tag longo. & 31 bytes de tag longo. \\
\hline 21 & $\begin{array}{l}\text { Ler identificador } \\
\text { único associado } \\
\text { com o tag longo. }\end{array}$ & 16 bytes de identificação e estado. \\
\hline 22 & Escrever tag longo. & 31 bytes do tag longo. \\
\hline
\end{tabular}




\subsection{Arquitetura do Sistema Transmissor de Pressão Piezoresistivo com Protocolo de Comunicação HART $^{\circledR}$.}

A arquitetura proposta está baseada no transmissor de pressão com protocolo de comunicação ModBus da MEMS Ltda. O estudo desse circuito indicou que a principal limitação é o consumo de corrente (máximo $4 \mathrm{~mA}$ a zero de pressão no laço de corrente). O circuito estudado faz uso de diferentes técnicas para a redução do consumo: uso de chips de baixo consumo, baixas frequências nos osciladores dos processadores e uma corrente de excitação do sensor de $261 \mu \mathrm{A}$. O DSSP do transmissor com saída 4-20 mA, consume entre 3,2mA e 3,8mA em operação e 30mA durante a programação (corrente necessária para programar a memoria EEPROM interna). Para implementar o protocolo de comunicação HART $^{\circledR}$, deve-se usar um microcontrolador, para dar resposta aos comando enviados pelo mestre da rede. Portanto, será necessário que o transmissor possua uma memória EEPROM de 256 bytes. Também para que o código seja facilmente usado para outras aplicações $\left(\mathrm{HART}^{\circledR}\right.$ com camada física RS-485 e WilessHART) será codificada numa linguagem de alto nível como $\mathrm{C}$, isto gera um código que pode ser não ótimo e precisará de maior espaço na memoria de programa. Estima-se baseado no código do ModBus um uso de 16KB de memória de programa como mínimo.

Para suportar a camada física Bell 202, será necessário um circuito que module o sinal digital a $1200 \mathrm{~Hz}$ e $2200 \mathrm{~Hz}$ segundo o nível lógico da interface UART (Universal Asynchronous Receiver-Transmitter) do microcontrolador. Além disso, a fonte que controla o laço de corrente tem que ser modificada para permitir a modulação do sinal digital. Para a recepção de dados um filtro e um demodulador serão 
necessários, para converter o sinal $1200 \mathrm{~Hz}$ e $2200 \mathrm{~Hz}$ em uma sequência de bits que seja recebida pela UART do microcontrolador. A arquitetura proposta é apresentada na figura 11, na qual por simplicidade os filtros e circuitos moduladores e demoduladores da camada Bell 202 são chamados modems HART ${ }^{\circledR}$.

\subsubsection{Requisitos Transmissor de Pressão Piezoresistivo com Protocolo de Comunicação HART ${ }^{\circledR}$.}

Como o objetivo de transmissor é um uso industrial, deve-se cumprir com os requisitos do setor, portanto, o sistema deve possuir as seguintes características operacionais:

- Sinal de saída analógico a dois fios: 4-20 mA

- Sinal de saída digital: HART

- Alimentação: 15 V a 36 VDC

- Faixa de pressão: Depende do sensor usado (faixas tipicas entre 1 a 800 bar)

- Tipo de sensor: piezoresistivo em silício (media isolated pressure sensor)

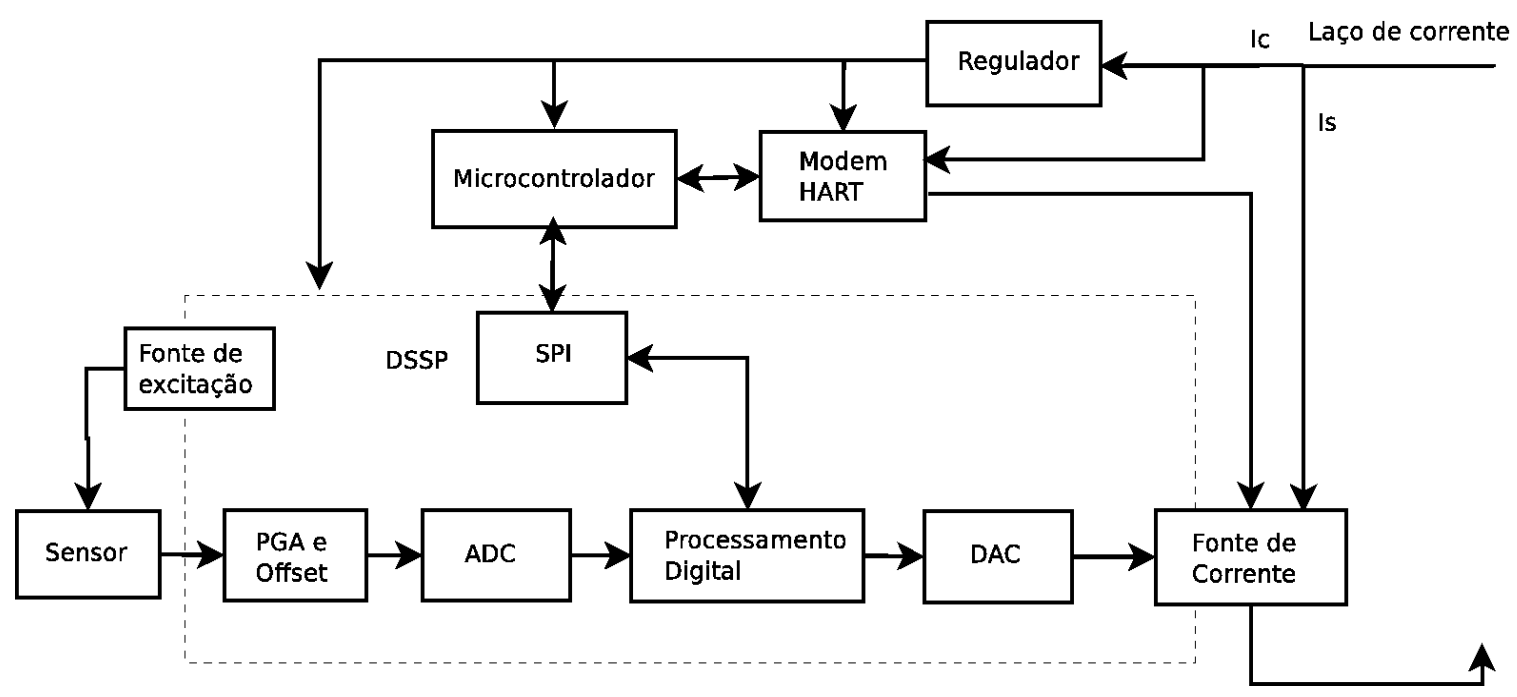

Figura 11: Blocos do transmissor 4-20mA com protocolo de comunicação HART ${ }^{\circledR}$. 
- Precisão (incluindo Linearidade, Histerese, repetibilidade): 0,1\%FS

- TBE, Faixa de erro total $\left(0^{\circ} \mathrm{Ca}+50^{\circ} \mathrm{C}\right): 0,2 \% \mathrm{FS}$

- Temperatura do invólucro (ambiente): $50^{\circ} \mathrm{C}$

- Proteção contra inversão de polaridade.

- Calibração e compensação via software.

Na tabela 6 são resumidos os requisitos para os diferentes componentes da arquitetura proposta.

Tabela 6: Requisitos para os blocos que compõem o transmissor HART ${ }^{\circledR}$.

\begin{tabular}{|l|l|}
\hline \multicolumn{1}{|c|}{ Bloco } & \multicolumn{1}{c|}{ Requisito } \\
\hline Regulador & $15 \mathrm{~V}$ a 36V \\
Tensão de entrada & $35 \mathrm{~mA}$ \\
Corrente de saída & $100 \mu \mathrm{A}$ \\
Consumo de Corrente & \\
\hline Modem HART ${ }^{\circledR}$ & $2200 \mathrm{~Hz} \pm 1 \%$ \\
0 Lógico & $1200 \mathrm{~Hz} \pm 1 \%$ \\
1 Lógico & $1.2 \mathrm{~mA}$ máximo, $0,8 \mathrm{~mA}$ mínimo \\
Modulação da corrente no & \\
laço & Menor que 0,3mA \\
Consumo de corrente & Maior que 16KB \\
\hline Microcontrolador & Maior que 256 bytes. \\
Memoria de programa & SPI e URT \\
Memoria EEPROM & Interfaces
\end{tabular}




\begin{tabular}{|l|l|}
\hline \multicolumn{1}{|c|}{ Bloco } & \multicolumn{1}{c|}{ Requisito } \\
Consumo de corrente & Menor que 0,4mA \\
\hline $\begin{array}{l}\text { Fonte de Corrente } \\
\text { Saída Analógica }\end{array}$ & 0 a $16 \mathrm{~mA} @ 25 \mathrm{~Hz}$ máximo \\
Saída Digital & $0,8 \mathrm{~mA}$ a $1,2 \mathrm{~mA} @ 1200 \mathrm{~Hz}$ e $2200 \mathrm{~Hz}( \pm$ \\
& $1 \%)$ \\
\hline DSSP & \\
Faixa de erro total & $0,2 \% \mathrm{FS}$ \\
Consumo de corrente & $3,2 \mathrm{~mA}$ máximo. \\
\hline
\end{tabular}




\section{PROJETO DO TRANSMISSOR}

Dentro da metodologia, esta seção corresponde à etapa Modelo da solução, composta pelo projeto do circuito, os códigos usados nos processadores, as ferramentas necessárias para a caracterização do transmissor e o procedimento de compensação e calibração.

\subsection{Projeto do hardware do transmissor}

Como a arquitetura proposta está composta de blocos independentes com interfaces entre eles, a continuação serão apresentados os projetos de cada um desses blocos, além das modificações feitas nos blocos do transmissor ModBus da MEMS Ltda.

\subsubsection{Seleção dos Componentes}

Levando em consideração os requisitos foram estudados os componentes do circuito ModBus atual, especificamente o modem RS-485 e o microcontrolador. Do primeiro é importante notar que possui um consumo de corrente baixo $(10 \mu A)$,

mas para nosso circuito não é útil, por que o HART ${ }^{\circledR}$ usa interface física Bell 202. O segundo componente estudado, o microcontrolador é um PIC 16F688 com uma memoria de programa de $4 \mathrm{~KB}$ e com nanoWatt Technology que permite um consumo de corrente baixo durante a operação. Também durante o estudo se observou que o consumo total do transmissor está fixo em $3.8 \mathrm{~mA}$ DC o que gera 
dificuldades no momento da compensação e calibração em zero de pressão.

Baseados nesta informação foi decidido usar um microcontrolador da Microchip permitindo reutilizar partes do código já desenvolvido e o uso das ferramentas de programação que estavam disponíveis no grupo. Também como o microcontrolador deve ser de baixo consumo, a pesquisa dentro dos microcontroladores desta família levo à seleção do PIC18F26K22, que possui curvas de consumo semeIhantes as do PIC 16F688, mas com uma capacidade de memoria de programa de $64 \mathrm{~KB}$, memoria ROM de $1 \mathrm{~KB}$ e memoria RAM de $3.8 \mathrm{~KB}$. O consumo de corrente é maior a do 16F688 e é esperado que com uma frequência de operação de $1 \mathrm{MHz}$ o consumo máximo seja de $0.7 \mathrm{~mA}$ e a $16 \mathrm{MHz}$ de $2.8 \mathrm{~mA}$ alimentado a $3.0 \mathrm{~V}$. O outro componente critico do sistema é o modem $\mathrm{HART}^{\circledR}$, atualmente no mercado existem 4 fabricantes de modems Bell 202 integrados ver tabela 7, sendo as principais diferenças entre eles o formato da onda e o consumo de corrente. Entre eles o que apresenta o menor consumo de corrente, uma onda senoidal e menor quantidade de elementos externos é o DS8500 da Maxim, com um consumo segundo a folha de dados de $0.285 \mathrm{~mA}$ a 3.0V. Tanto o modem $\mathrm{HART}^{\circledR}$ como o microcontrolador precisam de uma tensão máxima de 3.3V e como parte dos requisitos é usar o DSSP MAX1464 da Maxim que precisa 5V de alimentação, um regulador adicional deve ser utilizado. O regulador que foi decidido usar é o LP3984 da Linear Technologies de 3.1V, que apresenta um consumo de $0.15 \mathrm{~mA}$.

Somando os consumos esperados dos componentes a serem usados temos um consumo de $1.135 \mathrm{~mA}$ que ultrapassa os limite de corrente de 0,8 mA dos requisitos (3,2 mA para o MAX1464 e 0,8 mA para os demais componentes), isto faria com que o transmissor tivesse um consumo maior que $4 \mathrm{~mA}$ em zero de pressão. A solução para esse problema é o uso de um regulador chaveado, que faz uma transformação de potência, como a tensão minima é de $15 \mathrm{~V}$ e desejamos um consumo máximo de 3,4mA para a eletrônica do transmissor (Valor de corrente que facilita uma boa C\&C e permite a modulação do sinal digital sem saturação com a 
Tabela 7: Comparação modems Bell 202.

\begin{tabular}{|l|l|c|l|c|}
\hline $\begin{array}{l}\text { Fabricante/ } \\
\text { Referência }\end{array}$ & $\begin{array}{l}\text { Consumo [A]/ } \\
\text { Tesão [V] }\end{array}$ & Onda & Adicionais & Preço [USD] \\
\hline $\begin{array}{l}\text { Maxim/ } \\
\text { DS8500 }\end{array}$ & $285 \mu / 3$ & Senoidal & $\begin{array}{l}\text { Filtro passa banda de } \\
\text { entrada, condensador } \\
\text { acople saída }\end{array}$ & 5,92 \\
\hline $\begin{array}{l}\text { LSI Logic/ } \\
20 \mathrm{C} 15\end{array}$ & $\begin{array}{l}400 \mu \text { e } 600 \mu / \\
3,3 \text { e } 5\end{array}$ & Trapezoidal & $\begin{array}{l}\text { Referencias de ten- } \\
\text { são, filtros de entrada } \\
\text { e saída, e resistências } \\
\text { de polarização }\end{array}$ & 8 \\
\hline Smar/HT2012 & $\begin{array}{l}400 \mu \text { e } 600 \mu / \\
3,3 \text { e 5 }\end{array}$ & Quadrada & $\begin{array}{l}\text { Filtros e referencias de } \\
\text { tensão }\end{array}$ & - \\
\hline $\begin{array}{l}400 \mu \text { e } 600 \mu / \\
\text { OnSemi/ }\end{array}$ AND8346 5 & Trapezoidal & $\begin{array}{l}\text { Filtros e referencias de } \\
\text { tensão }\end{array}$ & 13,5 \\
\hline Inlink/- & $450 \mu / 3,3$ & - & $\begin{array}{l}\text { Conexão direta ao } \\
\text { lazo }\end{array}$ & 95 \\
\hline
\end{tabular}

saída fixa em $4 \mathrm{~mA}$ ), teremos uma potência disponível de $51 \mathrm{~mW}$. A saída do regulador comutado deve ser de $5 \mathrm{~V}$, o que supõe idealmente uma corrente disponível de 10,2mA para a eletrônica do transmissor, mas o circuito do regulador consume corrente e a transformação não é ideal. Uma pesquisa de um circuito integrado que desempenhasse esta função levou à seleção do chip LTC3642 da Linear Technologies, que na folha de dados garante uma eficiência superior a $90 \%$ para consumos superiores a $2 \mathrm{~mA}$. Ajustando os cálculos temos que para uma tensão de alimentação do transmissor e uma eficiência do $90 \%$ do regulador estarão disponíveis $9,18 \mathrm{~mA}$ para a eletrônica do transmissor. Na figura 12 pode-se observar a nova arquitetura do sistema.

\subsubsection{Projeto Bloco Fonte Chaveada}

O LTC3642 é um Step-Down Converter, que regula a tensão de saída em 5V DC. Para o que precisa de um filtro LC na saída. O objetivo principal desse filtro é armazenar a energia entre os chaveamentos da fonte, permitindo a regulação. 


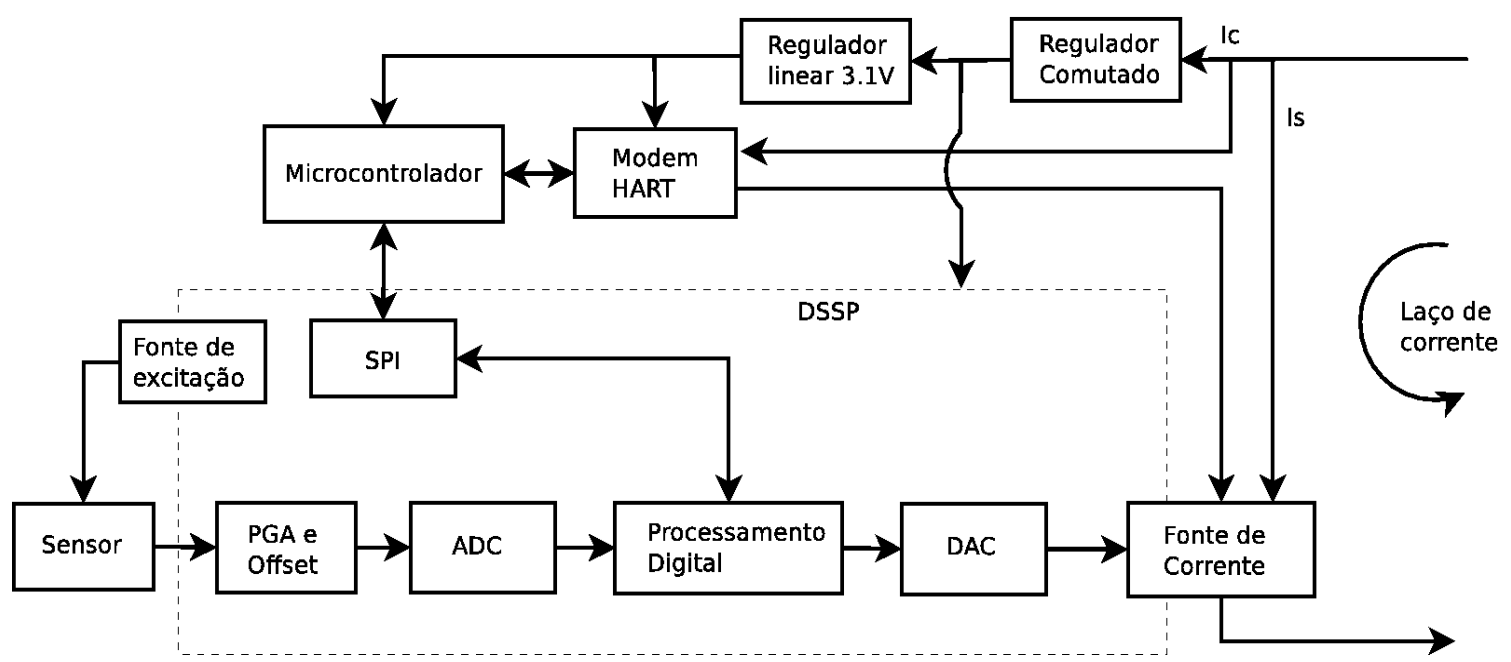

Figura 12: Arquitetura modificada do transmissor 4-20mA com protocolo de comunicação $\operatorname{HART}^{\circledR}$.

O algoritmo de controle usado nesse chip é o seguinte: para elevar a tensão o transistor que une a entrada com a saída é configurado em condução, a corrente pelo transistor é medida e quando atinge um valor $\left(I_{\text {peak }}\right)$, configurável entre $25 \mathrm{~mA}$ e $115 \mathrm{~mA}$, o transistor é posto em corte. Esta corrente circulará pela indutância de saída e o capacitor, e quando diminuir a próximo de zero amperes uma nova comutação acontecerá. Este ciclo se repete até atingir o nível de tensão de referência (mínimo de 4.965V).

Como para esta aplicação se deve introduzir a menor quantidade de ruído no laço, é configurada a corrente mínima durante a operação da fonte chaveada (Pino Iset conectado a GND, então $I_{\text {peak }}=25 \mathrm{~mA}$ ). Os primeiros componentes que devem ser calculados são os do filtro de saída, pois deles depende a frequência de operação do circuito, as equações para o cálculo estão disponíveis na folha de dados do chip:

$$
L_{\text {min }}=\frac{V_{i n(\max )} t_{o n(\min )}}{I_{\text {peak }(\max )}}=144 \mu \mathrm{H},
$$

onde $t_{o n(\min )}$ é 100ns, $V_{i n(\max )}$ é $36 \mathrm{~V}$. Respeitando o valor $L_{\min }$ calculado e por facilidade na disponibilidade para o protótipo, foi decidido usar uma inductância de 
$470 \mu \mathrm{H}$. para o calculo da frequência é usada a seguinte equação:

$$
L=\left(\frac{V_{\text {out }}}{F I_{\text {peak }}}\right)\left(1-\frac{V_{\text {out }}}{V_{\text {in }}}\right) \Rightarrow F=284 K H z,
$$

em donde $V_{\text {out }}$ é $5, V_{\text {in }}$ é $15 \mathrm{~V}$ e $L$ é $470 \mu \mathrm{H}$. A continuação foi calculado o valor mínimo do capacitor de saída usando a seguinte equação.

$$
C_{\text {out }}>50 L\left(\frac{I_{\text {peak }}}{V_{\text {out }}}\right)^{2} \Rightarrow C_{\text {out }}>587 n F
$$

Para diminuir a frequência dos ciclos de carga e descarda do capacitor de saída da fonte e com isso os erros gerado na medição da pressão, foi decidido usar uma capacitância $C_{\text {out }}$ de $22 \mu \mathrm{F}$. Com este valor é esperado um ruido na faixa dos 10 $\mathrm{KHz}$ a $15 \mathrm{KHz}$. Com os valores do filtro de saída definidos, deve-se calcular os valores para o filtro de entrada, pois o pico na corrente de entrada é maior que o permitido para nosso sistema, então é necessário usar um filtro de entrada para o regulador. Baseados na proposta de (SCLOCCHI, 2010), foi decidido usar um filtro LC com amortecimento paralelo, para evitar os problemas de ressonância na frequência de corte do filtro. Para garantir que as componentes de alta frequência não vão afetar o sinal analógico do transmissor, decidiu-se usar uma frequência de corte para o filtro dez vezes menor que a frequência de operação da fonte comutada, isto é $\omega_{o}=20,8 \mathrm{KHz}$, como $\omega_{o}=\frac{1}{\sqrt{L_{i n} C_{i n}}}$ e usando um indutor do mesmo valor que o usado no filtro de saída temos que $C_{i n}=4,9 \mu \mathrm{F}$. Por facilidade foram usados dos capacitores em paralelo de $2,2 \mu \mathrm{F}$ e de $2,7 \mu \mathrm{F}$. Finalmente para o amortecedor paralelo $C_{d}=4 C_{i n}$ e $R_{d}=\sqrt{\frac{L_{i n}}{C_{i n}}}=5 \Omega$. Por disponibilidade de componentes foi usada uma resistência de $10 \Omega$.

Este filtro possui uma impedância baixa para as frequências de operação do protocolo $\mathrm{HART}^{\circledR}$, pois o capacitor é de um valor grande (baixa impedância) e a indutância por razões de compatibilidade electromagnética e espaço não pode ser maior. Portanto, foi adicionada uma resistência em série com o valor de $300 \Omega$ para cumprir com os requisitos do protocolo HART ${ }^{\circledR}$. Na figura 13 é mostrado o circuito 
da fonte chaveada.

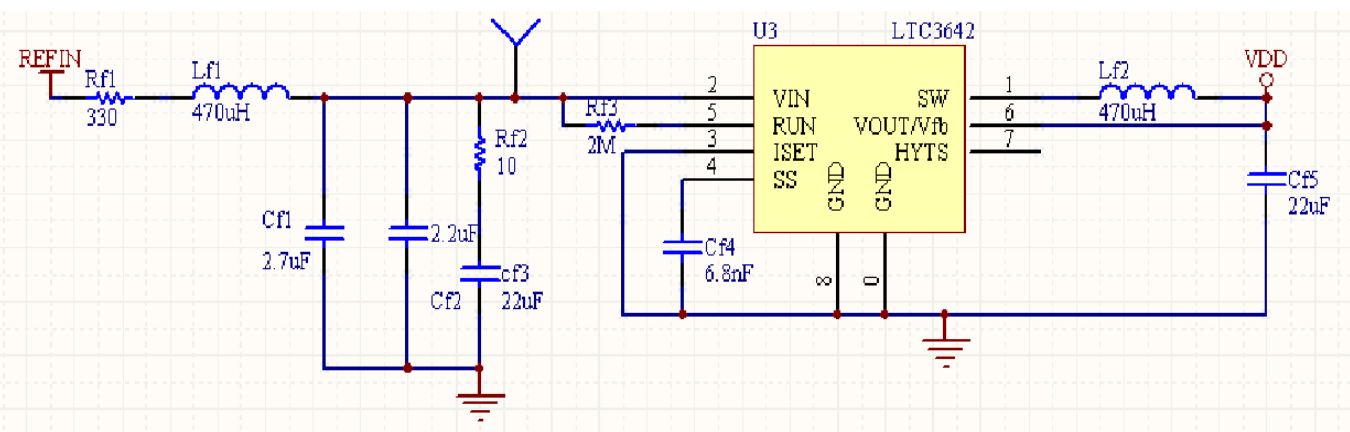

Figura 13: Esquemático da Fonte Comutada .

\subsubsection{Projeto Bloco Fonte Linear 3v}

Esta é uma fonte linear, pelo que somente deve-se usar um capacitor na entrada e na saída para filtrar os componentes de alta frequência gerados pelos osciladores dos processadores do DSSP e do microprocessador. Na figura 14 é apresentado o circuito usado. Deve-se levar em consideração que o valor do capacitor Cf6 é somado ao valor do capacitor Cf5 (ver 13) para resultar na capacitância $C_{\text {out }}$ da fonte chaveada.

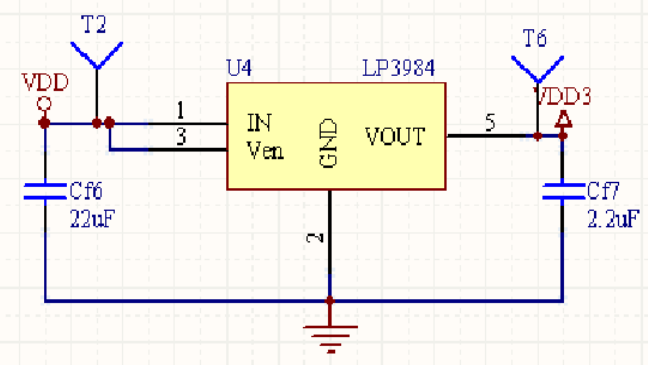

Figura 14: Esquemático da Fonte Linear .

\subsubsection{Projeto Bloco Fonte de Excitação do Sensor}

Deve ser uma fonte de corrente constante, implementada usando um amplificador operacional em realimentação negativa. Baseados no circuito proposto em 
(FATHI, 2010) será usado um dos amplificadores integrados no DSSP, como é apresentado na figura 15. Pelo princípio do terra virtual, $R 2$ e $R 3$ estão na mesma tensão, como a corrente por $R 3$ é aproximadamente igual à corrente $I B$, que é a corrente de excitação do sensor, essa pode ser controlada modificando a tensão em $R 2$ (modificando a relação $R 1$ e $R 2$, pois eles compõem um divisor de tensão). A equação para o cálculo da corrente é $I B \approx \frac{V_{d d} \cdot R 2}{(R 1+R 2) \cdot R 3}$. Para um baixo consumo $R 1$ e $R 2$ possuem valores altos de resistência, $330 \mathrm{~K} \Omega$ e $150 \mathrm{~K} \Omega$. Fixando $R 3$ em $6,8 \mathrm{~K} \Omega$ se obtêm uma corrente de excitação de aproximadamente $229,7 \mu \mathrm{A}$.

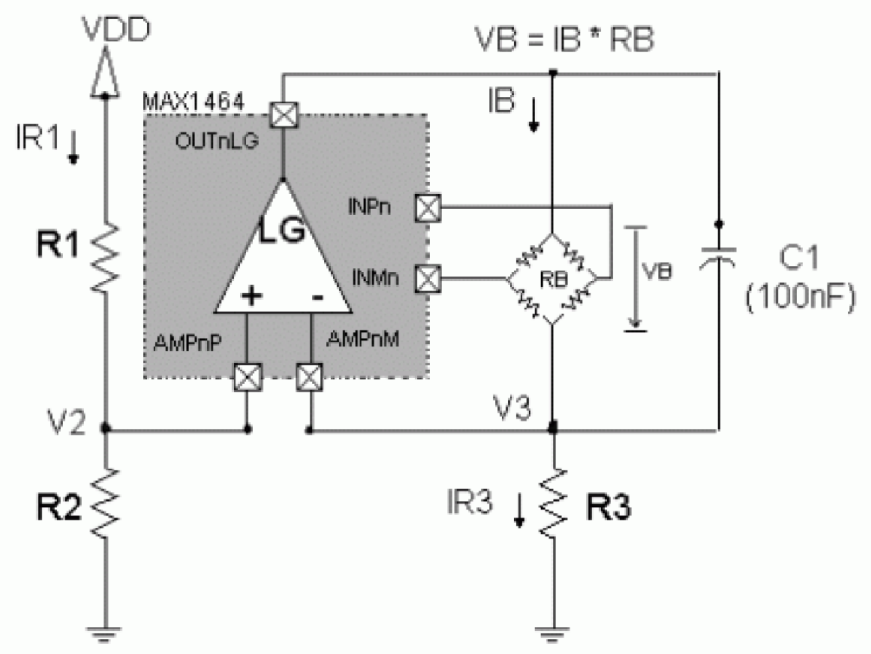

Figura 15: Fonte de excitação do sensor .

\subsubsection{Projeto Bloco Fonte de Corrente de Laço}

Para permitir a modulação da sinalização $\mathrm{HART}^{\circledR}$ no laço de corrente a fonte de saída dos transmissores 4-20 mA da MEMS deve ser modificada. O circuito usado é baseado no circuito apresentado em (MAXIM, 2002), na figura 16 podese observar o circuito. O principio de operação é o seguinte, a realimentação negativa do amplificador operacional cria um terra virtual, portanto $R_{f d b k}$ e $R_{\text {sense }}$ estão nesta tensão. Como a corrente de laço será a soma das correntes por esses resistores, deve-se usar valores que garantam que a corrente por $R_{\text {sense }}$ seja muito 
maior, de tal forma que a corrente será aproximadamente a corrente por $R_{\text {sense }}$. Então a corrente de laço vai-se controlar modificando a tensão em $R_{f d b k}$, isto é feito controlando a corrente por $R_{o f s t}$ e $R_{g a i n}$, pois a corrente por $R_{f d b k}$ é igual à soma das correntes por essas resistências. Para poder calcular os demais resistores é necessário definir em primeiro lugar $R_{f d b k}$ e $R_{\text {sense }}$, portanto, basados nas considerações anteriores foram escolhidos os valores de $100 \mathrm{k} \Omega$ e $50 \Omega$. $R_{\text {gain }}$ tem como objetivo garantir os $16 \mathrm{~mA}$ do fundo de escala da saída analógica, que em nosso caso varia de $0,5 \mathrm{~V}$ a $4,5 \mathrm{~V}$, portanto, para uma variação de $4 \mathrm{~V}$ deve-se obter uma variação de $16 \mathrm{~mA}$ na corrente por $R_{\text {sense }}$, isto é $R_{\text {gain }}=\frac{4 R_{f d b k}}{R_{s e n s e} \cdot 16 m}$ que é igual a $500 \mathrm{~K} \Omega$. Como o sinal de saída analógico para zero pressão é de $0,5 \mathrm{~V}$, a corrente de laço será $I_{\text {sense }}=\frac{0,5 \cdot R_{\text {fdbk }}}{R_{g a i n} \cdot R_{\text {sense }}}=2 m A$, então $R_{o f s t}$ é ajustado para somar $2 \mathrm{~mA}$ ao laço e garantir os $4 \mathrm{~mA}$ em pressão zero, $R_{o f s t}=\frac{5 \cdot R_{f d b k}}{R_{s e n s e} \cdot 2 m}=5 M \Omega . R_{x}$ dissipa potência para proteger o transistor, mas deve-se usar um valor que não sature o transistor, então $R_{x}<\frac{15-(20 m A \cdot 50)}{20 m A}$, isto é menor que $700 \Omega$, pelo que para ter uma margem maior é usado $390 \Omega$. $C_{f}$ é recomendado para a diminuição do ruido e parar ajudar a compensar o amplificador, mas não é necessário (FATHI, 2010), pelo que o valor utilizado para esta capacitância não deve afetar a modulação do sinal digital. Considerando estas recomendações foi usado um valor de 20pF, pois um valor maior filtraria os sinais de modulação do sinal digital.

\subsubsection{Projeto Circuitos Adicionais Para o Modem HART ${ }^{\circledR}$}

O modem HART $^{\circledR}$ precisa de um filtro passa banda de entrada para evitar ruídos na demodulação do sinal digital, portanto, deve-se garantir uma banda de passagem de $500 \mathrm{~Hz}$ a $10 \mathrm{KHz}$. Em (MAXIM, 2010) é apresentado o circuito usado, o qual é composto por filtro $\mathrm{RC}\left(R_{m 1}\right.$ e $\left.C_{m 3}\right)$ passa-baixa a $10 \mathrm{Khz}$ e um filtro $\mathrm{RC}$ $\left(R_{m 2}\right.$ e $\left.C_{m 2}\right)$ passa-altas com frequência de corte em $480 \mathrm{~Hz} . R_{m 2}$ é usado para 


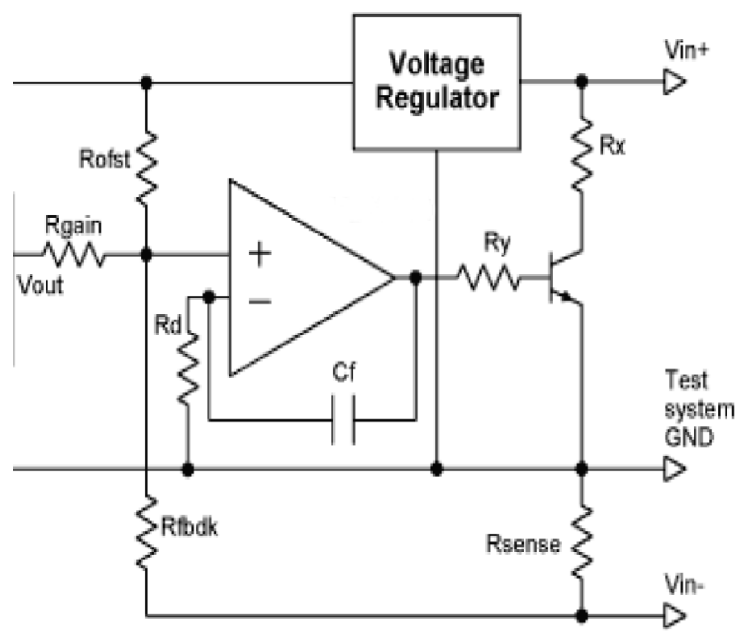

Figura 16: Esquemático da Fonte de Corrente do laço (MAXIM, 2002).

somar um nível de DC ao sinal. Na figura 17 pode-se observar o circuito usado. O DS8500 também precisa de um cristal externo de $3.6864 \mathrm{MHz}$ e o sinal de saída é de 500 mVp-p. Logo, deve-se calcular o valor da resistência de acoplamento à fonte de corrente que gere uma saída em corrente de 1,2mAp-p. Para não alterar o funcionamento da fonte de corrente de saída antes calculada (ver 3.1.3) não devem ser somados níveis de DC nesse circuito, somente o sinal AC. Para garantir isto um capacitor em série é usado $\left(C_{m 5}\right)$. Para calcular a resistência de acoplamento é usada a equação $R_{m 4}=\frac{0,5 \cdot R_{f d b k}}{R_{\text {sense }} \cdot 1,2 m}=833 \mathrm{~K} \Omega$.

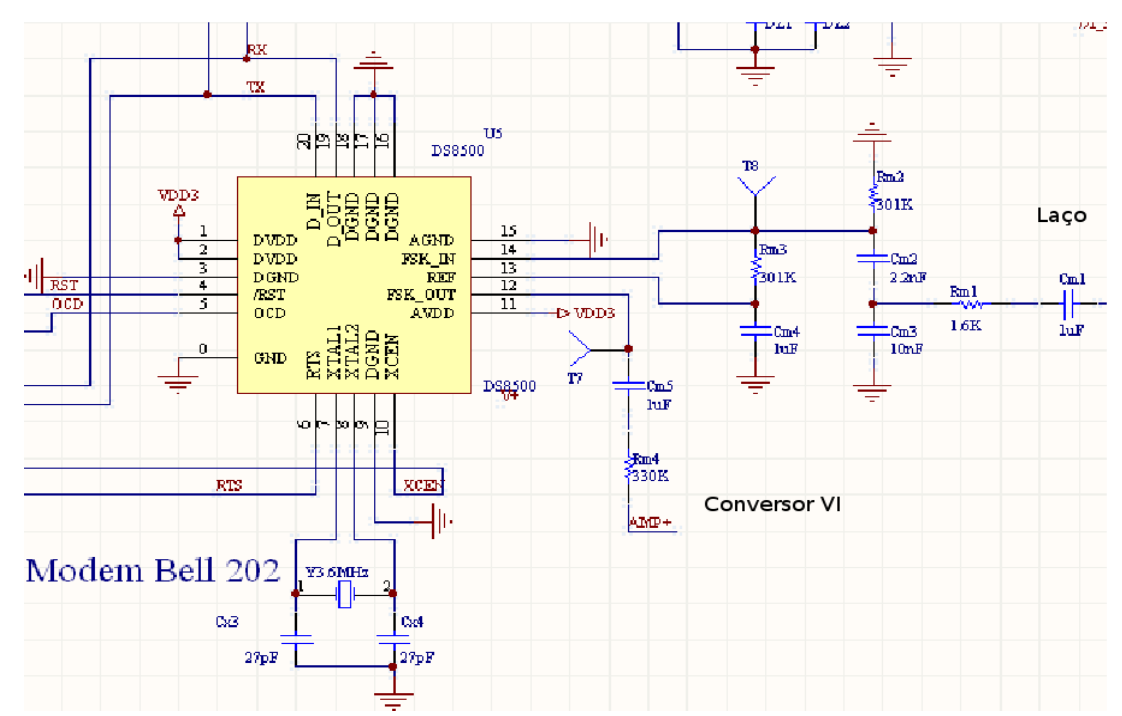

Figura 17: Circuito do modem $\operatorname{HART}^{\circledR}($ MAXIM, 2010). 


\subsubsection{Microcontrolador e as Suas Interfaces}

O microcontrolador somente precisa de uma resistência externa para o reset e opcionalmente de um cristal. O principal problema do microcontrolador é a interface com o MAX1464, pois cada um deles opera com tensões diferentes e os sinais digitais não são compatíveis, portanto um deslocador de nível foi utilizado. Este circuito composto por um Field-Effect Transistor (FET) canal n permite deslocar o nível de tensão de 5V a 3V e vice-versa, figura 18 (NXP, 2007), e deve ser usado um desses para cada um dos sinais necessários para a comunicação SPI (CS, DI e SCLK).

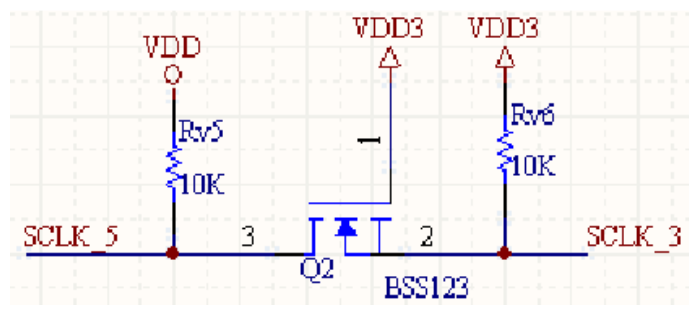

Figura 18: Deslocador de nível .

\subsubsection{Simulações}

Para validar o circuito proposto foram feitas simulações dos blocos que compõem o sistema transmissor sem simular o comportamento do MAX1464, pois não estão disponíveis os modelos de simulação. O software usado para a simulação foi o LTSpice, fornecido pela Linear Technologies, porque o modelo da fonte de corrente chaveada só está disponível para essa distribuição do Spice. A primeira simulação foi feita para verificar o nível de ruido nos $5 \mathrm{~V}$. Os resultados são apresentados na figura 19, na qual pode-se observar um nível de ruído de $1 \mathrm{mV}$ aproximadamente com uma frequência de $2 \mathrm{KHz}$. Isto é um problema, pois o máximo ruído permitido pelo protocolo $\mathrm{HART}{ }^{\circledR}$ na faixa de $500 \mathrm{~Hz}$ a $10 \mathrm{KHz}$ é de $2 \mathrm{mVrms}$, pois esse sinal pode interferir o sinal digital se for maior no circuito real. 
No laço de corrente o ruído gerado pelo chaveamento da fonte é o mostrado na

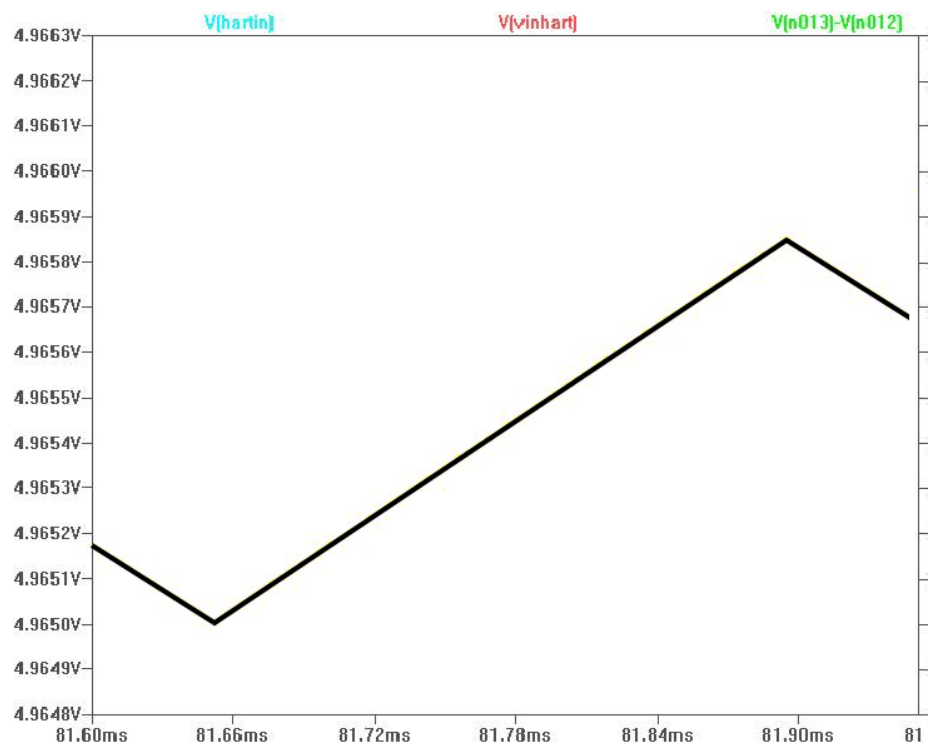

Figura 19: simulaçõo saída fonte comutada.

figura 20, esta simulação indica que o ruído tem uma amplitude de $50 \mu \mathrm{A}$, mas a uma frequência alta, pelo que é esperado que o filtro do sinal analógico (passabaixa de $25 \mathrm{~Hz}$ ) diminua está amplitude a $10 \mu \mathrm{A}$. O nível de DC está em 3,96mA, o que difere do valor desejado de $4 \mathrm{~mA}$, mas que pode ser corrigido no processo de compensação e calibração.

Uma simulação foi feita para verificar o sinal digital modulado no laço de corrente, em $20 \mathrm{~mA}$ DC e 4 mA DC. Para $20 \mathrm{~mA}$ DC o sinal HART ${ }^{\circledR}$ é modulado corretamente, mas no caso de $4 \mathrm{~mA}$ o sinal pode apresentar distorção, devido ao corte do transistor de controle de laço, pois a corrente tenta diminuir além da corrente minima do circuito. Para uma modulação sem distorção a corrente drenada pelo regulador chaveado deve ser menor que $4 m-(1,2 m / 2)=3,4 m A$. Na figura 21 é mostrado o problema. Uma simulação foi feita para verificar o consumo de corrente pela fonte de corrente, supondo uma corrente drenada pelo circuito de $5 \mathrm{~mA}$ e com uma alimentação de $24 \mathrm{~V}$, o que gerou como resultado uma corrente de 2,2mA máximo pelo que é esperado que nessas condições o sinal HART ${ }^{\circledR}$ não seja modificado (ver figura 22). 


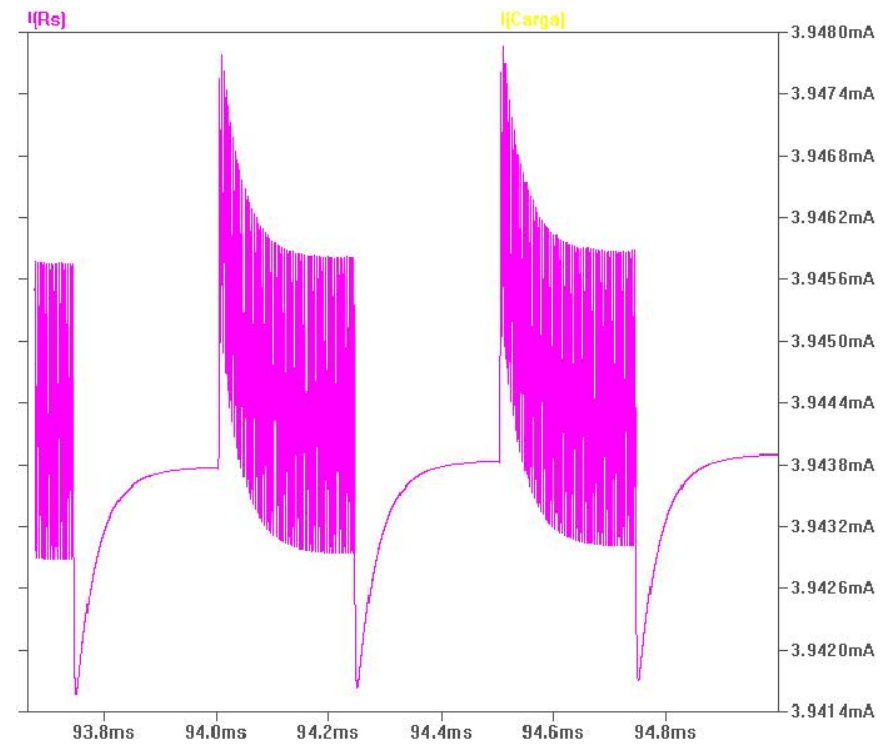

Figura 20: simulação ruído na corrente de laço.

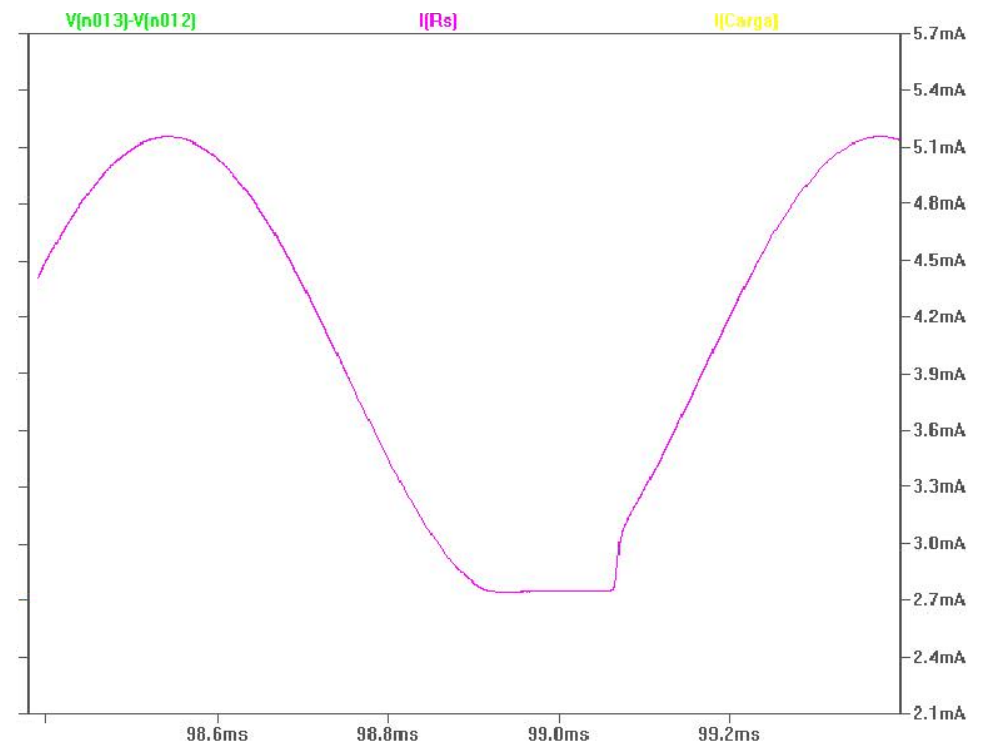

Figura 21: Saturação no sinal $\mathrm{HART}^{\circledR}$.

\subsubsection{Projeto de Circuito Impresso}

As simulações permitiram validar teoricamente alguns blocos do circuito, em especial aqueles que são novos no sistema (fonte de corrente chaveada, filtros do modem HART ${ }^{\circledR}$ e as modificações à fonte de corrente de saída). Os demais blocos que não foram simulados, têm sido testados nos projetos desenvolvidos pelo grupo, de modo que, espera-se funcionem corretamente. 


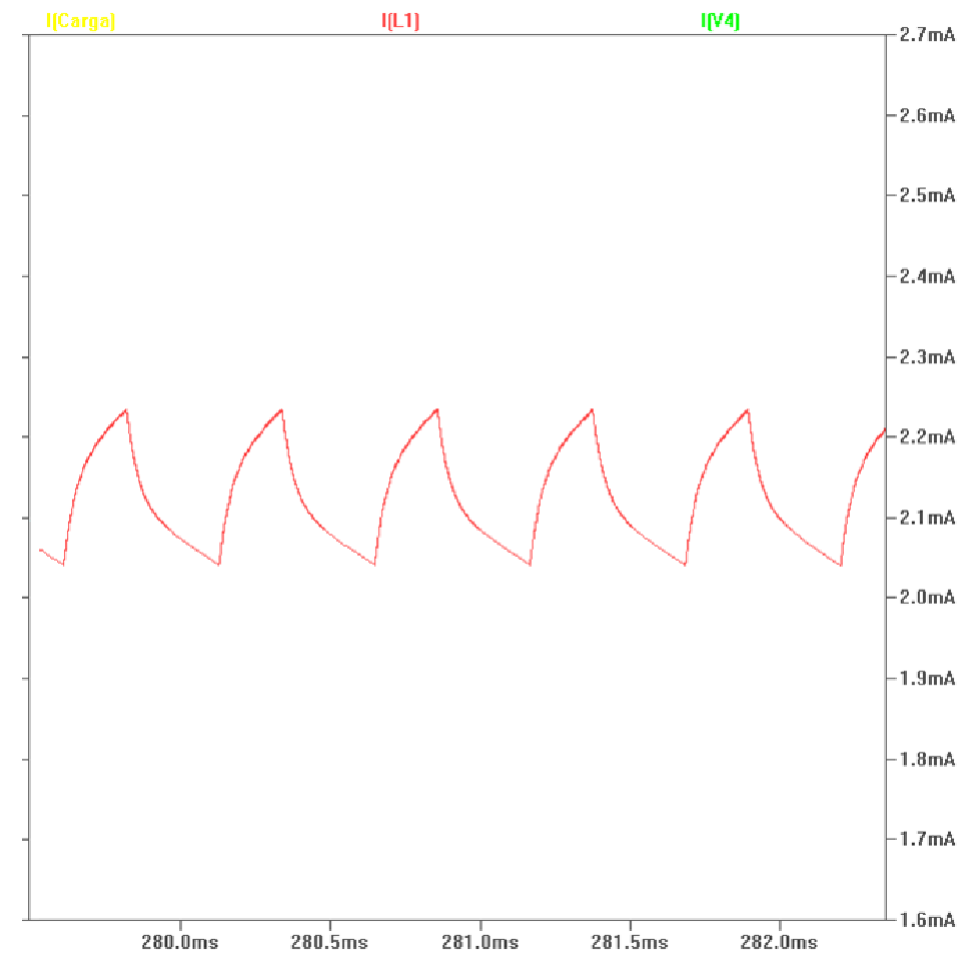

Figura 22: Corrente de laço para uma corrente de $5 \mathrm{~mA}$ de carga no regulador chaveado .

Para o projeto da placa de circuito impresso, foram usadas as mesmas normas dos projetos anteriores da MEMS Ltda., visando cumprir com os requisitos de tamanho e proteções elétricas (Inversão de tensão e compatibilidade eletromagnéticaEMC). Na figura 23 pode-se observar o circuito completo. A localização dos componentes foi baseada nas placas de circuito impresso existentes, incluindo os novos componentes de forma tal que não modificaram a distribuição original. $\mathrm{O}$ tamanho da nova placa é de $86,51 \mathrm{~mm}$ de comprimento por $21,95 \mathrm{~mm}$ de largura. 


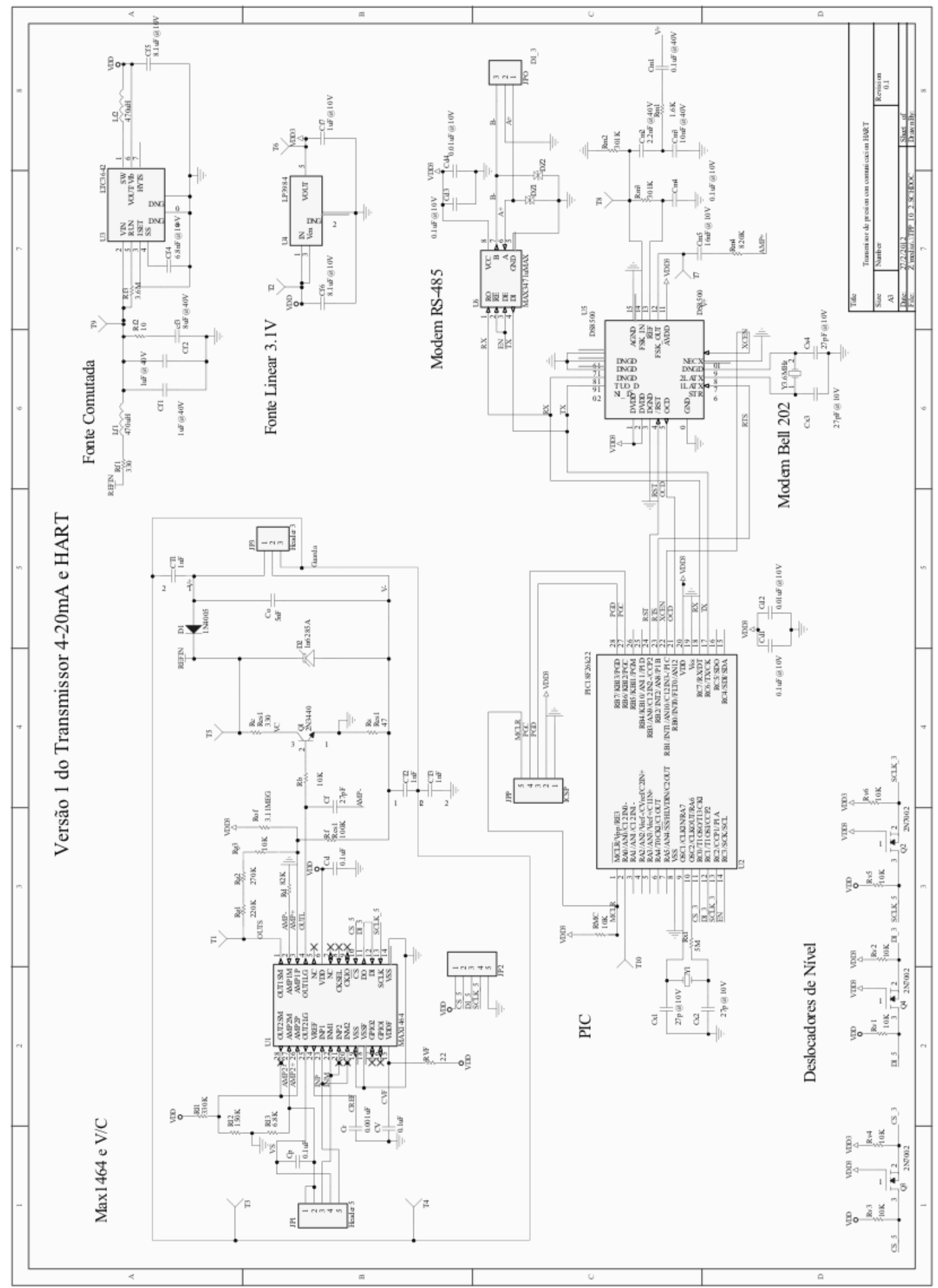

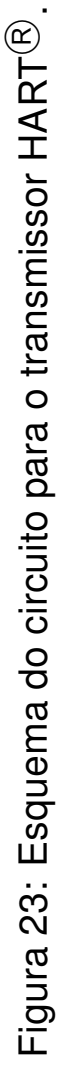




\subsubsection{Projeto do firmware do transmissor}

Para desenvolver um código que possa ser usado com outras camadas físicas, de rede ou aplicação, é necessário usar os SAPs definidos no padrão e também garantir que a execução de um SAP não será bloqueante, ou seja dependente das variáveis de outras camadas. Portanto, foi proposto o uso de um sistema operacional de tempo real no microcontrolador. Por facilidade foi usado o RTOS (real time operation system) do compilador CSS-PICc.

Um teste deste RTOS confirmou que as tarefas não são executadas de forma periódica, pois o tempo de execução de uma tarefa dependente do seu código interno, pelo que deve-se ter precaução na codificação para evitar tempos de execução excessivos. As tarefas que são sensíveis ao tempo, como medição de tempos de bit usada pela camada MAC, devem ser implementadas usado interrupções por timers e não como tarefas do sistema operacional.

A operação de cada uma das camadas é baseada numa tarefa periódica que verifica o estado das flags da cada camada, as quais indicam que ação deve ser executada. A ativação das flags é feita usando as SAPs definidas pelo padrão. Nesta arquitetura proposta deve-se ter cuidado do gerenciamento das variáveis, e em alguns casos é melhor passar os ponteiros para evitar o uso excessivo da memoria RAM.

\subsubsection{Projeto SAPs Camada Física}

As duas primeiras SAPs implementadas foram resetRequest e resetConfirm. A primeira ativa o sinal RST (reset) do DS8500 por 20ms e depois, a segunda informa que o reset foi executado com sucesso. As funções executadas no SAP resetConfirm são responsabilidade da camada dois.

O SAP EnebleRequest permite ativa ou desativar o sinal RTS (ready to send) do DS8500, os flags enableStart é usada para identificar a ação solicitada. A tarefa 
periódica da camada chama o SAP enableConfirm para indicar que o DS8500 está pronto para enviar dados. Para o caso do enablelndicate a implementação foi totalmente baseada na interrupção externa, usando o sinal OCD do DS8500.

Os dois últimos SAPs implementados foram o dataRequest e dataConfirm. O primeiro simplesmente transfere o byte recebido como parâmetro ao buffer de saída serial e habilita a interrupção de buffer serial vazio. Então quando a UART envia todo o byte, a interrupção é chamada primeiro é verificado o valor do flag Eliportadora, se for verdadeiro o sinal RTS é desativado e solicitado o envio do enableConfirm, se for falso solicita o envio do dataConfirm. O SAP datalndicate é chamado na interrupção de recepção serial imediatamente um dado é recebido. Funções de teste foram usadas para validar o desempenho do código criado. Verificando o envio e recepção de dados, no SAP datalndicate um buffer de 20 bytes é usado para armazenar os dados, uma função a cada 20 segundos envia um pacote com as primeiras 10 posições desse buffer. Na terminal, foi verificado o envio e recepção exitoso dos dados: Send:(18:06:34) 0123456789ABCDF; Status:(18:06:34)Clear to Send (CTS) signal changed state. CTS State = False; Rec:(18:06:41)0123456789. Na figura 24 é apresentado o diagrama da implementação dos SAPs da camada física.

\subsubsection{Projeto SAPs Subcamada MAC}

A camada MAC, é encarregada de controlar o acesso ao meio. Nela está implementada a máquina de estados de recepção e de transmissão, as quais utilizam os SAPs da camada física. Estas máquinas de estados garantem que os dados enviados e recebidos pelas camadas superiores cumpram com os requisitos de temporização e estrutura do quadro do protocolo. Nesta camada não é feito o processamento dos dados, simplesmente é verificada a integridade deles. 


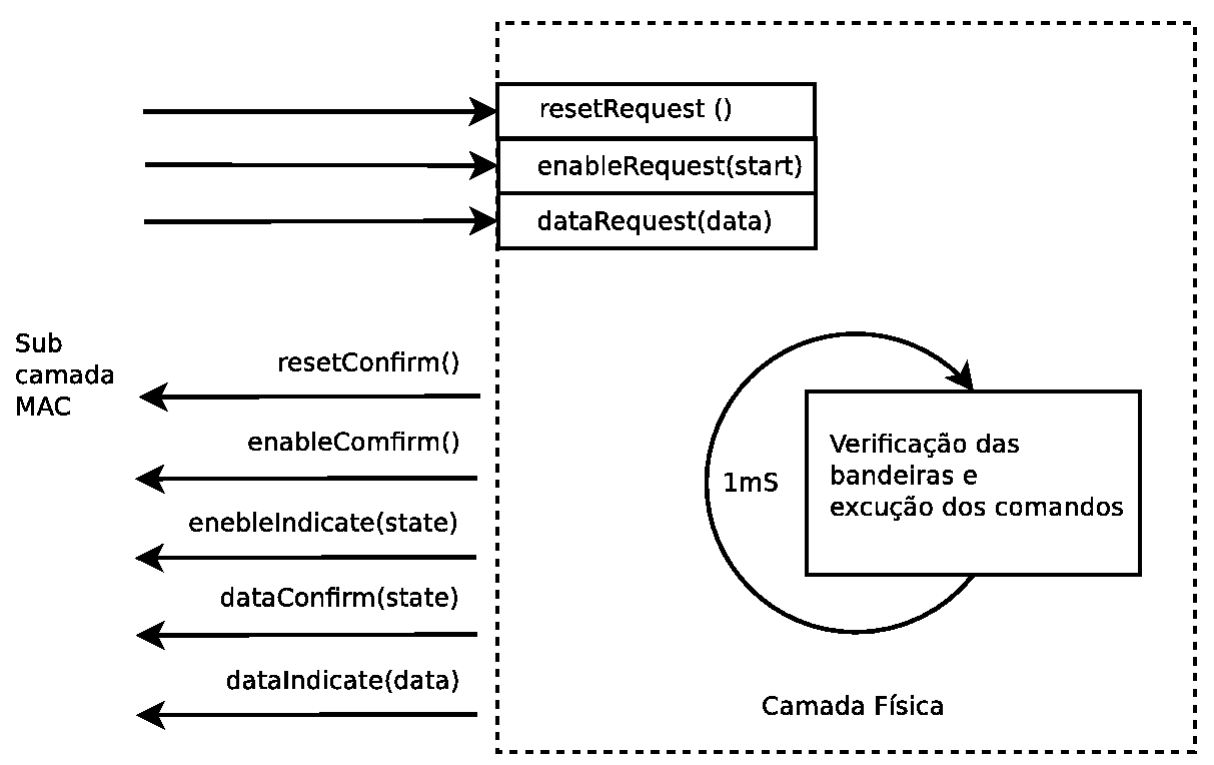

Figura 24: Diagrama implementação SAPs camada física.

\begin{tabular}{|l|l|l|l|l|l|l|l|l|}
\hline Preâmbulo & Preâmbulo & Delimitador & Endereço & $\begin{array}{l}\text { [Bytes de } \\
\text { expansão] }\end{array}$ & Comando & $\begin{array}{l}\text { Quantidade } \\
\text { de bytes }\end{array}$ & [Dados] & $\begin{array}{l}\text { Check } \\
\text { Byte }\end{array}$ \\
\hline
\end{tabular}

Figura 25: Quadro Padrão HART ${ }^{\circledR}$.

\subsubsection{Recepção:}

a principal tarefa na recepção é verificar que os dados recebidos cumpram com o quadro do protocolo HART $^{\circledR}($ figura 25), e gerar as resposta definidas no padrão para erros de dados e de estrutura. Para a implementação desta camada, uma máquina de estados executada por uma tarefa periódica do RTOS foi usada.O SAP enablelndicate inicializa ou para a máquina de recepção. O SAP datalndicate armazena os bytes recebidos num buffer e em cada execução da tarefa periódica são processados todos os dados disponíveis. O tamanho do quadro $H A R T^{\circledR}$ varia segundo os dados transmitidos, então nos bytes Delimitador e quantidade de bytes deve-se decodificar o tamanho do quadro recebido. Um SAP foi definido entre a camada MAC e a LLC, nomeado IIclndicate que recebe os dados validados pela sub-camada MAC válido. Na figura 26 é mostrada a máquina de estados de recepção, cada estado corresponde a um quadrado e o nome do estado em maiúsculas. O estado "WAIT_SOM" é o estado de parada 
da máquina e somente é possível entrar e sair dele com o SAP enalbelndicate, na figura não é apresentado, mas em qualquer momento com a recepção de um enablelndicate(STOP) a máquina é levada nesse estado. Nos demais estados os dados recebidos somente são usados para determinar os valores dos contadores que determinam a estrutura do quadro, e também armazenar os dados que serão necessários para as camadas superiores.

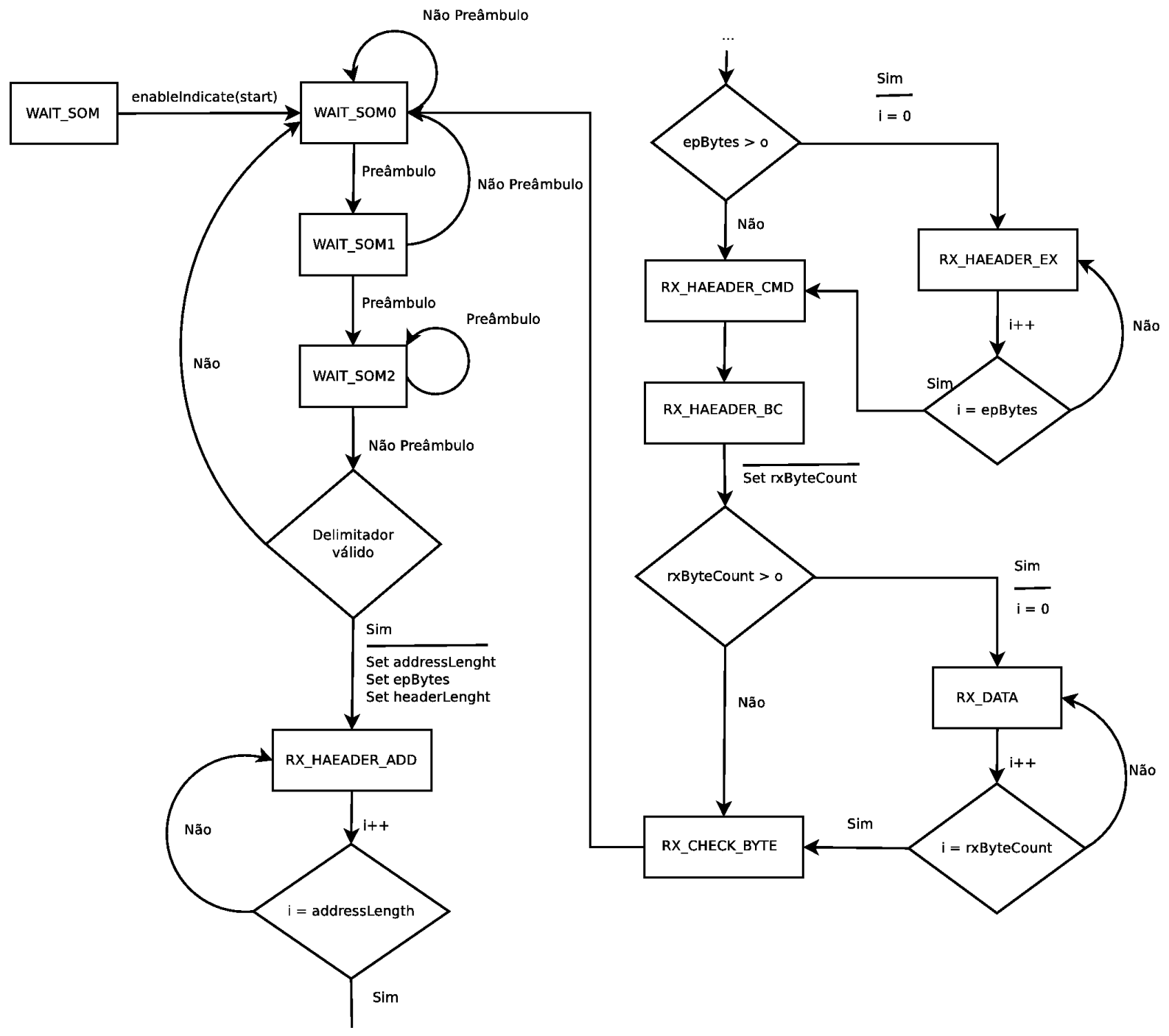

Figura 26: máquina de estados de recepção da subcamada MAC. 


\subsubsection{Transmissão:}

No caso da transmissão a tarefa principal da camada MAC é respeitar os tempos para o inicio da transmissão, para o qual um contador é inicializado com a recepção de um quadro completo e aumentado em 1 cada tempo de byte. O SAP transmitMAC recebe os dados que devem ser transmitidos e verifica que o tempo limite seja maior que o tempo atual. Se for certo uma bandeira solicita a inicialização da camada física (enbaleRequest). Com a recepção do enableConfirm por parte da camada física modifica-se o estado da máquina de transmissão para "WRITE", de forma tal que a cada dataConfirm recebido um novo dado é enviado usando o SAP dataRequest().

\subsubsection{Erros:}

A recepção de um erro (errolndicate)modifica o estado da máquina de estados de recepção ou transmissão, geralmente os erros não geram uma resposta. No caso de erros na paridade ou um esgotamento do buffer, flags de estado do transmissor são ativadas, para no próximo envio de dados serem informadas nos bits de estado.

Na figura 27 são apresentados os SAP da sub-camada MAC.

\subsubsection{Projeto SAPs Sub-camada LLC}

Esta sub-camada se encarrega do processamento do cabeçalho do padrão. No caso da recepção constata-se que o endereço destino seja o endereço do transmissor e que a combinação endereço-comando seja válido antes de entregar a informação à camada de aplicação. No caso da transmissão a sub-camada

LLC faz o cabeçalho, criando um quadro $H A R T^{\circledR}$ válido. O quadro é armazenado num buffer e depois usado o SAP transmitMAC(). A função mais importante nesta 


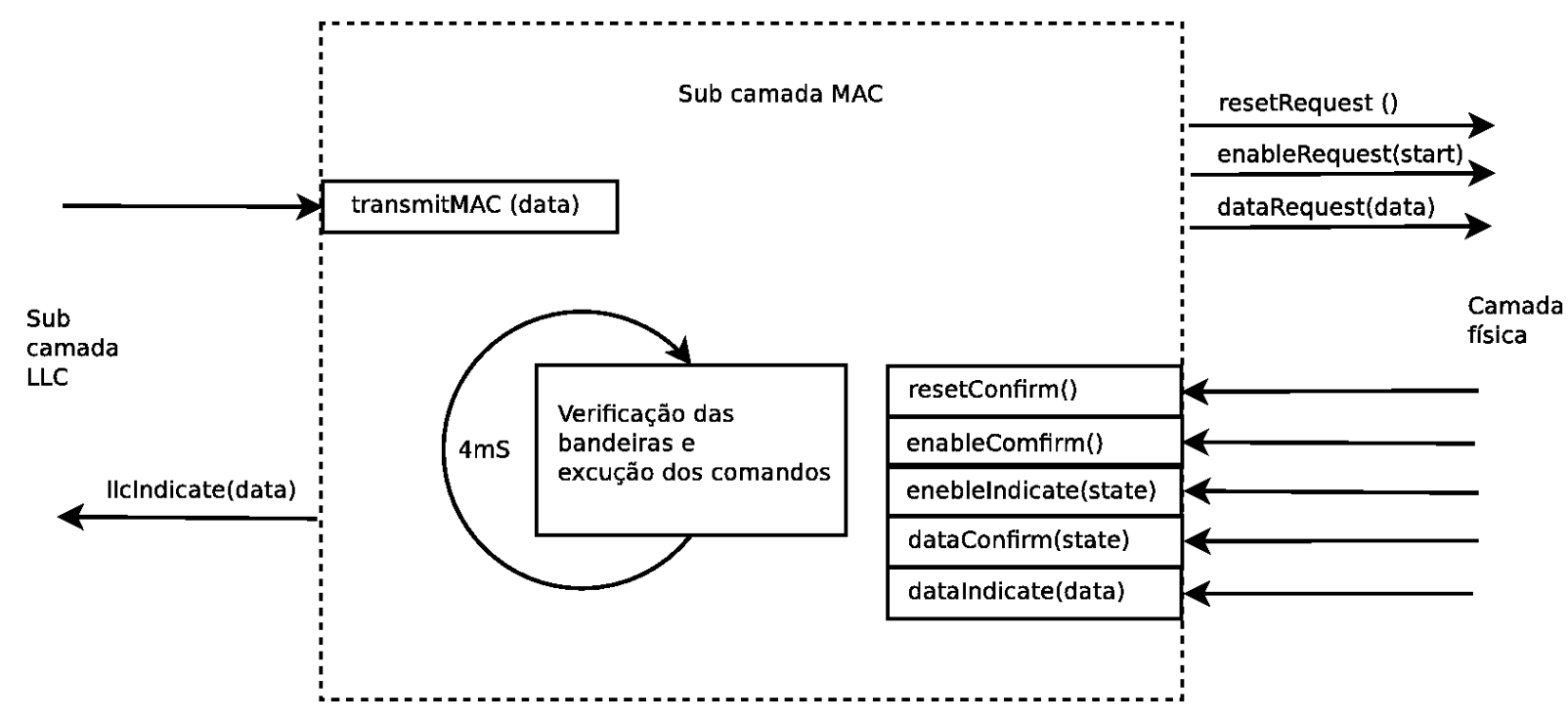

Figura 27: SAPs subcamada MAC.

camada é o gerenciamento dos endereços, pois é a única camada que mantem registro do endereço do mestre da rede e do transmissor mesmo. A implementação usa uma tarefa periódica para a execução das tarefas desta camada.

Para garantir uma resposta rápida aos comandos, uma modificação foi introduzida no modo de programação. Antes de usar o SAP transmitlndicate, todas as tarefas dos RTOS são paradas, liberando o processador para a execução do comando. Na figura 28 é apresentada a implementação desta sub-camada.

Com a implementação completa da camada física, LLC e MAC foram feitos testes para medir o tempo que demora a recepção de um comando pela camada de aplicação e o tempo que demora para ser transmitido um dado pela interface serial depois de ser gerado pela camada de aplicação. Os resultados foram um atraso de 9,6ms entre a recepção de um quadro $\mathrm{HART}^{\circledR}$ válido e a recepção dos dados pela camada de aplicação. E um tempo médio de 8,8 ms entre uma resposta gerada pela camada de aplicação e a transmissão do primeiro byte pelo meio físico. Com esses resultado é determinado que a camada de aplicação pode demorar até 238,2 ms para gerar uma resposta antes de exceder o limite de tempo STO (start time out).

Uma das ações que devem ser feitas é a leitura e escrita de dados na EEPROM 
do microcontrolador, pelo que foi feita uma medição do tempo de demora destes processos. Encuentram-se os valores de aproximadamente um milissegundo para leitura e 68ms para escrita. Tempo suficiente para o envio das respostas aos comandos, pelo que espera-se cumprir com os tempo STO em todos os comandos.

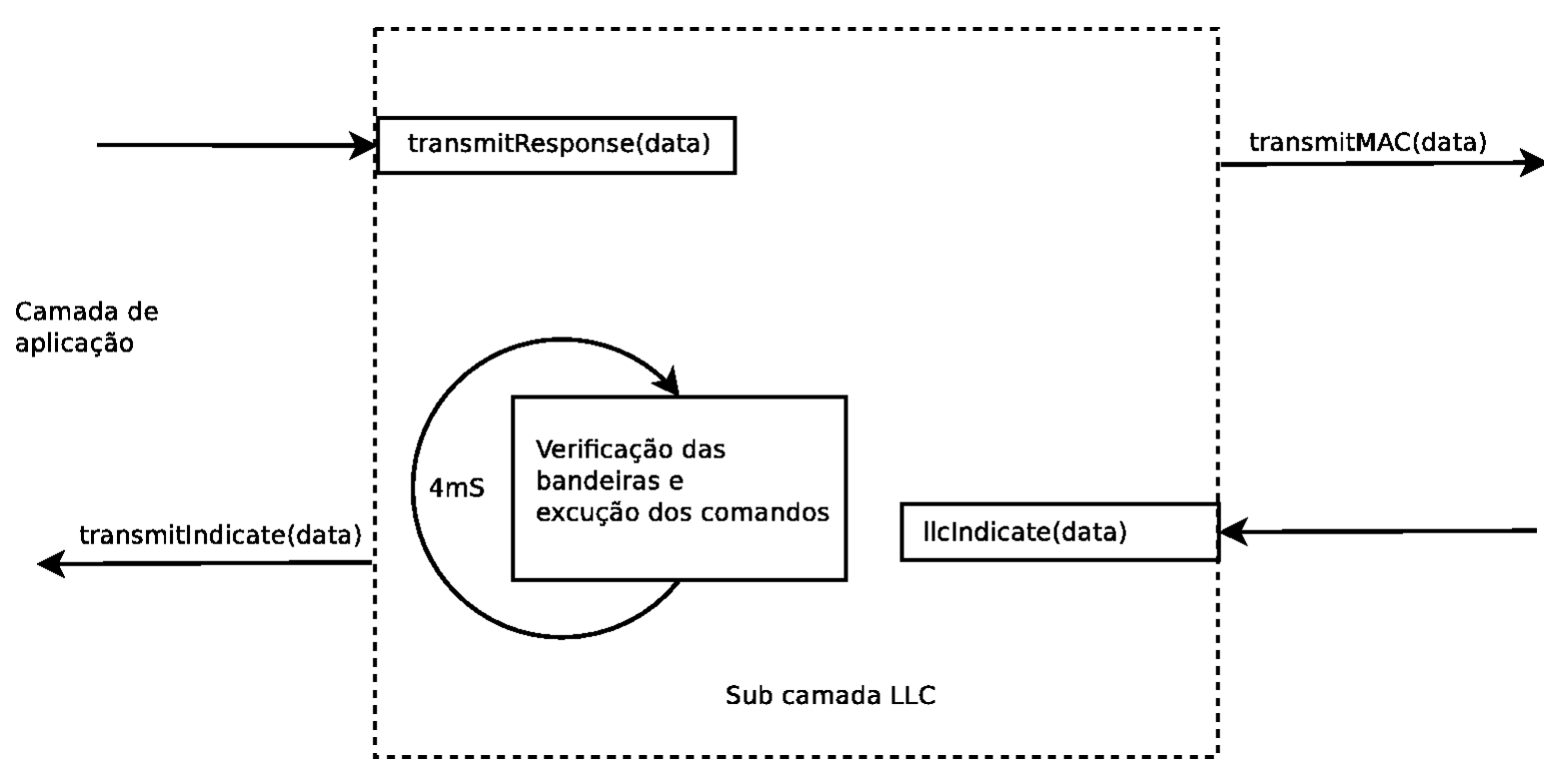

Figura 28: Sub-camada LLC.

\subsubsection{Projeto SAPs Camada de Aplicação}

A camada de aplicação é encarregada de gerar a resposta aos comando solicitados pelo mestre HART ${ }^{\circledR}$. Um equipamento precisa pelo menos cumprir os comandos universais do padrão (ver Tabela 5). Esses comandos podem dividir-se em quatro grupos: comandos de leitura de parâmetros, comandos de escrita de parâmetros, comandos de pesquisa de dispositivo e comandos sobre as variáveis medidas.

Os comandos de leitura de parâmetros não possuem bytes nas solicitações. As respostas são geradas com a leitura dos parâmetros solicitados da EEPROM do PIC18f26k20. Na tabela 8 se mostra o mapa de memória EEPROM usado no transmissor. Os comandos desta categoria são: o comando 0, 7, 8, 12, 13, 14, 15, 
16 e 20.

A segunda categoria de comandos se encarrega de modificar os parâmetros ar-

Tabela 8: Mapa da memória EEPROM.

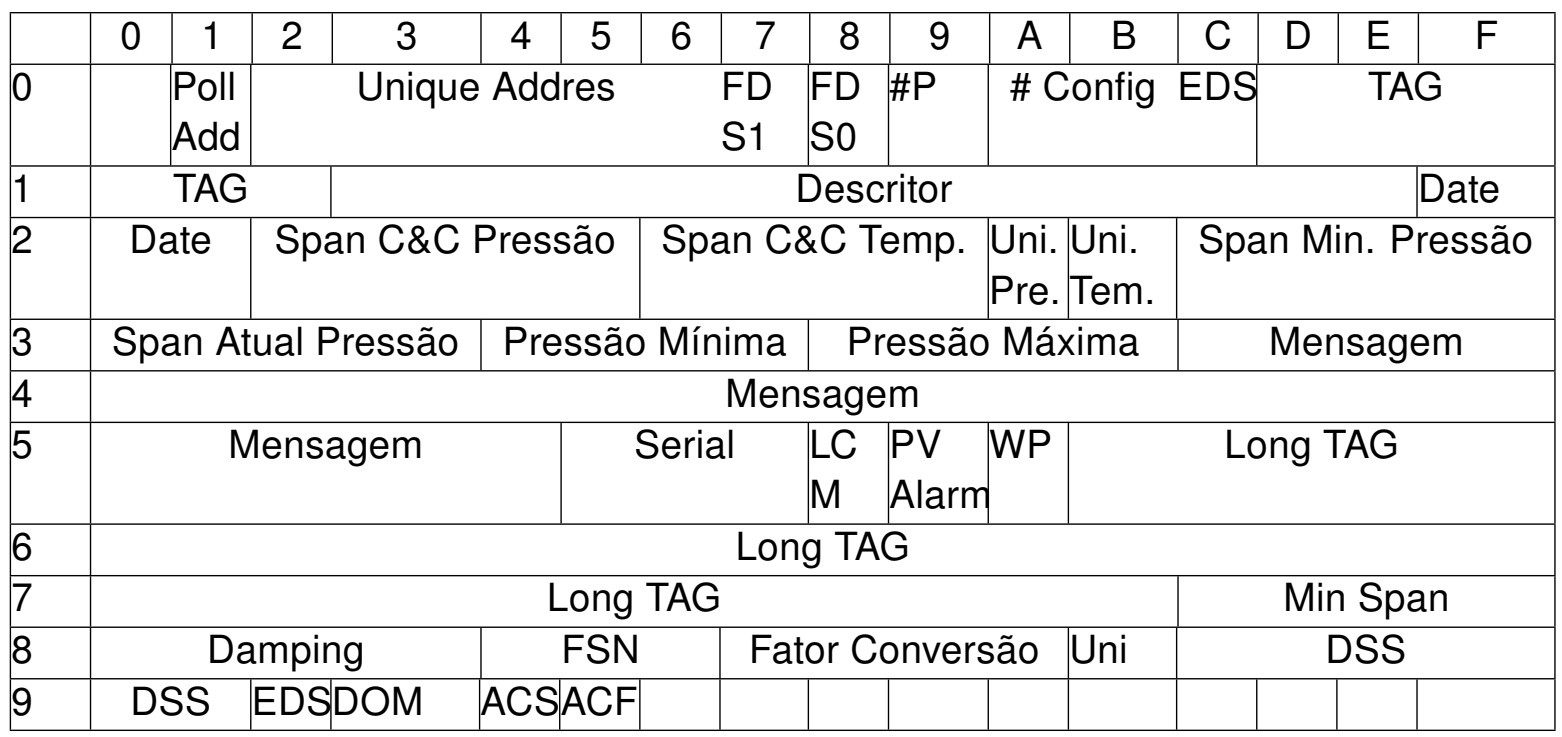

mazenados na EEPROM. Este tipo de comando toma mais tempo de execução, pois a escrita na EEPROM demora mais que a leitura. Adicionalmente a resposta a esses comandos precisa que sejam retornados os dados que têm sido armazenados na memória, para verificar que foi correta. A informação é enviada pelo mestre em forma de parâmetro no comando. Os comandos deste grupo são o comando 17,18 e 22. O terceiro grupo de comandos é usado pelo mestre para procurar transmissores na rede. Esses comandos são enviados com o endereço de broadcast, e somente são respondidos em caso que o TAG ou LONG TAG coincida com o TAG ou LONG TAG armazenado na EEPROM do transmissor. A este grupo pertencem o comando 11 e 21 . O último grupo de comados realiza alguma ação sobre as variáveis medidas. Para isto é necessário identificar as variáveis do transmissor segundo as classificações do padrão HART ${ }^{\circledR}($ ver tabela 9). Os comandos que pertencem a este grupo são: 1, 2, 3, 6 e 9. O comando 1 é a medição da variável primária em unidades de engenharia, o comando 2 é a leitura da cor- 
rente de laço e a porcentagem da escala. O comando 3 é a leitura das variáveis do equipamento, em nosso caso as quatro variáveis descritas na tabela 9 junto com as unidades de cada variável. O comando 6 permite a escrita do endereço curto (polling Address) e do modo do laço de corrente (habilitado e não habilitado). Quando o laço esta desabilitado a corrente é fixa em $4 \mathrm{~mA}$ e não varia com a pressão. E finalmente o comando 9 é de estado das variáveis de equipamento.

Além dos comandos universais foram implementados alguns comandos de prá-

Tabela 9: Classificação das variáveis do transmissor.

\begin{tabular}{|l|l|l|l|}
\hline Slot & $\begin{array}{l}\text { Tipo de Variá- } \\
\text { vel } \\
\text { Var. Terciaria } \\
(\text { TV) }\end{array}$ & Corrente de Lazo & $\begin{array}{l}\text { Classificação } \\
\text { da Variável }\end{array}$ \\
\hline 0 & $\begin{array}{l}\text { Var. Secun- } \\
\text { daria (SV) }\end{array}$ & $\begin{array}{l}\text { Medição da pres- } \\
\text { são em porcenta- } \\
\text { gem }\end{array}$ & 65 \\
\hline 2 & $\begin{array}{l}\text { Var. Primaria } \\
\text { (PV) }\end{array}$ & $\begin{array}{l}\text { Medição da pres- } \\
\text { são em unidades } \\
\text { de Eng. }\end{array}$ & 65 \\
\hline 3 & $\begin{array}{l}\text { Var. Quater- } \\
\text { nária (QV) }\end{array}$ & $\begin{array}{l}\text { Temperatura de la } \\
\text { eletrônica. }\end{array}$ & 64 \\
\hline
\end{tabular}

tica comum, que expandem as capacidades do transmissor. A HFC faz uma classificação dos equipamentos $\mathrm{HART}^{\circledR}$ segundo os comandos suportados pelos dispositivos. Com os comandos universais e os comandos $34,35,44,48,50$ e 54 de prática comum o transmissor é considerado um equipamentos HART ${ }^{\circledR}$ classe 2 , com algumas funções de classe 3.

O comando 34, permite a escrita do valor de damping ou fator de amortecimento da variável primária. O transmissor deve ajustar o filtro de saída da variável analógica segundo este parâmetro. Com o comando 35 é mudada a escala de pressão sinalizado na saída analógica, isto é, mudar os valores da pressão para os quais a corrente de laço está entre $4 \mathrm{~mA}$ e $20 \mathrm{~mA}$. A mudança de unidades usadas na saída digital é permitida pelo comando 44 . 
As unidades suportadas atualmente são: polegada de mercúrio a $0^{\circ} \mathrm{C}[\mathrm{in} \mathrm{Hg}]$, milímetros de mercúrio a $0^{\circ} \mathrm{C}[\mathrm{mm} \mathrm{Hg}$, libras força por polegada quadrada [PSI], bar, milibares [mbar], gramas força por centímetro quadrado [gf/cm2], quilo gramo força por centímetro quadrado [kgf/cm2], pascais [Pa], quilo pascais [KPa], torr, atmosferas [atm], polegadas de água a 60 $\mathrm{F}$ [in $\mathrm{H} 2 \mathrm{O} @ 60^{\circ} \mathrm{F}$ ], centímetros de água a $4^{\circ} \mathrm{C}$ [cm H2O], metros de água a $4^{\circ} \mathrm{C}$ [m H2O], centímetros de mercúrio a $0^{\circ} \mathrm{C}$ [cm Hg], libras força por pé quadrado [psf], hetopascais [hPa], quilogramas por metro quadrado $[\mathrm{kgf} / \mathrm{m} 2]$, pés de água a $4^{\circ} \mathrm{C}\left[\mathrm{ft} \mathrm{H} 2 \mathrm{O} @ 4^{\circ} \mathrm{C}\right.$ ], pés de água a $60^{\circ} \mathrm{C}\left[\mathrm{ft} \mathrm{H} 2 \mathrm{O} @ 60^{\circ} \mathrm{C}\right.$ ], metros de mercúrio a $0^{\circ} \mathrm{C}$ [m Hg], mega pascais [MPa], polegadas de água a $4^{\circ} \mathrm{C}\left[\mathrm{in} \mathrm{H} 2 \mathrm{O} @ 4^{\circ} \mathrm{C}\right]$ y milímetros de água a $4^{\circ} \mathrm{C}[\mathrm{mm} \mathrm{H} 2 \mathrm{O} @$ $4^{\circ} \mathrm{C}$ ]. O comando 48 lê o estado do equipamento, principalmente usado para diagnostico. A leitura da ordem dos slots para as variáveis do equipamento (primária, secundária, terciária e quaternária) é feita usando o comando 50 . Finalmente o comando 54 permite ler informação específica de cada variável.

\subsubsection{Projeto SAPs Camada de LLM}

A camada LLM é uma camada de enlace entre a camada de aplicação e o MAX1464. Como esta camada precisa interagir diretamente com o MAX1464, inicialmente será explicado de forma resumida a implementação do algoritmo de calibração e compensação usado no MAX1464.

\subsubsection{Firmware MAX1464}

Na seção 2.3.2 é explicado o algoritmo usado para a compensação e calibração dos transmissores de pressão. O processo de C\&C pode-se dividir em quatro passos: primeiro é medida e compensada a temperatura usando os coeficientes armazenados na memória no momento da calibração, depois deste processo a temperatura é compensada em offset, ganho e não linearidade; o segundo passo 
consiste no cálculo dos coeficientes de compensação para a pressão e o DAC, para o qual são usados o coeficientes calculados no momento da calibração e a temperatura do primeiro passo. Ao finalizar este passo são obtidos sete coeficientes independentes da temperatura, cinco dos quais são para a pressão e dois para o DAC.

Com esses dados, no terceiro passo é compensada a pressão. Neste passo a saída está normalizada entre -0,9 e 0,9 para os valores mínimo e máximo de pressão. O passo final é a compensação do DAC, para o que dois coeficientes são usados para a ajuste do ganho e offset do DAC.

\subsubsection{Modificações Firmware MAX1464}

Como alguns comandos HART ${ }^{\circledR}$ precisam atuar sobre o laço de corrente, foram feitas modificações ao firmware. Dois blocos foram adicionados, um multiplexador e uma transformação linear. O bloco de transformação linear é adicionado depois do terceiro passo (compensação da pressão) e permite modificar a excursão de saída do sinal analógico. O bloco multiplexador é adicionado depois e a função principal é escolher o valor que vai ser usado para o sinal analógico, o valor compensado e modificado ou um valor fixo. Na figura 29 é apresentado o diagrama do firmware modificado do MAX1464. No bloco da transformação linear um valor de inclinação e de coeficiente linear são calculados para modificar linearmente os valores do sinal de saída analógico. Também foi implementado um saturador, para evitar que o sinal analógico apresente valores válidos para valores de pressão fora da escala.

Para os novos blocos seis parâmetros devem ser modificados pelo PIC (dois da pendente, um do offset, um indicador de saturação, o valor de corrente fixa e o controle do multiplexador). Isto cria a necessidade de reprogramar o MAX1464 desde o PIC. Para facilitar esta tarefa todos esses parâmetros são armazenados 


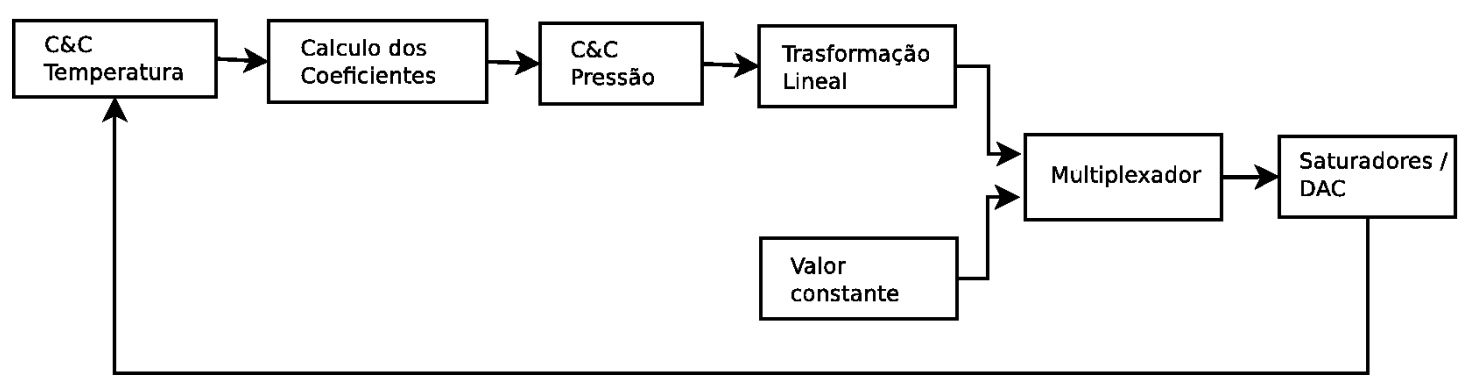

Figura 29: Firmware MAX1464.

na ultima página da memória de programa do MAX1464, de forma tal que o PIC apaga essa página e a reprograma. As últimas instruções armazenadas devem retornar o ponteiro de programa à posição de memória da qual foi dado o salto de programa. Para permitir leitura das variáveis pelo $\mathrm{PIC}$, os valores $\mathrm{C} \& \mathrm{C}$ da pressão, temperatura e valor de entrada os CAD são armazenados nas portas 1, 0 e 2 do MAX1464, permitindo a leitura pela interface SPI.

\subsubsection{Camada LLM no PIC}

Esta camada recebe as solicitações da camada de aplicação e imediatamente executa as ações requeridas. As leituras são as ações mas simples, pois simplesmente são lidos os valores da porta correta do MAX1464 e convertidos em formato IEEE 754 nas unidades de engenharia previamente configuradas para cada variável. As ações de escrita no MAX1464 precisam de maior tempo de execução, pois além do tempo requerido para o cálculo dos diferentes parâmetros, uma verificação da página programada deve ser feita para indicar a ocorrência de erros.

\subsection{Procedimento de Compensação e Calibração.}

Como o algoritmo de compensação e calibração não foi modificado neste trabalho, utiliza-se o mesmo procedimento usado nos transmissores 4-20 mA. Somente duas pequenas modificações devem ser feitas: a primeira é programar o PIC antes de iniciar a C\&C, para que ele esteja em modo sleep durante o tempo 
todo; a segunda é usar como base para a modificação dos coeficientes o firmware modificado e não o comumente usado nos transmissores 4-20 mA (ver secção 3.1.12.2). 


\section{RESULTADOS}

Nesta seção serão apresentados os resultados dos testes, tanto do hardware como de software, com os quais foi feita a verificação do transmissor. Dentro da metodologia do projeto esta seção corresponde à etapa solução inicial.

\subsection{Medições de Validação dos Blocos do Protótipo}

Com o circuito impresso pronto, ver figura 30, foram feitas uma série de medições para validar o hardware do protótipo. Para verificar cada parte do circuito de forma independente, foram montadas varias placas unicamente com os componentes necessários para realizar as medições de cada bloco funcional. A continuação serão apresentadas as medições feitas.

\subsubsection{Regulador Chaveado}

Inicialmente, foram soldados unicamente os componentes dos circuitos de proteção e regulação. Como carga foram usadas umas resistências de valor constante entre a saída do regulador e terra. O objetivo deste teste é medir o nível de ruido e a tensão de saída, emulando uma carga de $3 \mathrm{~mA}, 5 \mathrm{~mA}$ e $6,9 \mathrm{~mA}$ (excursão esperada de consumo do circuito). Na tabela 10 são apresentados os dados, os quais permitem ver que o circuito regula a tensão Vdd em 5,0V DC e que a amplitude do ruído (Vddpp) é constante para as diferentes cargas. A frequência varia com a carga na faixa de $7,6 \mathrm{kHz}$ a $10 \mathrm{Kz}$, que é maior que as frequências 


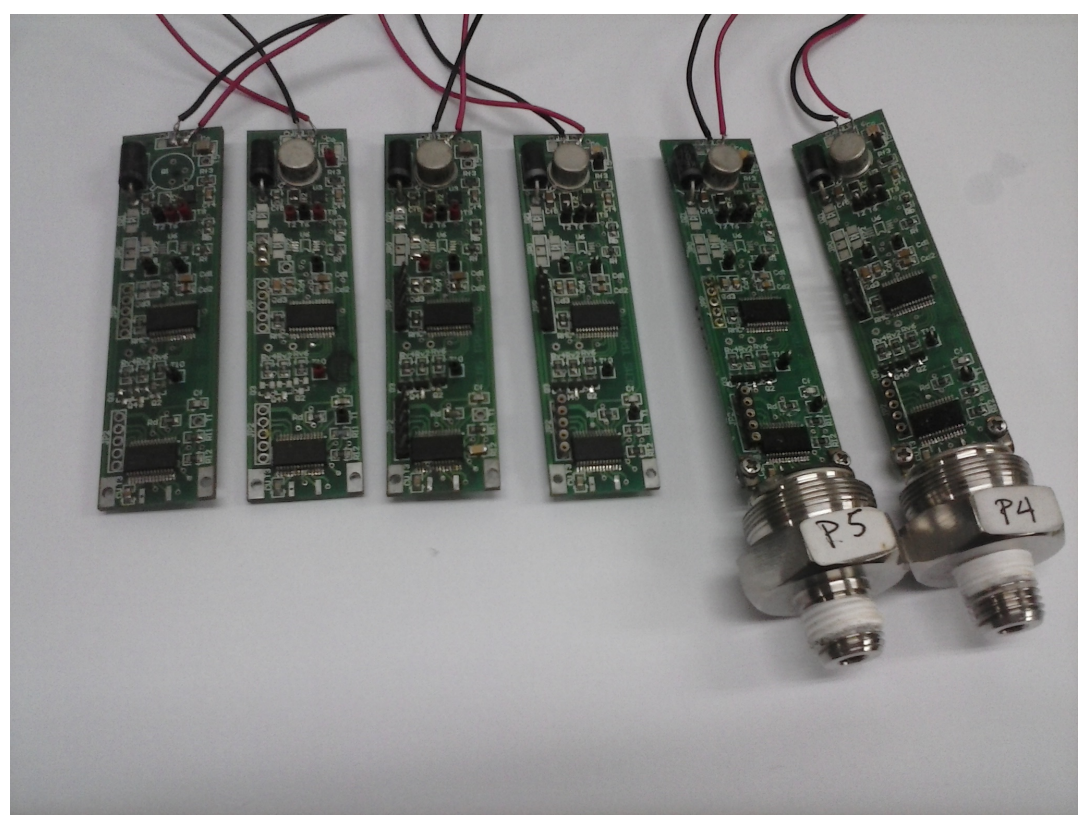

Figura 30: Transmissores usados para testes.

HART ${ }^{\circledR}$ usadas em nosso circuito $(1,2 \mathrm{KHz}$ e $2,2 \mathrm{KHz})$, porém, está na faixa de $500 \mathrm{~Hz}$ a $10 \mathrm{kHz}$ definida como faixa de comunicação digital na especificação, pelo que poderia afetar os testes finais para certificação. Uma diminuição na carga capacitiva na saída do regulador pode aumentar essa frequência.

Depois de verificar a regulação do circuito foi calculada a eficiência real para diferentes tensões de entrada (Vin) e diferentes resistências de carga (diferentes correntes de carga "lload"), dados apresentados na tabela 11. Como requisitos temos que a corrente de laço máxima é de $3,4 \mathrm{~mA}$, e que para uma tensão de alimentação Vin de 12V DC, a corrente máxima que pode consumir a eletrônica é de $5,263 \mathrm{~mA}$, e para uma tensão Vin de 15V DC a corrente máxima para a eletrônica é de $6,3 \mathrm{~mA}$. A eficiência diminui para valores de tensão maiores mas a corrente mantém um valor menor que o limite de $3,4 \mathrm{~mA}$.

O Consumo total esperado teoricamente do circuito é de $4.235 \mathrm{~mA}$ (ver seção 3.1.1) pelo que com uma tensão de $15 \mathrm{~V}$ os requisitos são atingidos. 
Tabela 10: Medições Circuito Regulador Comutado.

\begin{tabular}{|c|c|c|c|c|c|c|c|}
\hline \multicolumn{8}{|c|}{ Regulação com carga de $3 \mathrm{~mA}(1,655 \mathrm{k} \Omega)$} \\
\hline Vin [V] & $\overline{12}$ & $\overline{15}$ & 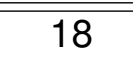 & $\overline{21}$ & $\overline{24}$ & 27 & 30 \\
\hline Vdd [V] & 5,014 & 5,014 & 5,015 & 5,014 & 5,014 & 5,0147 & 5,014 \\
\hline Vddpp [mV.] & 44 & 40,8 & 44 & 42 & 43 & 41,6 & 42 \\
\hline Frequência[Hz] & $7,8 \mathrm{~K}$ & $7,3 \mathrm{~K}$ & $7,1 \mathrm{~K}$ & $7,6 \mathrm{~K}$ & $7,6 \mathrm{~K}$ & $7,4 \mathrm{~K}$ & $7,5 \mathrm{~K}$ \\
\hline \multicolumn{8}{|c|}{ Regulação com carga de $5 \mathrm{~mA}(1,005 \mathrm{k} \Omega)$} \\
\hline Vin [V] & 12 & 15 & 18 & 21 & 24 & 27 & 30 \\
\hline Vdd [V] & 5,014 & 5,014 & 5,0137 & 5,0132 & 5,0136 & 5,0134 & 5,013 \\
\hline Vddpp[mV] & 44 & 42 & 43,2 & 42,4 & 41,6 & 41,6 & 40,8 \\
\hline Frequência[Hz] & $9 \mathrm{k}$ & $9,1 \mathrm{k}$ & $9,5 \mathrm{k}$ & $9,9 \mathrm{k}$ & $9,5 \mathrm{k}$ & $10 \mathrm{k}$ & $10 \mathrm{k}$ \\
\hline \multicolumn{8}{|c|}{ Regulação com carga de $6,9 \mathrm{~mA}(0,722 \mathrm{k} \Omega)$} \\
\hline Vin [V] & 12 & 15 & 18 & 21 & 24 & 27 & 30 \\
\hline Vdd [V] & 5,012 & 5,012 & 5,012 & 5,012 & 5,012 & 5,012 & 5,012 \\
\hline Vddpp[mV] & 40 & 40 & 41,6 & 41,6 & 40,8 & 41,6 & 40 \\
\hline Frequência[Hz] & $10,1 \mathrm{~K}$ & $9,5 \mathrm{~K}$ & $9,9 \mathrm{~K}$ & $9,9 \mathrm{~K}$ & $9,7 \mathrm{~K}$ & $9,7 \mathrm{~K}$ & $9,4 \mathrm{~K}$ \\
\hline
\end{tabular}

\subsubsection{Regulador Linear}

Ao circuito de teste foi adicionado o regulador linear, no qual a tensão de saída medida foi de 3,3V DC estáveis. Com os reguladores de tensão verificados, o passo seguinte para a verificação do circuito, foi a medição do consumo de corrente por parte dos demais componentes. Para tal fim, foram adicionados ao circuito cada um dos blocos para determinar o consumo total do sistema.

Tabela 11: Eficiência Circuito Regulador Comutado.

\begin{tabular}{|c|c|c|c|c|c|c|c|}
\hline Vin[V] & Res [Ohm] & 603 & 720 & 791 & 871 & 950 & 1555 \\
& Iload [mA] & 8,292 & 6,944 & 6,321 & 5,740 & 5,263 & 3,215 \\
\hline 12 & $\operatorname{lin}[\mathrm{mA}]$. & & & 4 & 3,562 & 3,29 & 1,917 \\
& Eficiência & & & 0,658 & 0,672 & 0,667 & 0,699 \\
\hline 15 & $\operatorname{lin}[\mathrm{mA}]$. & & & 3,256 & 2,927 & 2,7 & 1,599 \\
& Eficiência & & & 0,809 & 0,817 & 0,812 & 0,838 \\
\hline 24 & $\operatorname{lin}[\mathrm{mA}]$. & 2,99 & 2,6 & 2,28 & 2,06 & 1,917 & 1,162 \\
& Eficiência & 0,578 & 0,556 & 0,578 & 0,581 & 0,572 & 0,576 \\
\hline 36 & $\operatorname{lin}[\mathrm{mA}]$. & 2,35 & 2,06 & 1,8 & 1,6 & 1,5 & 0,99 \\
& Eficiência & 0,490 & 0,468 & 0,488 & 0,498 & 0,487 & 0,451 \\
\hline
\end{tabular}




\subsubsection{Corrente do Transmissor}

Mediu-se a corrente de laço. Para não interferir nas medições, o controle da corrente do laço foi desativado no circuito de testes.

O primeiro circuito adicionado foi o DSSP e os circuitos adicionais que ele precisa (para a fonte de corrente do sensor e do laço). A corrente medida foi de $2,015 \mathrm{~mA}$ DC para uma tensão de laço de 12V. Este resultado é interessante, pois sob as mesmas condições o circuito do transmissor 4-20mA MEMS consome 3,1mA, de forma que, o uso da fonte chaveada representa um ganho de $1.1 \mathrm{~mA}$. O seguinte passo foi adicionar todos os componentes alimentados com 3,3V ( PIC, modem Hart e regulador linear). O problema para o consumo desses componentes é que o PIC têm um consumo variável dependendo da configuração do modo de operação. Portanto inicialmente foi configurado em modo sleep que o menor consumo possível. Nesta configuração a corrente de entrada foi de 2,0185mA, e as tensão dos reguladores de $\mathrm{Vdd}=5,012 \mathrm{~V}$ e $\mathrm{Vdd} 3=3,327 \mathrm{~V}$.

Para determinar a configuração que deve ser usada no microcontrolador, foi medido o consumo total do sistema nas diferentes configurações. Os resultados destas medições são apresentados na tabela 12 para o circuito alimentado com 15V como são os requisitos, a frequência máxima do oscilador interno do PIC é de $8 \mathrm{MHz}$, equivalente a uma corrente de laço de $3,051 \mathrm{~mA}$. Esse resultado é muito importante, pois indica que com todo o circuito o limite de $3,2 \mathrm{~mA}$ de corrente de laço para a eletrônica foi respeitado.

\subsubsection{Modem HART $^{\circledR}$}

Com a verificação do cumprimento dos requisitos de consumo, o passo seguinte foi verificar os circuitos do modem HART ${ }^{\circledR}$ : o acoplamento ao laço de corrente e o filtro de entrada. Inicialmente foi retirado do circuito o capacitor de 
Tabela 12: Consumo vs. Frequência PIC.

\begin{tabular}{|l|c|c|c|c|c|c|c|}
\hline $\begin{array}{l}\text { Frequência } \\
{[\mathrm{MHz}]}\end{array}$ & 0,250 & 0,5 & 1 & 2 & 4 & 8 & 16 \\
\hline $\begin{array}{l}\text { Corrente [mA] / } \\
12 \mathrm{~V}\end{array}$ & 2,276 & 2,316 & 2,404 & 2,568 & 2,908 & 3,731 & 5,108 \\
\hline $\begin{array}{l}\text { Corrente [mA] / } \\
15 \mathrm{~V}\end{array}$ & 1,896 & 1,93 & 2 & 2,133 & 2,405 & 3,051 & 4,086 \\
\hline
\end{tabular}

acoplamento (Cm5) e usado um gerador de sinais para emular um sinal senoidal gerado pelo modem. Verificando a resposta dos filtros foram usadas diferentes frequências $(286 \mathrm{~Hz}$ até $40 \mathrm{KHz})$.

Condições dos testes: o padrão HART ${ }^{\circledR}$ precisa de uma resistência no laço para converter o sinal de corrente para tensão, pois o mestre HART ${ }^{\circledR}$ e o filtro de entrada detetam o sinal em tensão. O valor deste resistor é tipicamente $250 \Omega$, mas o valor usado para o teste foi de $215,7 \Omega$. Para o circuito poder modular a corrente de laço é necessário que a fonte de controle de corrente esteja funcionando, por tanto, um nível de corrente DC no laço foi fixado em $12 \mathrm{~mA}$.

Resultados: Na tabela 13 são apresentados os valores de tensão medidos na resistência de laço. Como pode-se ver, a resposta em frequência é boa, pois não há atenuação até $20 \mathrm{KHz}$, o que indica que o sinal HART ${ }^{\circledR}$ de $1200 \mathrm{~Hz}$ e de $2200 \mathrm{~Hz}$ não apresentará atenuação na modulação.

Durante a modulação também foi medido o sinal no filtro de entrada do modem

Tabela 13: Resposta em Frequência sinal $\operatorname{HART}^{\circledR}$ Modulado.

\begin{tabular}{|l|c|c|c|c|c|c|c|c|c|c|c|}
\hline $\mathrm{F}[\mathrm{KHz}]$ & 0,294 & 0,54 & 0,90 & 2,2 & 4,8 & 10 & 14,5 & 19,6 & 25 & 30,8 & 39,37 \\
\hline $\mathrm{V}[\mathrm{mVpp}]$ & 420 & 420 & 420 & 432 & 432 & 472 & 472 & 356 & 300 & 236 & 208 \\
\hline
\end{tabular}


HART $^{\circledR}($ sinal de entrada no demodulador), os resultados dessas medições são apresentados na tabela 14, claramente, a banda de passagem do filtro está dentro dos $500 \mathrm{~Hz}$ e $10 \mathrm{KHz}$, como é esperado, com um ganho perto de um na banda de passagem, em relação ao sinal de tensão medido no laço.

Finalmente foi ajustada a amplitude do gerador de sinais em $500 \mathrm{mVpp}$ que é a amplitude esperada do modulador. Com essa configuração o sinal medido no laço foi de $240 \mathrm{mVpp}$ a $1213 \mathrm{~Hz}$ e $244 \mathrm{mVpp}$ a $2192 \mathrm{~Hz}$. Supondo um ganho de um do filtro de entrada temos $240 \mathrm{mVpp}$ na entrada do modem, tensão superior à precisada pelo circuito (120mVpp) para uma correta demodulação. Pelo que são cumpridos todos es requisitos para os filtros do modem HART ${ }^{\circledR}$

Tabela 14: Resposta em Frequência Filtro de entrada HART $^{\circledR}$.

\begin{tabular}{|l|c|c|c|c|c|c|c|c|c|c|c|}
\hline $\mathrm{F}[\mathrm{KHz}]$ & 0,29 & 0,52 & 0,92 & 1,14 & 2,1 & 9,4 & 13,9 & 19,23 & 25,9 & 32,1 & 41 \\
\hline $\mathrm{V}[\mathrm{mVpp}]$ & 244 & 336 & 424 & 436 & 452 & 420 & 284 & 202 & 120 & 82 & 58 \\
\hline
\end{tabular}

\subsubsection{Corrente de Laço}

Uma prova a mais foi feita no laço de corrente para verificar que o sinal analógico 4-20mA. O uso da resistência de laço faz que a tensão de alimentação real do circuito seja diferente da tensão da fonte que alimenta o laço, sendo o pior cenário quando a saída analógica está em 20mA, por que na resistência de laço a tensão fixada é de quase $5 \mathrm{~V}$ e somando os $0,7 \mathrm{~V}$ do diodo de proteção da entrada do transmissor temos uma tensão no regulador de menos $5,7 \mathrm{~V}$ da tensão da fonte usada no laço. Na figura 31 pode-se observar que com uma alimentação de $12 \mathrm{~V}$ o circuito satura antes dos $20 \mathrm{~mA}$, mas em $15 \mathrm{~V}$ opera sem saturação na faixa de 4-20mA atingindo os requisitos da alimentação. 


\subsubsection{Circuito Modem HART DS8500}

Para controlar o sinal modulado do DS8500 são necessários dois sinais RTS (ready to send) e DIN (data in). RTS estabelece a portadora e DIN determina a frequência do sinal, então no PIC foi programada uma rotina simples para comutar o sinal RTS a cada 5 segundos, com valores de DIN fixos. A primeira medição visou determinar o efeito da modulação no sinal DC, então com uma corrente DC fixa em 3,9957mA foi modulado um "zero" lógico e observou-se um pico transitório máximo de $4,015 \mathrm{~mA}$ (diferença de $19,3 \mu \mathrm{A}$ ou $0,12 \% \mathrm{FS}$ ), no caso

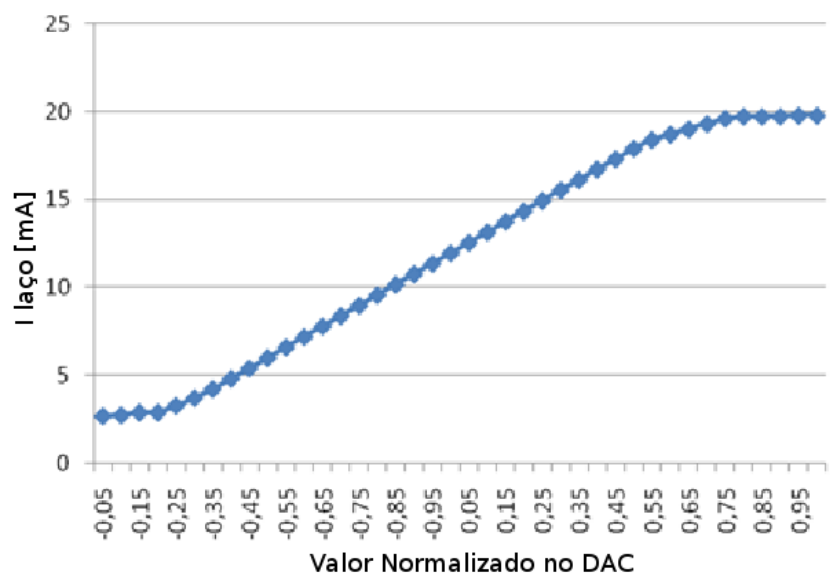

(a) Tensão 12V

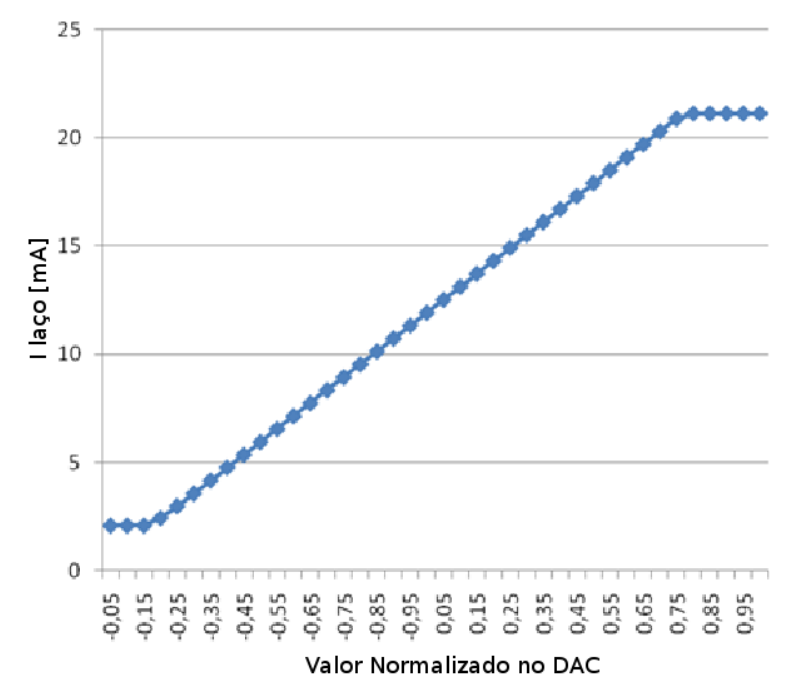

(b) Tensão 15V

Figura 31: Corrente de laço vs. saída normalizada do MAX1464. 
do "um" lógico o transitório foi de $3,9827 \mathrm{~mA}$ (diferença de $-13 \mu \mathrm{A}$ ou $0,08 \% \mathrm{FS}$ ), mas o sinal rapidamente retorna ao valor inicial. Usando um modem HART ${ }^{\circledR}$ Bell 202/USB da Microflex é possível o intercâmbio de pacotes entre um computador e um dispositivo HART $^{\circledR}$, usando esse equipamento, foi testada a detecção por parte do mestre do sinal HART ${ }^{\circledR}$.

Usando o mesmo programa no PIC, e o software Comm Operator Pal no micro, verificou-se que o sinal CD (carrier detect) do modem Microflex mudara de estado a cada 5 segundo, como efetivamente aconteceu. Em continuação se mostram as mensagens do terminal "Status:(11:59:35) Carrier Detect (CD) signal changed state. $C D$ State = True; Status:(11:59:40) Carrier Detect $(C D)$ signal changed state. $C D$ State $=$ False". A mesma prova foi feita no sentido contrário, para verificar que o DS8500 ativa o sinal CD quando o mestre HART ${ }^{\circledR}$ envias um dado, para o que foi modificado o programa do PIC para comutar o sinal T10 (Pino A0) com a detecção da portadora. O sinal foi detectado, mas apresentou oscilações, pelo que foi modificado o programa para somente comutar se receber o caractere "s". Com esse novo programa o comportamento foi o esperado.

\subsubsection{Deslocadores de tensão}

O último teste feito no hardware do circuito foi a verificação da comunicação SPI entre o PIC e o DSSP, validando os circuitos deslocadores de nível. Para isso, um programa que modifica os registros do MAX1464 foi usado no PIC, de forma que a corrente de laço é controlada pelo PIC no DSSP. A prova teve êxito, pois observaram-se as mudanças automáticas na corrente de laço esperadas (4, 12 e $20 \mathrm{~mA})$. 


\subsection{Testes protocolo de comunicação HART ${ }^{\circledR}$}

Para testar o código desenvolvido no PIC, foi usado o software HART server basic edition, fornecido pela HFC, que é um servidor object linking and embedding for process control (OPC) para equipamentos $\mathrm{HART}^{\circledR}$. Isto é, um servidor que implementa o protocolo $\mathrm{HART}^{\circledR}$ e ao mesmo tempo permite a leitura de variáveis usando o protocolo OPC.

A montagem para as provas é apresentada na figura 32. O HART server basic edition usa uma porta tipo COM para se comunicar com os equipamentos HART $^{\circledR}$, portanto, um modem USBHART foi usado para esse fim. Com o software configurado e o modem em funcionamento foram testados os diferentes comandos do padrão usando um protótipo $100 \%$ funcional do transmissor.

Devido à necessidade de ter uma combinação válida de fabricante e código de equipamento, para o correto funcionamento do servidor, o nosso protótipo usou durante os testes códigos correspondentes a um transmissor comercial. Tal prática foi utilizada devido a que para obter um código de fabricante é necessário ser membro da HCF e a MEMS atualmente não é membro. Na figura 33, pode-se ver como os parâmetros de identificação do equipamento são corretamente lidos pelo servidor $($ Quality $=$ Good $)$, indicando uma boa comunicação HART ${ }^{\circledR}$ entre eles, pelo menos nos comandos usados para a leitura dos parâmetros do transmissor. Na figura 34 é apresentado o estado da variável principal do equipamento, em nosso caso a pressão em bar. Também é possível observar o valor da corrente de laço e a porcentagem de fundo de escala. Indicando que o transmissor responde aos comando de leitura das variáveis dinâmicas. Com os dois testes anteriores, pode-se dizer que o transmissor cumpre com o protocolo $\mathrm{HART}^{\circledR}$, pelo menos nos comandos universais.

O servidor usado, permite verificar alguns comandos de prática comum, sendo nosso interesse principal os comandos que permitem a mundança de unidade na 


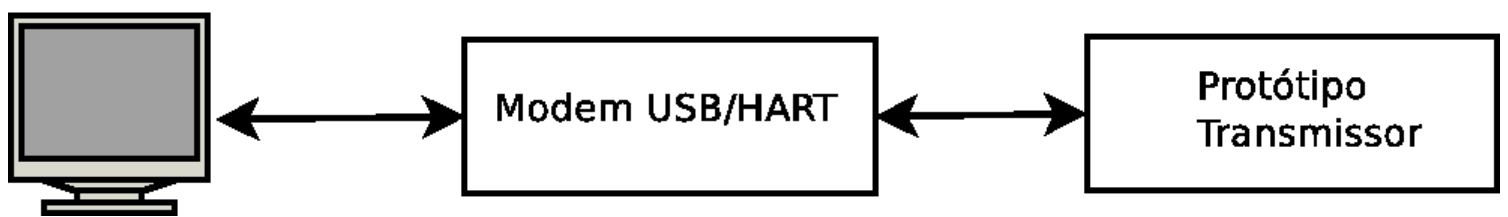

Figura 32: Esquema para os testes do protótipo .

saída digital e da excursão da saída analógica. Na figura 35 são apresentadas as telas antes e depois da mudança desses parâmetros. O fato dos parâmetros aparecerem na tela indica que foram modificados pelo comando de escrita e lidos depois como respostas aos comandos de leitura.

\subsection{Caracterização dos Protótipos}

Com as mudanças necessárias no procedimento de C\&C usado nos transmissores 4-20mA da MEMS (ver 3.2), foram calibrados e compensados cinco protótipos do transmissor HART ${ }^{\circledR}$.

Com os protótipos C\&C e com comunicação digital HART ${ }^{\circledR}$ operando satisfato-

\begin{tabular}{|c|c|c|c|}
\hline Device Data & & & $x$ \\
\hline \multicolumn{3}{|l|}{$\left[\begin{array}{l}\text { Device } \\
\text { Tag: MENSHART }\end{array}\right.$} & 맴 \\
\hline Item & Data & Quality & Time \\
\hline (I) CommFailure & 0 & Good & $10 / 18 / 201013: 42$ \\
\hline (1) ManufacturerCode & 62 & Good & $10 / 18 / 2010 \quad 13: 42$ \\
\hline (I) ManulacturerName & Smar & Good & $10 / 18 / 2010 \quad 13: 42$ \\
\hline (I) DeviceCode & 1 & Good & $10 / 18 / 2010 \quad 13: 42$ \\
\hline (1) DeviceName & LD301 & Good & $10 / 18 / 2010 \quad 13: 42$ \\
\hline (I) DeviceRevision & 1 & Good & $10 / 18 / 2010 \quad 13: 42$ \\
\hline (I) Device'Variable & 3 & Good & $10 / 18 / 2010 \quad 13: 42$ \\
\hline$\overline{\mathbf{1}}$ ConfigChangeCount & 1 & Good & $10 / 18 / 201013: 42$ \\
\hline (I) PVsRange & 50 & Good & $10 / 18 / 2010 \quad 13: 42$ \\
\hline (1) LoopCinrent & 12 & Good & $10 / 18 / 2010 \quad 13: 42-1$ \\
\hline \multirow[t]{2}{*}{1} & & & 1. \\
\hline & & Help & \\
\hline
\end{tabular}

Figura 33: Testes comandos universais (Descrição do equipamento) . 
riamente, foi realizada uma caracterização da saída analógica e digital de cada transmissor. Durante os testes realizados para dar inicio à calibração, o protótipo \#1 apresentou um problema com o MAX1464, que impedia qualquer comunicação ou medição, pelo que foram caracterizados os quatro transmissores restantes. $O$ procedimento de caracterização foi realizado usando dois ciclos de temperatura com dez pontos cada $\left(0^{\circ} \mathrm{C}, 12,5^{\circ} \mathrm{C}, 25^{\circ} \mathrm{C}, 37,5^{\circ} \mathrm{C}, 50^{\circ} \mathrm{C}, 50^{\circ} \mathrm{C}, 37,5^{\circ} \mathrm{C}, 25^{\circ} \mathrm{C}\right.$, $12,5^{\circ} \mathrm{Ce} 0^{\circ} \mathrm{C}$ ). Em cada um desse pontos de temperatura foram realizados três ciclos de pressão, com 11 pontos cada ( 0 a 100\% do span com passos de 10\%), para cada um desses pontos foram medidas as saídas analógica e digital de cada transmissor. O tempo de espera entre cada temperatura foi de no mínimo duas horas. Na figura 36 pode se observar os resultados para a saída analógica do protótipo \#4 em $50^{\circ} \mathrm{C}$ do primeiro ciclo de temperatura. Depois de processados

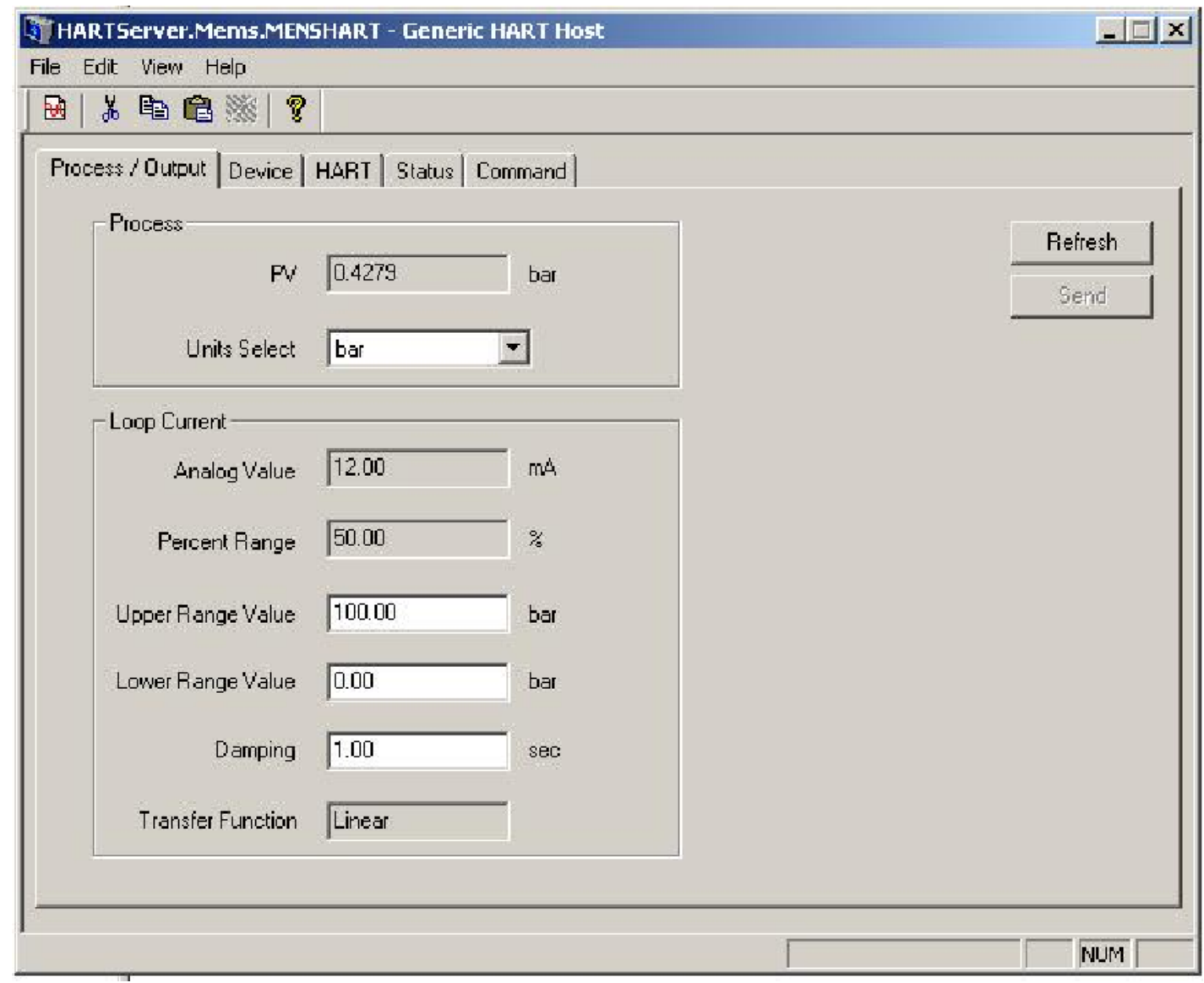

Figura 34: Testes comandos universais (Variáveis dinâmicas). 
todos os dados gerados durante a caracterização, foi possível calcular o erro total na faixa de operação (TEB) que representa os limites dentro dos quais se encontra o erro do transmissor. Os resultados são resumidos na tabela 15.

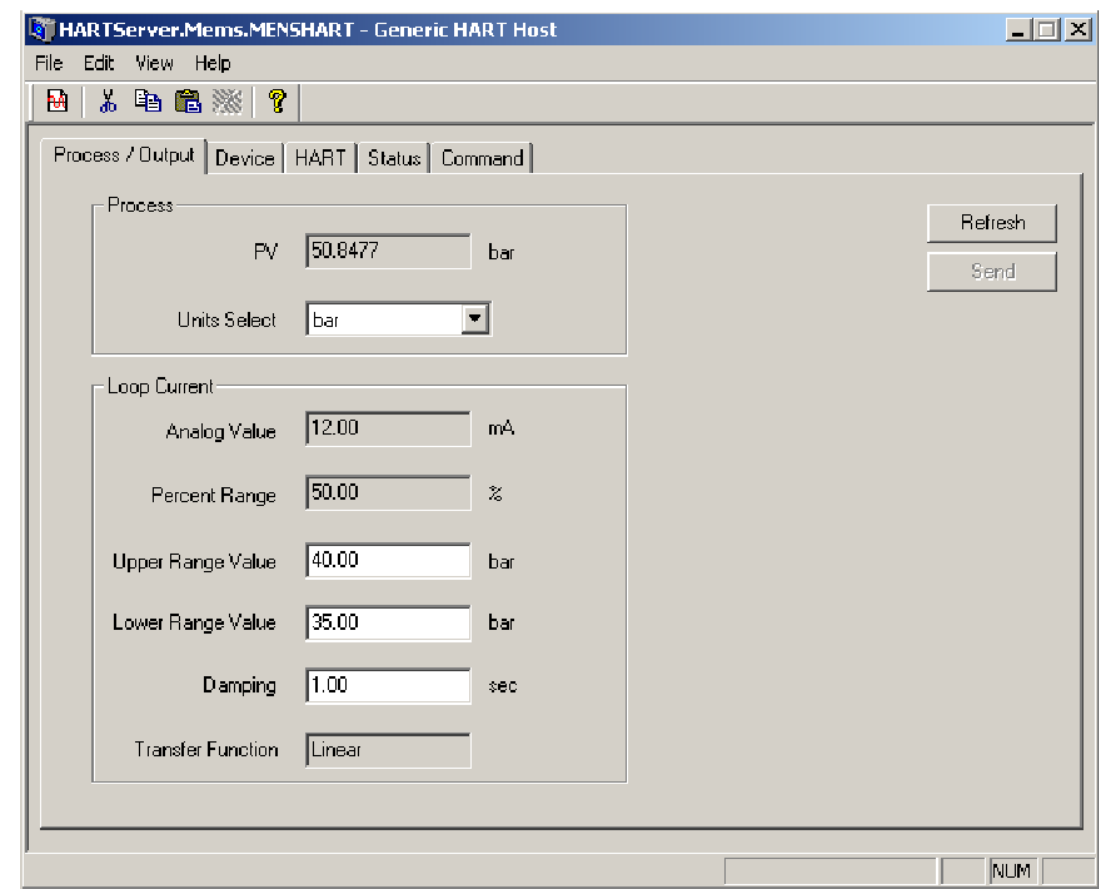

(a) Antes

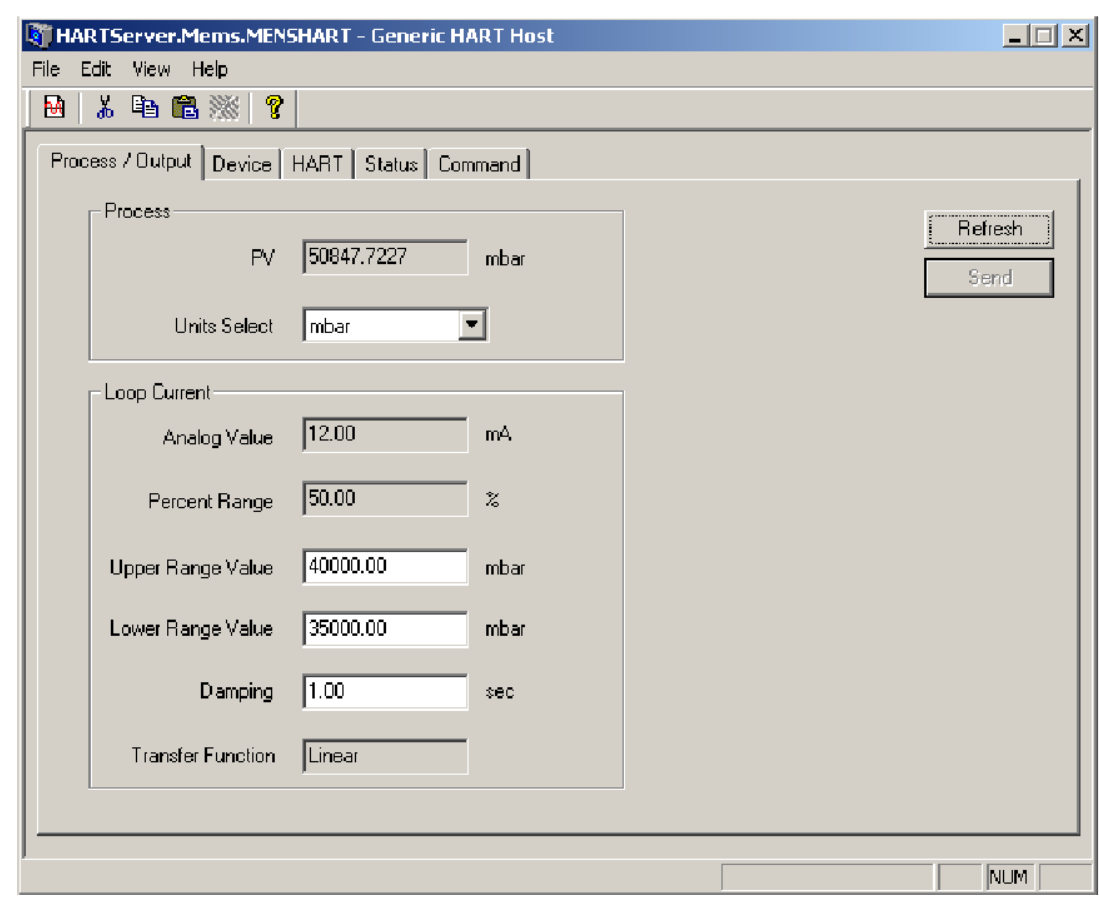

(b) Depois

Figura 35: Testes comandos pratica comum. 


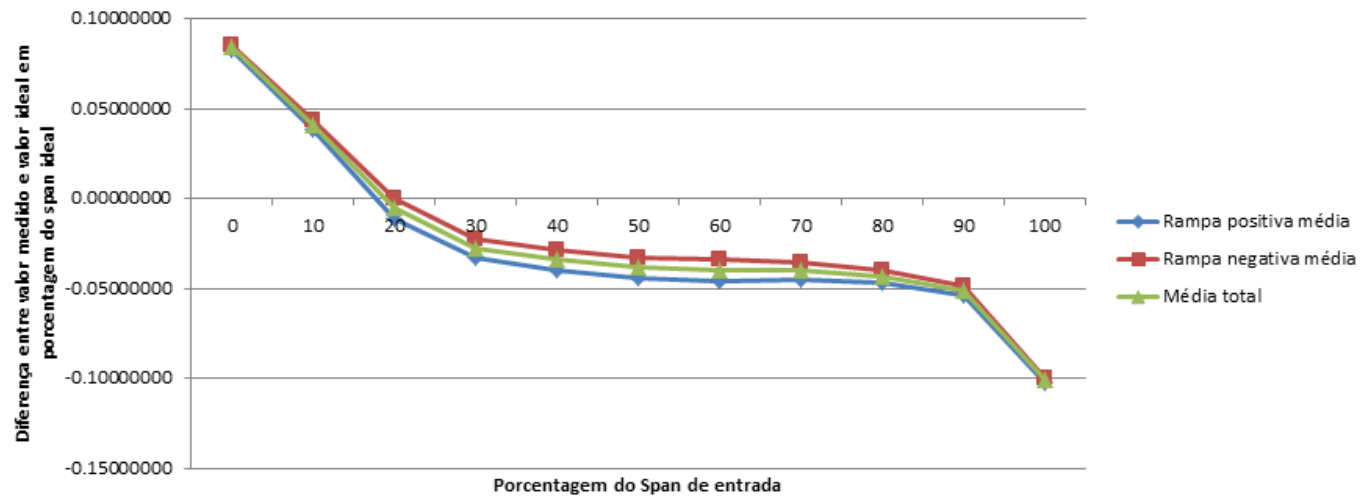

Figura 36: Erro da saída analógica do protótipo \#4 em a 50 Cdo primeiro ciclo de temperatura.

Tabela 15: Resultados da Calibração dos protótipos do transmissor $\mathrm{HART}^{\circledR}$.

\begin{tabular}{|l|c|c|c|c|c|}
\hline $\begin{array}{l}\text { Saída Pro- } \\
\text { tótipo }\end{array}$ & $\begin{array}{l}\text { Não Li- } \\
\text { nearidade } \\
{[\% F S]}\end{array}$ & $\begin{array}{l}\text { Histeresis } \\
{[\% F S]}\end{array}$ & $\begin{array}{l}\text { Repetividade } \\
{[\% F S]}\end{array}$ & \multicolumn{2}{|l|}{ TEB [\%FS] } \\
\hline $\begin{array}{l}\text { \#2 Analó- } \\
\text { gico }\end{array}$ & 0,0473 & 0,0360 & 0,0239 & $+0,1916$ & $-0,0698$ \\
\hline \#2 Digital & 0,0204 & 0,0357 & 0,0287 & $+0,1482$ & $-0,0679$ \\
\hline $\begin{array}{l}\text { \#3 Analó- } \\
\text { gico }\end{array}$ & 0,0514 & 0,0326 & 0,0246 & $+0,1850$ & $-0,0757$ \\
\hline \#3 Digital & 0,0206 & 0,0345 & 0,0268 & $+0,1495$ & $-0,0495$ \\
\hline $\begin{array}{l}\text { \#4 Analó- } \\
\text { gico }\end{array}$ & 0,0562 & 0,0369 & 0,0284 & $+0,2149$ & $-0,0771$ \\
\hline \#4 Digital & 0,0205 & 0,0356 & 0,0342 & $+0,1443$ & $-0,0948$ \\
\hline $\begin{array}{l}\text { \#5 Analó- } \\
\text { gico }\end{array}$ & 0,1062 & 0,0510 & 0,0478 & $+0,3038$ & $-0,1471$ \\
\hline \#5 Digital & 0,0222 & 0,0520 & 0,0553 & $+0,2424$ & $-0,0382$ \\
\hline
\end{tabular}

Dos resultado pode ser observado que o erro da saída digital sempre é menor do que o nível de erro na saída analógica, para o caso do protótipo \#2 a diferença é de $0,0453 \% \mathrm{FS}$, para o \#3 de 0,0617\%FS, 0,0530\%FS para o \#4 e 0,1703 \%FS para protótipo \#5. Essa diferença apresenta a grande vantagem do uso de um protocolo de comunicação digital para a transmissão da informação da medi- 
ção, pois os erros da conversão digital analógica, são eliminados. Os resultados da tabela 15, também apresentam um valor de TEB maior do que o esperado para o projeto $(0,2 \% \mathrm{FS})$. Uma análise detalhada dos dados permite identificar um comportamento que justifica esses resultados: na figura 37 podem ser observadas as medições da saída digital do protótipo \#2 para cada passo pelo ponto de temperatura $0^{\circ} \mathrm{C}$. Os dados apresentam que o que realmente acontece com o transmissor é a aparição de um offset positivo com o tempo o que aumenta o erro total. As causas desse comportamento podem ser de diferentes fontes, mudanças no comportamento do sensor de pressão, mudanças no sensor de temperatura, mudanças na fonte de corrente ou mudanças nos circuitos internos do MAX1464. Essas mudanças podem ser devidas a estresse mecânico dos componentes e nas soldas devido aos ciclos de temperatura ou, à operação continuada dos transmissores. Um fato importante a ressaltar é que identificando e compensado essa fonte de erro poderíamos ter um nível de erro menor do que o 0,1 \%FS na saída digital (ver figuura 38), pois o algoritmo usado compensa facilmente um nível de offset, desde que esse comportamento esteja presente durante a tomada de dados usada para a C\&C. Pelo fato de ser um comportamento que depende do tempo, uma técnica simples amplamente usada na industria é realizar um processo de envelhecimento dos componentes antes de realizar o procedimento de compensação e calibração, mas o tempo necessário para realizar esse processo aumenta significativamente os custos do produto.

\subsection{Conclusões dos testes dos protótipos}

Algumas modificações foram feitas aos valores usados no circuito depois das provas: CF mudando para 27pF, CF1 = CF2 e tensão de 40V (capacitores de entrada da fonte chaveada), CF3 a $16 \mu \mathrm{F}$ e tensão de 40V, CM2 e CM3 com tensão

de 40V (capacitores do filtro de entrada do modem $\mathrm{HART}^{\circledR}$ ), $\mathrm{CX} 1$ e $\mathrm{CX} 2=27 \mathrm{pF}$ 
e finalmente RF3 igual a 3,6M $\Omega$. Tais modificações, foram feitas para facilitar a compra dos componentes e elevar a tensão de ruptura dos capacitores para $30 \mathrm{~V}$, aumentando a margem de segurança.

Finalmente foi verificado experimentalmente que todo o circuito cumpre com os

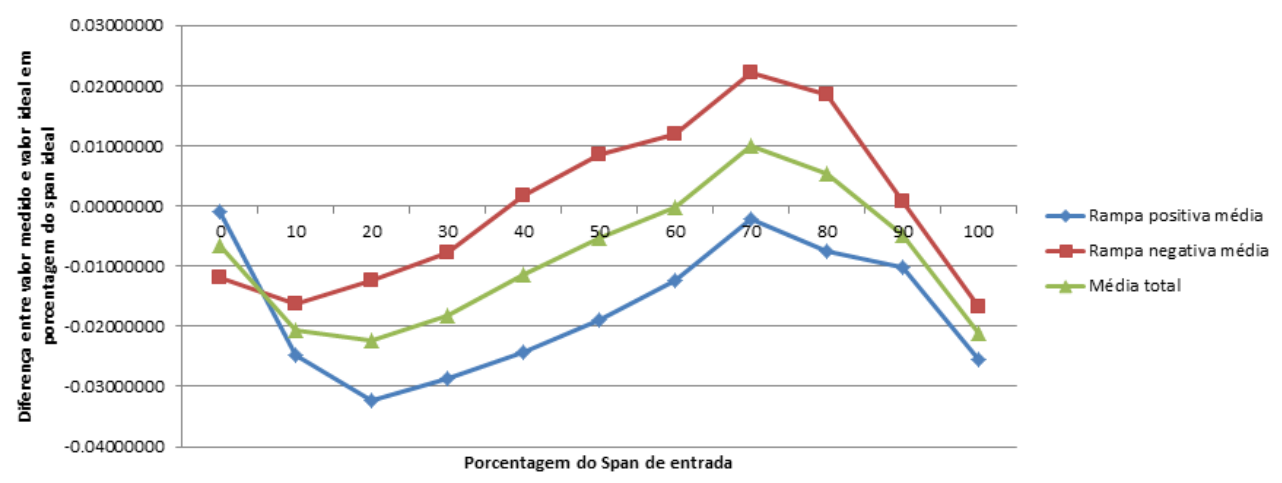

(a) 1

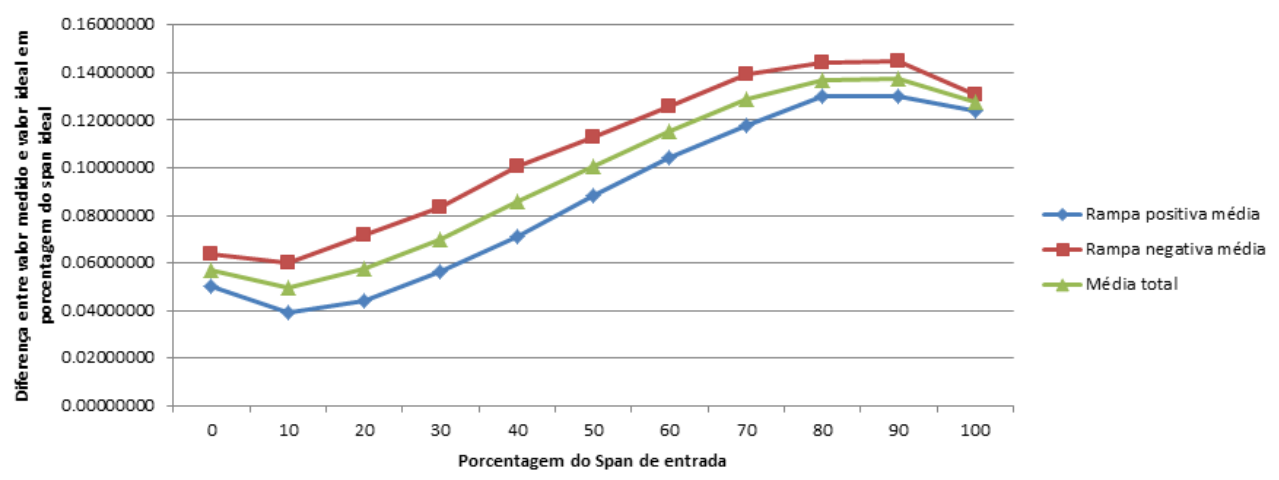

(b) 2

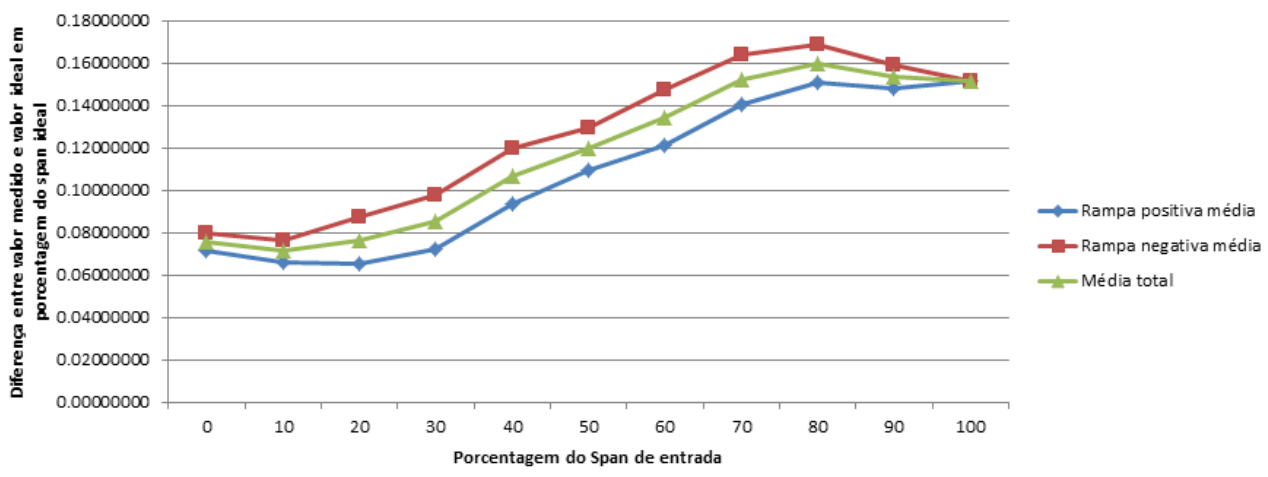

(c) 3

Figura 37: Mudanças do erro com o tempo para o protótipo \#2. 


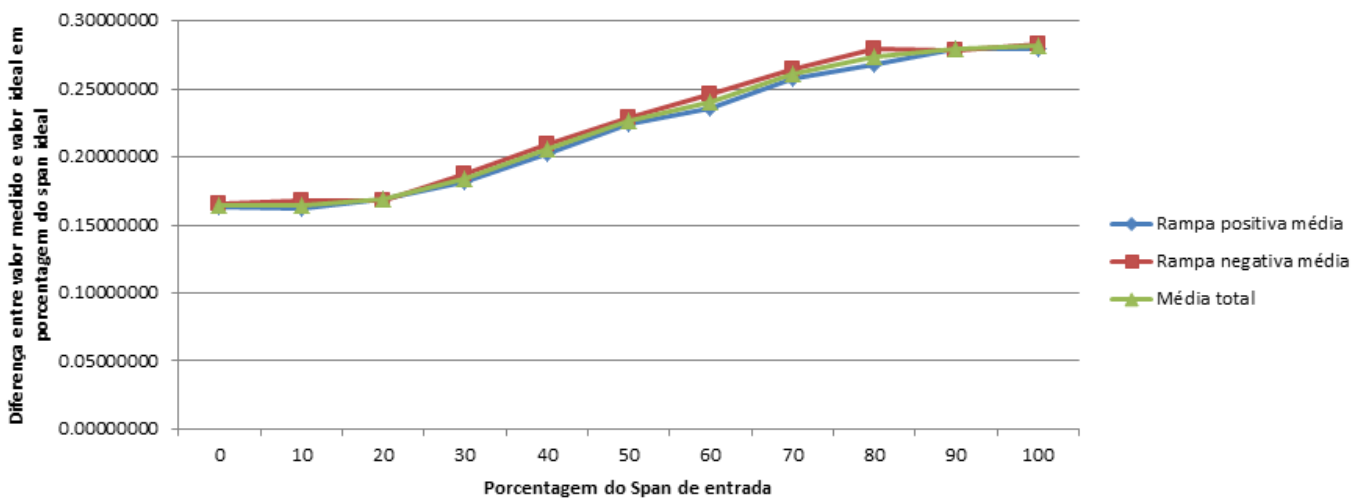

Figura 38: Erro da saída digital do protótipo \#5 em $0^{\circ} \mathrm{C}$ do último ciclo de temperatura.

requisitos do projeto no que tem a ver com o hardware, mas o nível de TEB está acima do nível esperado nos protótipos \#2, \#4 e \#5. Também, transmissor falhou logo depois da compensação e calibração, o que indica problemas no processo de montagem dos protótipos. Espera-se que com um processo de produção controlado e usando uma técnica de envelhecimento dos transmissores o nível de erro diminua para $0,1 \% \mathrm{FS}$ usando os mesmos algoritmos e projeto de circuito. Nas figuras 39 e 40 são apresentadas as superfícies de erro geradas durante a caracterização para as saídas digital e analógica. Nelas se apresenta a média do erro para cada ponto de temperatura. Por ser uma média, esses gráficos escondem a mudança com o tempo, mas permitem observar que para todos os casos o menor erro se encontra para uma temperatura de $25^{\circ} \mathrm{C}$ e nos pontos próximos ao $50 \% \mathrm{FS}$ do transmissor, pelo que uma alternativa para diminuir o erro total do transmissor é limitar seus pontos extremos de operação. 


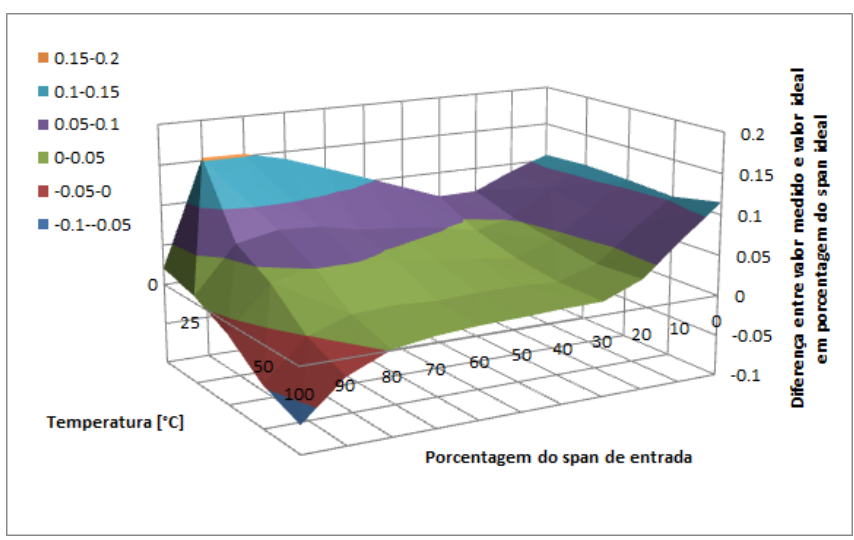

(a) \#2

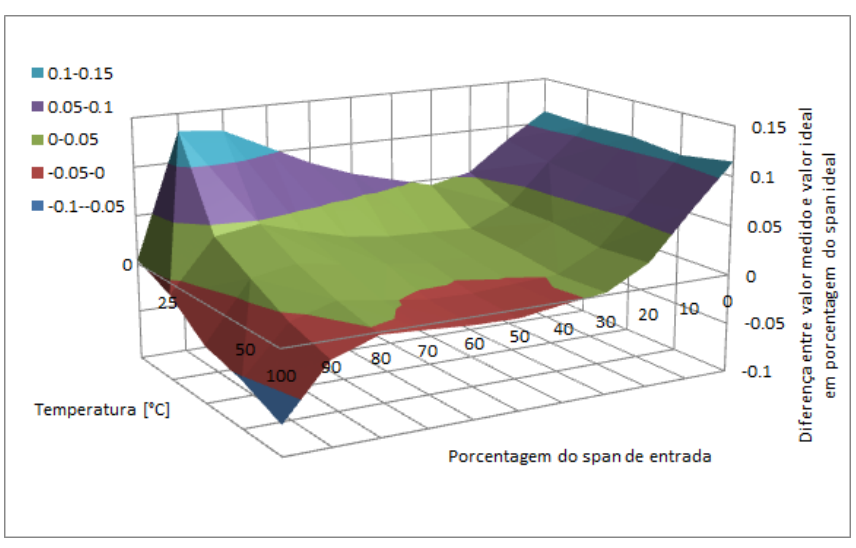

(b) \#3

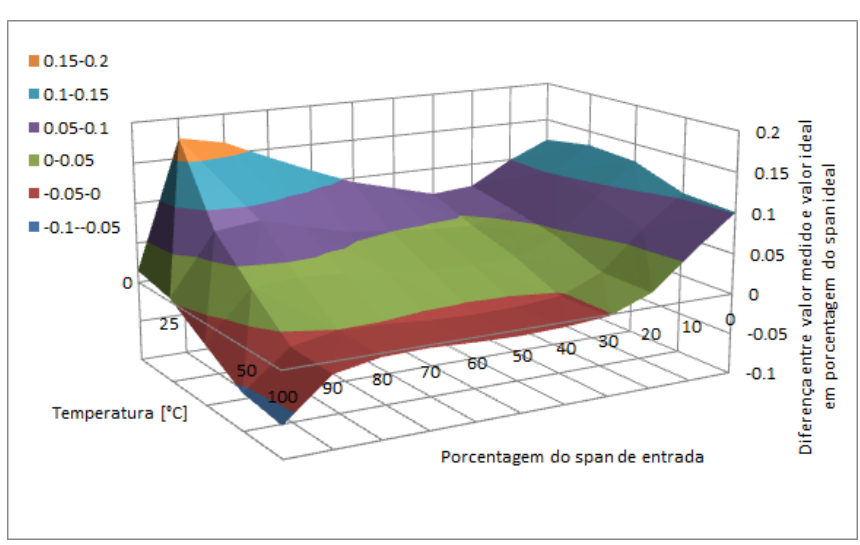

(c) \#4

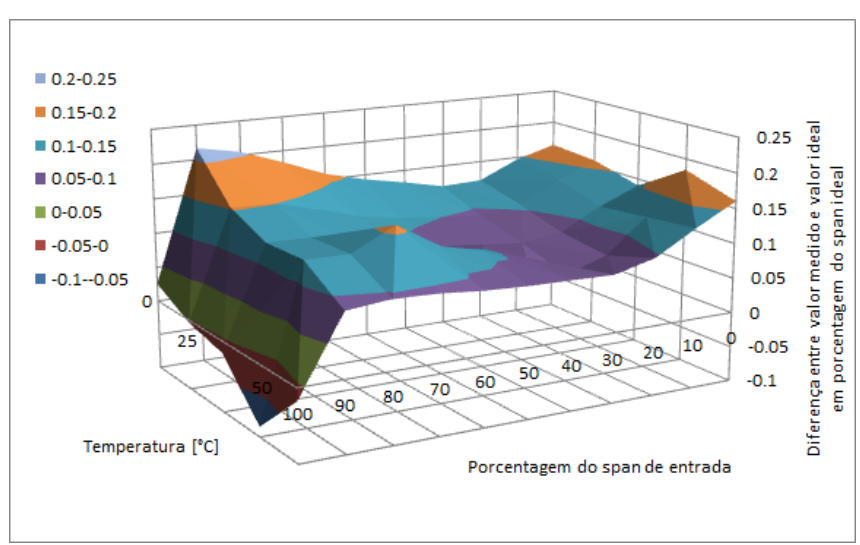

(d) \#5

Figura 39: Superfícies do erro para a saída analógica de todos os protótipos. 


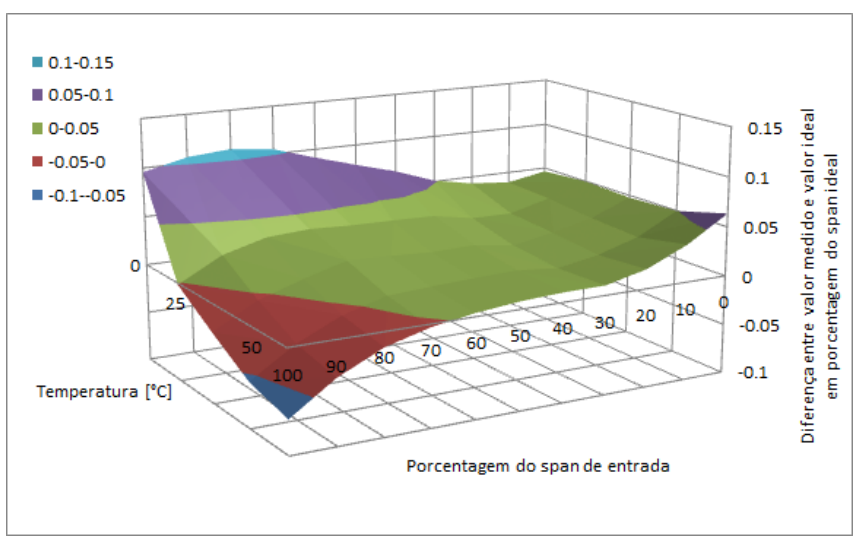

(a) \#2

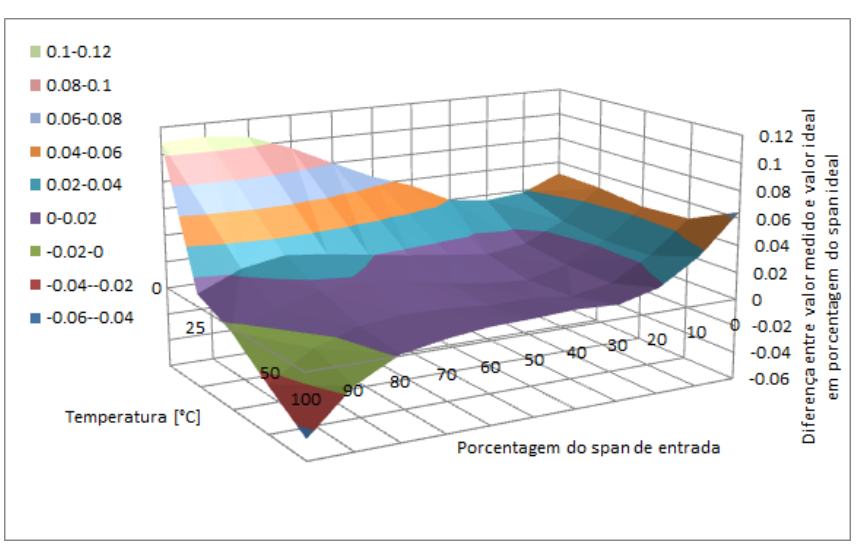

(b) \#3

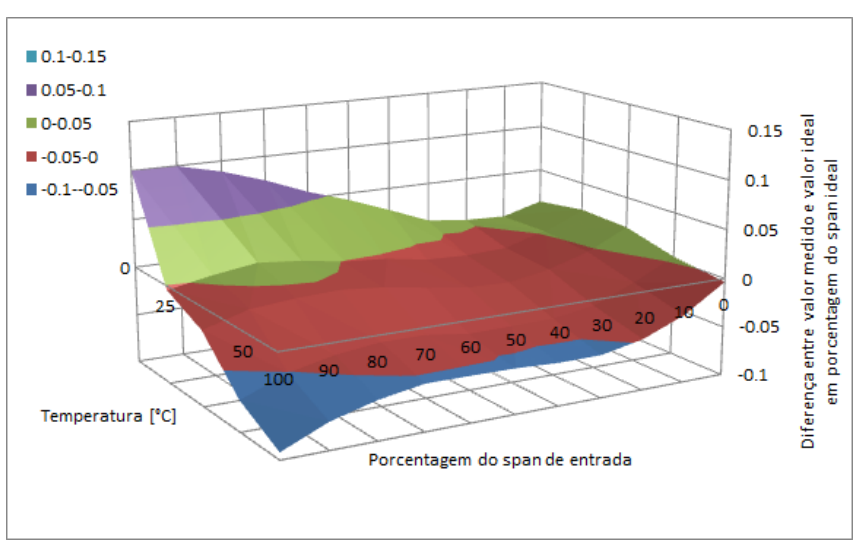

(c) \#4

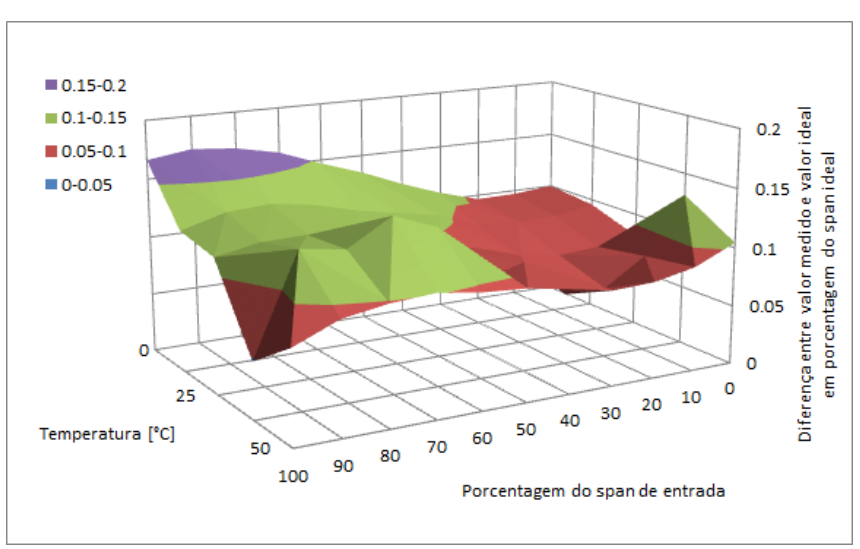

(d) \#5

Figura 40: Superfícies do erro para a saída digital de todos os protótipos. 


\section{CONCLUSÕES}

O uso do processamento digital permite compensar e calibrar o sinal de saída dos sensores de pressão piezoresistivos com um erro inferior ao $0.1 \% F S$ desde que sejam incluídos os efeitos do envelhecimento e operação continuada no processo de compensação e calibração. Esse fato é essencial para um transmissor de alta exatidão, mas o uso de processadores digitais incrementa o consumo de corrente do circuito. E o protocolo HART com camada física Bell 202 diminui a corrente máxima disponível para 3,4 $\mathrm{mA}$, dificultando o aproveitamento dos projetos de transmissores 4-20 mA para desenvolver transmissores HART.

A arquitetura proposta neste trabalho demonstrou ser funcional, permitindo manter todas as características do transmissor 4-20 mA e, ao mesmo tempo, adicionar todas as funções necessárias a um transmissor HART. Esta arquitetura não está limitada ao tipo de variável física medida, e pode ser utilizada em qualquer transmissor que use processamento digital do sinal para a compensação e calibração. A metodologia usada para a caracterização dos transmissores permitiu expôr erros que dependem do uso contínuo do equipamento, e os dados coletados permitiram identificar o efeito desses erros nas saídas do transmissor. é importante dizer que a metodologia de medição influencia nos resultados obtidos, pois um procedimento que não mantivesse os transmissores alimentados ou fosse mais rápido deveria gerar um resultado diferente, pois a caracterização dos transmissores levou um mes aproximadamente. Esse teste demostra também que o circuito e o software desenvolvidos são estáveis o suficiente para operar de forma ininterrupta 
por mais de um mes em situações ambientais extremas sem apresentar falhas.

Finalmente pode se dizer que o protótipo projetado atinge os requisitos especificados no inicio do projeto, salvo pelo TEB que foi maior que o esperado, pois durante a fase de definição do projeto não foram considerados os erros de deriva com o tempo. Eliminadas essas fontes de erro, os requisitos foram atingidos. Recomendações foram feitas para atingir o valor de erro usando os mesmos circuitos e algoritmos, mudando unicamente o procedimento de C\&C. 


\section{REFERÊNCIAS}

ABINEE. Panorama Econômico e Desempenho Setorial 2010. Associação Brasileira da Indústria Elétrica e Eletrônica, 2010. Panorama Econômico e Desempenho Setorial 2010. Disponível em: <http://www.abinee.org.br/informac/ arquivos/pan2011.pdf>.

AKBAR, M.; SHANBLATT, M. A. Temperature compensation of piezoresistive pressure sensors. Sensors and Actuators A: Physical, v. 33, n. 3, p. $155-162$, 1992. ISSN 0924-4247. Disponível em: <http://www.sciencedirect.com/science/ article/pii/092442479280161U>.

BELTRáN, J. R.; PRIETO, D. P.; R., C. E. Compensación térmica de la sensibilidad en sensores de presión piezorresistivos. Iberchip, 2002. Compensación térmica de la sensibilidad en sensores de presión piezorresistivos. Disponível em: <http://www.iberchip.net/VIII/docs/sesj4-2_3/beltran01.pdf>.

BOND, A. WirelessHART Is First Wireless Field Device Network Standard to Win International Status. controlglobal.com, 2010. Disponível em: <http://www.controlglobal.com/industrynews/2010/121.html>.

CASSIOLATO, C. WirelessHART. SMAR., 2011. Artigos Técnicos SMAR. Disponível em: <http://www.smar.com/newsletter/marketing/index98.html>.

CHAN, H. K. A low-cost integrated approach for balancing an array of piezoresistive sensors for mass production applications. IEEE Transactions on Industrial Electronics IEEE, v. 55, n. 2, p. 937-940, fev. 2008. ISSN 0278-0046.

CHUAN, Y.; CHEN, L. The intelligent pressure sensor system based on dsp. In: Advanced Computer Theory and Engineering (ICACTE), 2010 3rd International Conference on. [S.I.: s.n.], 2010. v. 5, p. V5-168-V5-171. ISSN 2154-7491.

DEWEY, A. R. Using HART ${ }^{\circledR}$ An Foundation Fieldbus Together In An Integrated Enviroment. [S.I.]: The Instrumentation, Systems and Automation Society, 2004. USING HART $R$ AND FOUNDATIONTM FIELDBUS TOGETHER IN AN INTEGRATED ENVIRONMENT.

EATONY, W. P.; SMITH, J. H. Micromachined pressure sensors: review and recent developments. Smart Materials and Structures, v. 6, n. 5, p. 530-539, out. 1997. ISSN 0964-1726.

ELSHAFEI, M. Industrial Instrumentation and Measurements. King Fahd University of Petroleum and Minerals, 2000. 1st chapter of my book. Disponível em: <http://www.ccse.kfupm.edu.sa/ elshafei/ch1v3.pdf>. 
FATHI, Y. Creating a Ratiometric Current Excitation in Sensors Using the MAX1464 Signal Conditioner. Maxim, 2010. APPLICATION NOTE 3364. Disponível em: <http://www.maximintegrated.com/en/app-notes/index.mvp/id/3364>.

FOUNDATION, F. Marketplace. Fieldbus Foundation, 2010. Disponível em: $<$ http://www.fieldbus.org/index.php?option=com_content\&task=view\&id=148\& Itemid=312>.

FOUNDATION, H. C. FSK Physical Layer Specification. [S.I.]: Hart Communication Foundation, 1999. HFC_SPEC54, Revision 8.1.

Data Link Layer Specification. [S.I.]: Hart Communication Foundation, 2001. HFC_SPEC81, Revision 8.0.

. Universal Command Specification. [S.I.]: Hart Communication Foundation, 2001. HFC_SPEC127, Revision 6.0.

HART Field communication Protocol Specification. [S.I.]: Hart Communication Foundation, 2006. HFC_SPEC12, Revision 6.4.

GAKKESTAD, J.; OHLCKERS, P.; HALBO, L. Compensation of sensitivity shift in piezoresistive pressure sensors using linear voltage excitation. Sensors and Actuators A: Physical, v. 49, n. 1?2, p. 11 - 15, 1995. ISSN 0924-4247. Disponível em: <http://www.sciencedirect.com/science/article/pii/0924424795009888>.

H., G. et al. Thin film strain gauges on polymers: main characteristics. Sensors and Actuators A: Physical, v. 46, n. 1, p. 213-217, 1995. Disponível em: <http://www. ingentaconnect.com/content/els/09244247/1995/00000046/00000001/art00892>.

HELSON, R. Tutorial HART. HART Communication Foundation, 2011. Disponível em: <http://www.smar.com/PDFs/catalogues/HARTTUTCP.pdf>.

HENNIG, C. H. Desafios No Desenvolvimento De Uma Rede Wireless Para Um Sistema De Controle De Válvulas Em Uma Refinaria. [S.I.]: Coester Automação S.A. - ISA, 2009. Palestra.

HORN, G. v. d.; HUIJSING, J. H. Integrated smart sensor calibration. Analog Integrated Circuits and Signal Processing, Springer Netherlands, v. 14, p. 207-222, 1997. ISSN 0925-1030. 10.1023/A:1008289918937. Disponível em: <http://dx.doi.org/10.1023/A:1008289918937>.

HSIEH, H.-S. et al. Method for sensitivity improvement and optimal design of a piezoresistive pressure sensor. IEEE Sensors Conference, p. 1799-1802, nov. 2010. ISSN 1930-0395.

JANUSZ; BRYZEK. Approaching performance limits in silicon piezoresistive pressure sensors. Sensors and Actuators, v. 4, n. 0, p. $669-678,1983$. ISSN 0250-6874. Disponível em: <http://www.sciencedirect.com/science/article/pii/ $0250687483850811>$. 
JOHN, P. et al. Signal conditioner for mems based piezoresistive sensor. In: Industrial and Information Systems (ICIIS), 2010 International Conference on. [S.I.: s.n.], 2010. p. 329-333.

JORDANA, J.; ARENY, R. P. s. A simple, efficient interface circuit for piezoresistive pressure sensors. Sensors and Actuators A: Physical, v. 127, n. 1, p. 69 - 73, 2006. ISSN 0924-4247. Disponível em: <http: //www.sciencedirect.com/science/article/pii/S0924424705006412>.

KASCHEL, C. H.; PINTO, L. E. Analisis del estado del arte de los buses de campo aplicados al control de procesos industriales. Ciencia Abierta, v. 19, n. 0, 2006. ISSN 0717-8948. Disponível em: <http://cabierta.uchile.cl/revista/19/articulos/pdf/ edu3.pdf $>$.

LUZ, S. D. Microssistema transmissor de pressão piezoresistivo de 4-20mA de alta precisão. [S.I.]: Universidade de São Paulo, 2006. Dissertação de Mestrado.

MAXIM. Designing a 4-20mA Current Loop Using the MAX1459 Sensor Signal Conditioner. Maxim, 2002. APPLICATION NOTE 1064. Disponível em: <http://www.datasheets.org.uk/MAX1459/Datasheet-081/DASF0036323.html>.

. The MAX1463 Sensor Compensation Algorithm. Maxim, 2003.

APPLICATION NOTE 2024. Disponível em: <http://www.maxim-ic.com/app-notes/ index.mvp/id/2024>.

. Introduction to the DS8500 HART modem. Maxim, 2010. APPLICATION

NOTE 4676. Disponível em: <http://www.maxim-ic.com/app-notes/index.mvp/id/ 4676>.

MCALLISTER, S. FIELDBUS. Brigham Young University, 2007. Notas de Clase. Disponível em: <http://www.slidefinder.net/f/fieldbus_stuart_mcallister_2007/ fieldbus/17893451>.

MNX. Fabricating MEMS and Nanotechnology. MEMS and Nanotechnology Exchange, 2014. Fabricating MEMS and Nanotechnology. Disponível em: <https://www.mems-exchange.org/MEMS/fabrication.html>.

MODBUS-IDA. Modbus Application Protocol Specification V1.1b. Modbus-IDA, 2006. Disponível em: <http://www.modbus.com/docs/Modbus_Application_ Protocol_V1_1b.pdf $>$.

MONTES, L. et al. Nems nanostructures with enhanced piezoresistive and piezoelectric properties. application to sensor devices and energy harvesting. IEEE International Conference on Nano/Micro Engineered and Molecular Systems (NEMS), p. 1064-1066, fev. 2011.

NGO H. D. AMD THAM, A.; SIMON, M.; OBERMEIER, E. Corner rounding to strengthen silicon pressure sensors using drie. IEEE SENSORS 2008, ?, n. ?, p. 1576-1579, out. 2008. ISSN 1930-0395. 
NXP. Level shifting techniques in I2C-bus design. NXP B.V., 2007. AN10441_1. Disponível em: <http://www.nxp.com/documents/application\_note/AN10441.pdf>.

PEREIRA, C. E. Profibus. Universidade Federal do Rio Grande do Sul, 2001. Notas de Clase. Disponível em: <www.ece.ufrgs.br/ fetter/ele00012/profibus.pdf>.

SAPONJIC, D.; ZIGIC, A. Correction of a piezoresistive pressure sensor using a microcontroller. Instruments and Experimental Techniques, Kluwer Academic Publishers-Plenum Publishers, v. 44, n. 1, p. 38-44, 2001. ISSN 0020-4412. Disponível em: <http://dx.doi.org/10.1023/A\%3A1004168614028>.

SCLOCCHI, M. Input Filter Design for Switching Power Supplies. National Semiconductor Corporation, 2010. Disponível em: <http://www.national.com/ assets/en/other/National_Input_Filter_Design_for_Switchers.pdf>.

SMITH, C. S. Piezoresistance effect in germanium and silicon. Phys. Rev., American Physical Society, v. 94, p. 42-49, Apr 1954. Disponível em: <http://link.aps.org/doi/10.1103/PhysRev.94.42>.

TIMOSHENKO, S.; WOINOSKY-KRIEGER, S. Theory of Plates and Shells, (Engineering Societies Monographs). 2. ed. [S.I.]: McGraw-Hill, 1959. 580 p. p.

YAMADA, K. et al. A piezoresistive integrated pressure sensor. Sensors and Actuators, v. 4, n. 0, p. 63-69, jun. 1983. ISSN 0250-6874.

ZATORRE, G. et al. Designing adaptive conditioning electronics for smart sensing. Sensors Journal, IEEE, v. 10, n. 4, p. 831 -838, april 2010. ISSN 1530-437X. 